OPEN ACCESS

Edited by:

Mingliang Tian,

Hefei Institutes of Physical Science

(CAS), China

Reviewed by:

Ambrish Kumar Srivastava,

Deen Dayal Upadhyay Gorakhpur

University, India

Xiaotian WANG,

Southwest University, China

${ }^{*}$ Correspondence:

Mazhar Amjad Gilani

mazhargilani@cuilahore.edu.pk

Specialty section:

This article was submitted to

Quantum Materials,

a section of the journa

Frontiers in Materials

Received: 25 September 2021 Accepted: 15 November 2021

Published: 15 December 2021

Citation:

Bano R, Asghar M, Ayub K, Mahmood T, lqbal J, Tabassum S,

Zakaria $R$ and Gilani MA (2021) A

Theoretical Perspective on Strategies

for Modeling High Performance

Nonlinear Optical Materials.

Front. Mater. 8:783239.

doi: $10.3389 /$ fmats.2021.783239

\section{A Theoretical Perspective on Strategies for Modeling High Performance Nonlinear Optical Materials}

\author{
Rehana Bano ${ }^{1}$, Maria Asghar ${ }^{2}$, Khurshid Ayub ${ }^{2}$, Tariq Mahmood ${ }^{2,3}$, Javed lqbal ${ }^{4,5}$, \\ Sobia Tabassum ${ }^{6}$, Rozalina Zakaria ${ }^{7}$ and Mazhar Amjad Gilani ${ }^{8 *}$
}

${ }^{1}$ School of Chemistry, University of the Punjab, Lahore, Pakistan, ${ }^{2}$ Department of Chemistry, COMSATS University, Abbottabad Campus, Abbottabad, Pakistan, ${ }^{3}$ Department of Chemistry, College of Science, University of Bahrain, Zallaq, Bahrain, ${ }^{4}$ Department of Chemistry, University of Agriculture, Faisalabad, Pakistan, ${ }^{5}$ Punjab Bio-energy Institute, University of Agriculture, Faisalabad, Pakistan, ${ }^{6}$ Interdisciplinary Research Centre in Biomedical Materials (IRCBM), COMSATS University Islamabad, Lahore Campus, Lahore, Pakistan, ${ }^{7}$ Photonics Research Centre, Faculty of Science, University of Malaya, Lembah Pantai, Malaysia, ${ }^{8}$ Department of Chemistry, COMSATS University Islamabad, Lahore Campus, Lahore, Pakistan

Nonlinear optical (NLO) materials have spanned a large area of science and technology owning to their potential applications in optoelectronics. The invention of the first Ruby laser has sparked a fresh interest in the area of nonlinear optics. The computational designing and experimental synthesis of organic and inorganic NLO materials with higher order nonlinearities come into vogue in the field of materials science. To date, several strategies including metal ligand framework, push pull mechanism, diradical character, and so on have been devised to enhance the NLO response of materials. In addition, introduction of diffuse excess electrons is an efficient approach to design noncentrosymmetric materials for nonlinear optics. The current review highlights a systematic array of different computational studies (covering the last decade of intensive research work) for the theoretical designing of NLO materials. In the present review, theoretical designing from the simplest NLO material to the complex alkali, alkaline earth, transition, and superalkali doped nanomaterials is summarized. The emergence of excess electrons strategy has played a pivotal role in enhancing the NLO properties especially hyperpolarizabilities. We expect that this review will provide a better understanding of the NLO responses of nanoclusters, paving the way for the advancement of hi-tech NLO materials to meet the real challenges in optoelectronics.

Keywords: nonlinear optical materials (NLO), fullerenes, hyperpolarizability, electrides, alkalides

\section{INTRODUCTION}

Nonlinear optics is a new and versatile branch of science that describes the light-matter interaction when induced polarization nonlinearly depends on external electric and magnetic fields (Boyd, 2020; Shen, 1984). Nonlinear optical (NLO) phenomenon arises when a material generates electromagnetic radiations of varying phase, amplitude, and frequency during its propagation on interaction with electromagnetic fields (Tessore et al., 2018). The NLO effect is produced when strong electrical fields under high intensity laser beams interact with matter. In 1960, the invention of the first Ruby laser by Maiman sparked fresh interest in the field of nonlinear optics (Maiman, 1960). 


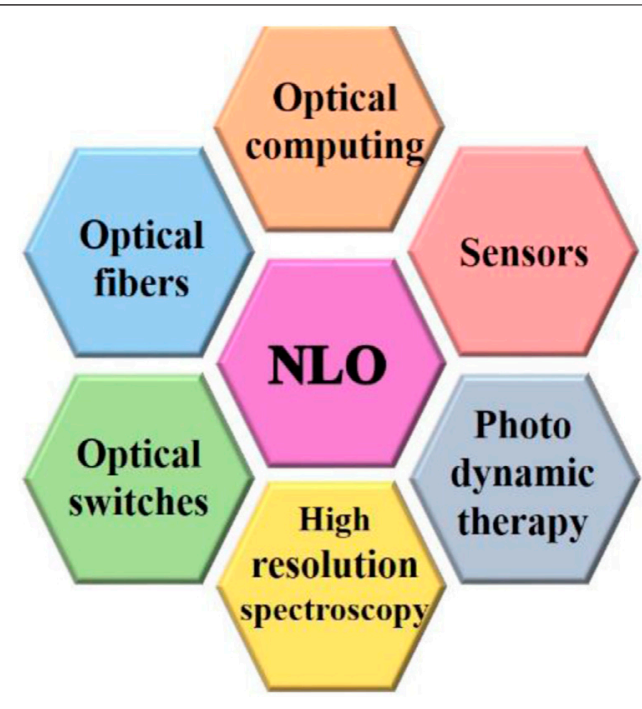

FIGURE 1 | Applications of nonlinear optical materials in various fields.

Franken et al. also complemented this phenomenon by observing the second harmonic generation (SHG) effect in quartz crystals (Franken et al., 1961). The simple manifestations of nonlinear optics include intensity-dependent light refraction and absorption (Majumdar et al., 2020; Wang et al., 2018). The formation of solitons (Z. Luo et al., 2015), power restriction of light transmission (Lettow and Martin, 2010), and multiphoton fluorescence (Wostyn et al., 2001) are all possible outcomes of this phenomenon. The field of nonlinear optics has become a Frontier area in the fields of ultrafast pulse measurement (X. Liu et al., 2017), light generation and modulation (J. Chen et al., 2018), optical parametric amplification (Kumbhakar and Kobayashi, 2007; Popov and Shalaev, 2006), laser frequency conversion (D. Hou et al., 2018a), modulators (Grote et al., 2002), and optical switches (Biswal et al., 2019; W. Li et al., 2014). In addition, nonlinear optics have remarkable applications in dynamic image processing (Van Steenwinckel et al., 2001), sensing (Ray, 2010), high resolution imaging (Miller et al., 2002), optical computing (Hutchinson and Milburn, 2004), optical fiber communication (Arivuoli, 2001), optical data storage (Iliopoulos et al., 2010), and materials analysis (Y. R. Shen, 1989). The biological applications in the field of NLO microscopic imaging (Huff et al., 2008; Wang et al., 2009) or photodynamic therapy (Kachynski et al., 2014) are also of great interest. Some major applications of nonlinear optical materials are represented in Figure 1.

Bulk crystals such as potassium titanyl phosphate (KTP) (Stucky et al., 1989), beta-barium borate $\left(\beta-\mathrm{BaB}_{2} \mathrm{O}_{4}\right)$ (Girisun et al., 2017), and lithium iodate $\left(\mathrm{LiIO}_{3}\right)$ (Kumar et al., 2010a; Kumar et al., 2010b) are currently used as commercial nonlinear media. NLO materials have covered a vast area of science and technology and many scientists are working on their exploration in various fields of optoelectronics. The increase in the number of publications year after year, approaching almost 570 papers in 2021, is evidence of the considerable efforts in the field of nonlinear optics. A bar graph showing the number of publications for the last 5 years is shown in Figure 2. The current state of technology necessitates a strong demand for on-chip integration of photonic and optoelectronic devices.

\section{Background of Nonlinear Optics}

The history of nonlinear optics can be traced by the work of John Kerr on carbon disulfide $\left(\mathrm{CS}_{2}\right)$ crystals. He observed the alteration in the refractive index by induced quadratic electric field (E) and this phenomenon is known as the electro-optic Kerr effect (Kerr, 1879). In 1883, a similar but linear electric field effect was also observed in quartz and is now known as Pockel's effect (Burland, 1994). These nonlinear phenomena were only used in a limited way until the laser was invented in 1960, followed by the discovery of the second harmonic generation in quartz (Maiman, 1960; Franken et al., 1961). Based on these developments, the area of nonlinear optics exploded in the 1960s, with Bloembergen's pioneering research into the complete range of NLO responses of different materials (Armstrong et al., 1962; Ducuing and Bloembergen, 1964). A. D. Buckingham and co-workers have added a key contribution in developing understanding of NLO processes at the atomic and molecular levels (Buckingham and Orr, 1967).

The basic sources of microscopic hyperpolarizabilities were studied in depth during the 1970s. In 1973, the transmission of stationary NLO pulses in dispersive dielectric fibers was observed by Hasegawa et al. (Buckingham and Orr, 1967). The experimental methodologies for measuring these molecular nonlinearities, and fabricating novel crystals that could be useful in second-harmonic production and optoelectronic modulation have been devised (Gibbs et al., 1976; Mollenauer et al., 1980; Cirilo et al., 2010). In the early 1990s, second and third order NLO responses in atoms and small molecules were calculated and measured in the gas phase by David Shelton and Julia Rice (Shelton and Rice, 1994). David et al. worked on identification of chromophores with higher order optical nonlinearities using a range of electronic structural models and computational approaches (Kanis et al., 1992, 1994). This literature demonstrates that advanced computational methodologies on isolated atoms and molecules might help us to understand the origin of nonlinear processes and to contribute toward the designing tools for forecasting their features. Currently, a majority of the NLO work is focused on the causes, processes, and applications of NLO materials.

\section{Basic Principle of Nonlinear Optics}

Nonlinear optics illustrate the light-matter nonlinear relationship in a medium under the intense light beam (laser) and electromagnetic fields (Becker, 1998). On propagation of light through a medium, the valence electrons produce a charge transfer relative to the atoms in the medium under the action of induced electric field and results in medium polarization (P). The relationship between polarization intensity of medium and electric field strength of the incident light can be expressed as in Equation 1.

$$
P=\epsilon_{\circ} \chi^{(1)} E+\epsilon_{\circ} \chi^{(2)} E^{2}+\epsilon_{\circ} \chi^{(3)} E^{3}+\ldots
$$




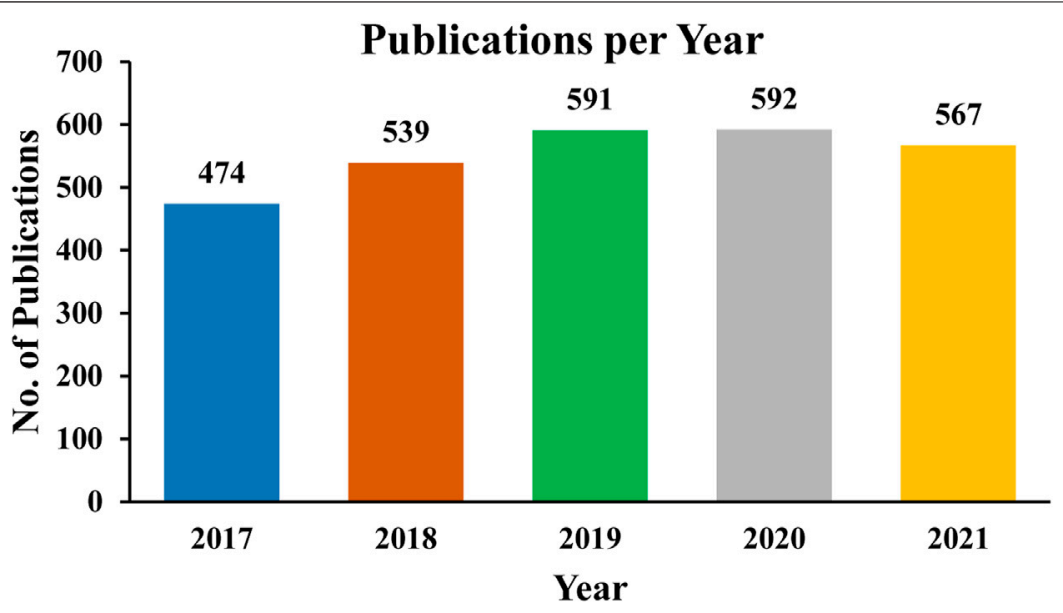

FIGURE 2 | Number of publications per year related to the theoretical studies on nonlinear optical materials: Data obtained by using keywords "Nonlinear optical, Theoretical" from Scopus as of November 2021.

Here, $P$ is the macroscopic polarization strength, $E$ is applied electric field strength, $\epsilon_{\circ}$ is vacuum dielectric constant, $\chi^{(1)}$ is the first order linear susceptibility, $\chi^{(2)}$ is the second order nonlinear susceptibility, and so on. At the microscopic level, Equation 1 can be written as

$$
p=\alpha E+\beta E^{2}+\gamma E^{3}+\ldots
$$

Here, $p$ is the microscopic polarization intensity of a molecule under electric field, $\alpha$ is the polarizability, $\beta$ is first hyperpolarizability, $\gamma$ is the second hyperpolarizability, and so on. In the presence of a weak electric field, higher order susceptibilities (from the second term and so on) can be neglected. As a result, polarization and electric field strength $\left(\mathrm{P}=\epsilon_{\circ} \chi E\right)$ have a linear response making linear optics possible. Under the action of intense laser light, higher order susceptibilities from second to onward cannot be neglected. Therefore, NLO phenomenon occurs when the medium microscopic polarization $\mathrm{p}$ and macroscopic polarization $\mathrm{P}$ are nonlinearly proportional to the $\mathrm{E}$ (strength of the applied electric field). As a result, higher order NLO effect (second order NLO, third order NLO effect, and so on) have been observed in materials.

NLO response is not the property of all systems. In centrosymmetric systems, the induced polarization is the same in all directions and has no NLO response. Therefore, hyperpolarizability is zero in all directions in such systems. While in the case of non-centrosymmetric systems, the restoring force is determined by the charges of displaced electrons. The direction and amount of the applied electromagnetic field will also influence the induced polarization. As a result, materials that can generate an asymmetric wave can also produce an NLO response. Noncentrosymmetry is a basic requirement for a system to show an NLO response (Fan et al., 2010; Luo et al., 2018). All kinds of non-centrosymmetric systems exhibit NLO effects, but in order to obtain their potential applications, they must have a maximum nonlinearity at low power. Therefore, the researchers have focused on designing novel materials with a higher order NLO response.

\section{STRATEGIES FOR ENHANCEMENT OF NLO RESPONSE}

A revolution in electronics is on the horizon with the uprising of two unique domains including spintronics and molecular electronics. Single-molecule magnets in spintronics can be used to establish a basic link between these two domains (Bogani and Wernsdorfer, 2010). Molecular optics may result by intriguing development in optics since the implementation and development of NLO materials at the molecular level. The NLO molecules can be used to make macroscopical NLO materials (Cheng et al., 1991; Delaire and Nakatani, 2000). Due to the discovery and diverse applications of nonlinear optics, the researchers are focused on improving the NLO response of various inorganic and organic materials by using a variety of strategies. To date, several approaches for tuning the NLO response of materials have been established. These include electron donor to accepter push-pull mechanisms, designing octupolar molecules, introducing diffuse excess electrons, using multi-decker sandwich clusters, applying bond length alteration theory, designing metal organic frameworks (MOFs), and so forth. Some of these are listed here.

\section{Electron Push-Pull Mechanism}

The electron push-pull strategy was first introduced by Zyss and his co-workers (Zyss and Ledoux, 1994). This approach is primarily employed for organic chromophores especially stilbenes, porphyrins, paracyclophanes (Vijayakumar et al., 2008; Orbelli Biroli et al., 2011), and so on. The structure of such organic compounds is a major contributor toward the development of NLO response. When the donor-acceptor 


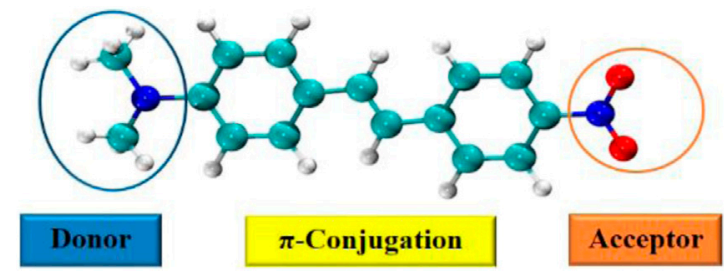

FIGURE 3 | 4-[N,N-dimethylamino]-4'-nitro stilbene (DANS) as push-pull NLO chromophore.

groups are connected via $\pi$-bonding, a conjugated (D- $\pi-A$ ) system is formed. This system is referred to as a push-pull mechanism based system because of the intermolecular charge transfer (ICT) from donor to acceptor (linked through $\pi$-bonding), which leads to induction of polarization under the presence of light and electric field. The best example of such NLO chromophores is DANS (4-[N,N-dimethylamino]-4'-nitro stilbene) which shows an intramolecular charge transfer (ICT) (Vijayakumar et al., 2008). It has an electron donor dimethylamino group $\left(-\mathrm{N}\left(\mathrm{CH}_{3}\right)_{2}\right)$ and nitro group $\left(-\mathrm{NO}_{2}\right)$ as electron acceptor with trans-stilbene as $\pi$-conjugated bridge as shown in Figure 3. Vijayakumar et al. observed that planar conformations would result in increased NLO activity (435.41 $\times 10^{-31} \mathrm{esu}$ ), but a departure from planarity results in decreased NLO activity $\left(285.16 \times 10^{-31} \mathrm{esu}\right)$.

Paracyclophane (pCP) is an important building block for complexes in which D-A substituents interact via a sterically restricted $(\pi-\pi)$ stack. In 2000, Zyss et al. observed the experimental and theoretical quadratic hyperpolarizability tensor $\left(60 \times 10^{-30} \mathrm{esu}\right)$ of dipolar 4-(4-dihexylaminostyryl)16-(4-nitrostyryl)[2.2] paracyclophane for the first time. The collective electron oscillator (CEO) approach was used to confirm collective nonlinear polarization involving the entire end-to-end molecular structure (Zyss et al., 2000). Since then, paracyclophanes are serving as novel NLO candidates in various fields. Recently, the NLO response of [2.2] paracyclophane based polymers has been investigated theoretically (Ivonina et al., 2020). The NLO properties of a series of diacetylene-functionalized organic molecules (DFOM) with $D-\pi-A$ stacking have been computed. These complexes were designed by structural tailoring of newly synthesized BDDA (4,4' -(buta-1,3-diyne-1,4diyl) dianiline) chromophores. The involvement of extended conjugation and charge transfer character have been explored via different DFT methods. The enhanced NLO response $(\beta=$ $2.5 \times 10^{4} \mathrm{au}$ ) of the designed diacetylene-functionalized organic complexes reflected that these complexes could serve as better NLO candidates (Khalid et al., 2019). The development of novel synthetic and theoretical techniques leads to more diverse substitution patterns of porphyrin rings because it widens the potential applicability in nonlinear optics. In this regard, NLO response of a series of substituted zinc(II) porphyrinates with $-\mathrm{N}\left(\mathrm{CH}_{3}\right)_{2}$ as donors and $-\mathrm{NO}_{2}$ as electron acceptors has been investigated. The experimental and theoretical investigation of a series of 5,15 push-pull meso-diarylzinc(II) porphyrinates with $-\mathrm{OCH}_{3}$ or $-\mathrm{N}\left(\mathrm{CH}_{3}\right)_{2}$ as donors and $-\mathrm{COOH}$ or $-\mathrm{COOCH}_{3}$ as electron acceptors in DMF and chloroform have been explored (Orbelli Biroli et al., 2017). Their NLO response was determined using the electric-field-induced second-harmonic generation technique.

\section{Metal Ligand Framework}

Metal organic frameworks, a fascinating class of hybrid NLO materials, have resulted by altering the central metal atom or adjusting the organic linkers (with different functional groups) as compared to traditional organic and inorganic NLO crystals. According to a recent research on ZIF-8 (zeolitic imidazolate) framework (Van Cleuvenbergen et al., 2016), it is observed that ZIF-8 has a strong SHG signal that is similar to the inorganic crystals of $\mathrm{KH}_{2} \mathrm{PO}_{4}$. A theoretical investigation on the structures and exploration of NLO response of experimentally synthesized Zr-based UiO-66 MOFs with BDC (1,4-benzene-dicarboxylate) linkers and its substituents $\left(-\mathrm{NH}_{2},-\mathrm{OH},-\mathrm{SH}\right.$, and halogen atoms) has been carried out to reveal the effect of ligand functionalization on NLO properties (Ni et al., 2020). Recently, the NLO response of titanium-based MIL-125 MOFs (crystals) has been investigated using DFT calculations. In this MOFs, the BDC linkers have been altered either by extending the $\mathrm{BDC}$ ligands or by substituting various functional groups as in MIL-126 and MIL-127. It was observed that the NLO response especially SHG intensity has been improved on introducing substituent groups into the BDC linker (Ni et al., 2019). These findings are helpful for developing novel NLO materials with hitech performance.

\section{Diradical Character}

Diradical character is an efficient approach for the enhancement of NLO response of open-shell singlet systems (Nakano et al., 2004, 2007; Nakano et al., 2006b). The chemical systems with intermediate diradical character exhibit greater NLO response (hyperpolarizabilities) than pure or closed shell diradical systems. The cause of this reliance has been speculated by using the VCI (valence configuration interaction) approach for $\mathrm{H}_{2}$ model (a two-site diradical system) (Nakano et al., 2006b) and a linear $\mathrm{H}_{4}$ model for tetraradical systems (Nakano et al., 2012). Several DFT calculations have been performed to investigate the relationship between hyperpolarizabilities and diradical character (y) of singlet diradical systems such as p-quinodimethane (PQM) molecule (Nakano et al., 2005), polycyclic diphenalenyl radicals (Ohta et al., 2007), graphene nanoflakes (Nakano et al., 2008), and imidazole ring based diradical systems (Nakano et al., 2006a; Qiu et al., 2008). Apart from these studies, a comparison of NLO response of cyclic/linear acenes vs. phenylenes has reflected a distinct enhancement in the tetraradical nature of cyclacenes as well as their second hyperpolarizabilities ( $\gamma_{\mathrm{zzzz}} \approx 10^{4} \mathrm{au}$ ) (Muhammad et al., 2013). These theoretical predictions have been observed in the TPA (two-photon absorption) analysis of experimentally synthesized diphenalenyl diradical compounds (Kamada et al., 2007), hepta/ octazethrenes (Li et al., 2012), and benzannulated Chichibabin's hydrocarbons (Zeng et al., 2012), as well as in the THG (third harmonic generation) effect of BDPI-2Y (1,4-bis-(4,5diphenylimidazole-2-ylidene)cyclohexa2,5-diene) (Kishida 


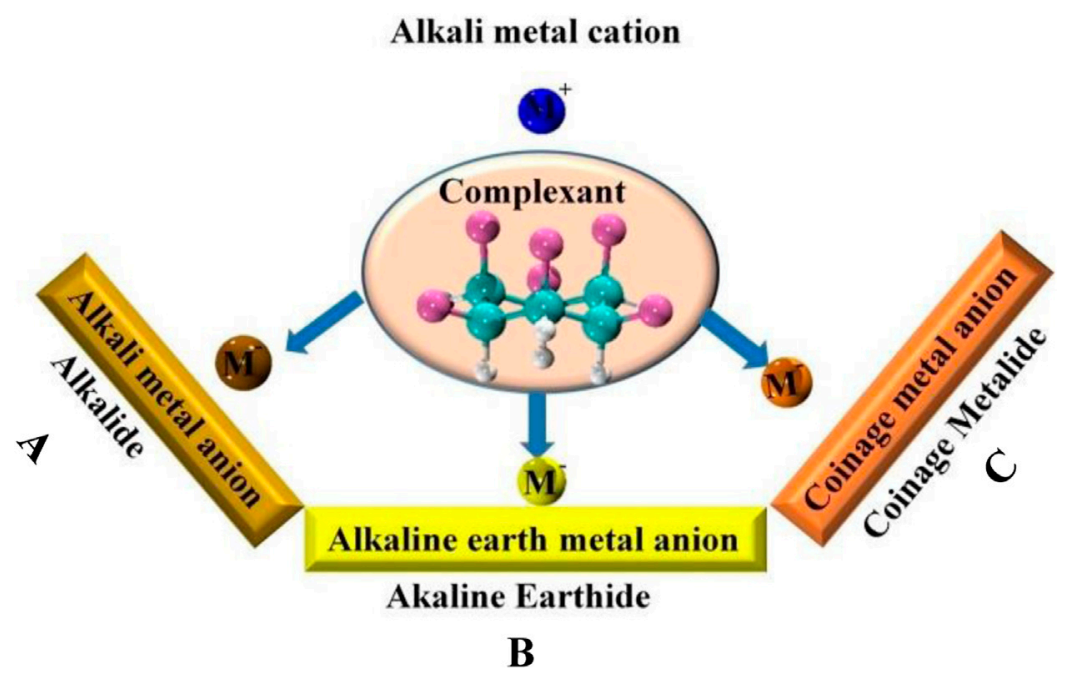

FIGURE 4 | A general representation of alkalide, alkaline earthide, and coinage metalide complexes.

et al., 2010). Muhammad et al. theoretically observed the dependence of NLO response on the diradical character of various fullerenes $\left(\mathrm{C}_{20}, \mathrm{C}_{26}, \mathrm{C}_{30}, \mathrm{C}_{36}, \mathrm{C}_{40}, \mathrm{C}_{42}, \mathrm{C}_{48}, \mathrm{C}_{60}\right.$, and $\mathrm{C}_{70}$ ). It was observed that $\mathrm{C}_{20}, \mathrm{C}_{60}$, and $\mathrm{C}_{70}$ were closed-shell systems while others were intermediate and open-shell systems. The larger second order hyperpolarizabilities were observed for fullerenes with intermediate diradical character such as $\mathrm{C}_{40}$ have shown $\gamma_{\text {zzzz }}$ up to $43.44 \times 10^{3}$ au. Similarly, the NLO responses of diradical character based various buckyferrocenes have been explored at the molecular level. The closed-shell bucky ferrocenes were $(\mathrm{CpFe})_{2} /{ }_{5} \mathrm{C}_{60} \mathrm{Me}_{10}$ and $(\mathrm{CpFe})_{2} \eta^{5} \mathrm{C}_{70} \mathrm{Me}_{10}$, intermediate open-shell singlets were $(\mathrm{CpFe})_{2} \eta^{5} \mathrm{C}_{70} \mathrm{Me}_{8}$ $(\mathrm{CpFe})_{2} \eta^{5} \mathrm{C}_{30}$, and $(\mathrm{CpFe})_{2} \eta^{5} \mathrm{C}_{70} \mathrm{Me}_{4}$ while others were purely open shell based complexes. The largest third order NLO response $\left(\gamma_{\mathrm{zzzz}}=130.71 \times 10^{4} \mathrm{au}\right)$ was observed for $(\mathrm{CpFe}){ }_{2} \eta^{5} \mathrm{C}_{70}$ buckyferrocenes with intermediate diradical character (Muhammad et al., 2015). These findings show that diradical character has enhanced the NLO response of complexes and served as a suitable approach for obtaining high performance NLO materials.

\section{EXCESS ELECTRONS STRATEGY}

Introduction of excess electrons into various systems is a novel approach that remarkably enhances their NLO properties. The NLO response of organic and inorganic systems can be boosted by excess electrons. In 2004, Li et al. introduced a new potential class of NLO materials with diffuse excess electrons for the first time (Li et al., 2004). They investigated theoretically the nonlinear optical response of $(\mathrm{FH})_{2}\{\mathrm{e}\}(\mathrm{HF})$ clusters with the highest hyperpolarizability of $8.1 \times 10^{6}$ au. Similarly, first hyperpolarizability $\left(\beta \approx 10^{7} \mathrm{au}\right.$ ) of excess electron bound water trimer anion $\left(\mathrm{H}_{2} \mathrm{O}\right)_{3} \square$ was extremely larger than molecular cluster of water trimer $\left(\mathrm{H}_{2} \mathrm{O}\right)_{3}$ itself $(\mathrm{W}$. Chen et al., 2004). These results indicate that the excess electrons have a potent role in improving the nonlinear optical features. A dispersive orbital is occupied by the diffuse excess electrons, which is in a Rydberg-like state. The nonlinear optical susceptibilities of a Rydberg atom or molecule are extremely high in the gas phase, as evidenced by available experimental data and theoretical studies (Manykin, 2002). The significant impact of excess electrons on clusters' hyperpolarizability opened new possibilities for the design and preparation of innovative NLO molecular materials. Doping of metal atoms (alkali, alkaline, transition) on complexants is an efficient approach to obtain excess electrons compounds (Ahsan and Ayub, 2020b; Munsif et al., 2018; Rad and Ayub, 2018c; Sun et al., 2017a). Electrides, alkalides, alkaline earthides, coinage metalides, and superalkalides are the various classes of excess electron compounds that show remarkable NLO response. A general representation for alkalide, alkaline earthide, and coinage metalide complexes is shown in Figure 4.

\section{Electrides}

Electrides are a representative type of diffuse excess electron compounds that have a great possibility to serve as NLO materials. They are formed when valance electrons of metal atom are pushed by complexants and become excess electrons in the system. Dye et al. synthesized the first electride $\mathrm{Cs}^{+}(18-$ crown-6) ${ }_{2} \mathrm{e}^{-}$as an excess electron system in 1983 (Ellaboudy et al., 1983; Dawes et al., 1986). In 2005, Chen et al. theoretically investigated the NLO response of $(\mathrm{HCN})_{\mathrm{n}}-\mathrm{Li}$ and $\mathrm{Li}-(\mathrm{HCN})_{\mathrm{n}}(\mathrm{n}=$ $1,2,3)$ electrides for the first time (W. Chen et al., 2005b). The $2 s$ valence electrons of $\mathrm{Li}$ have become excess electrons by the interaction of a $\mathrm{Li}$ atom and $(\mathrm{HCN})_{\mathrm{n}}$. Since then, many alkali metal based electride complexes with larger NLO response have been investigated. Electrides include cup-like Li@calix [4]pyrrole (W. Chen et al., 2005b), M@pyrrole ( $\mathrm{M}=\mathrm{Li}, \mathrm{Na}$, and K) (Yu et al., 
TABLE 1 | Some excess electron based electride complexes with enhanced NLO response.

\begin{tabular}{|c|c|c|c|c|}
\hline Complex & Hyperpolarizability (au) & Software & Level of theory & References \\
\hline Li@calix [4]pyrrole & $7.3 \times 10^{3}$ & Gaussian & $\begin{array}{l}\text { B3LYP/6-311++G for }(\mathrm{C}, \mathrm{H}, \mathrm{N}) \\
6-311++\mathrm{G}(3 \mathrm{df}, 3 \mathrm{pd}) \text { for } \mathrm{Li}\end{array}$ & W. Chen et al. (2005b) \\
\hline $\mathrm{M}_{3} \mathrm{O}^{+}\left(\mathrm{e} @ \mathrm{C}_{20} \mathrm{~F}_{20}\right)^{-}$ & $1.3 \times 10^{4}$ & Gaussian & CAM-B3LYP/6-311+G(d) & J.-J. Wang et al. (2012) \\
\hline $\mathrm{Li}_{4} \mathrm{~N} @ \mathrm{Al}_{12} \mathrm{P}_{12}$ & $6.3 \times 10^{4}$ & Gaussian & CAM-B3LYP/6-311++G (2days,2p) & Ullah et al. (2019b) \\
\hline $\mathrm{Li}_{2} \mathrm{~F} @ \mathrm{~B}_{12} \mathrm{P}_{12}$ & $3.4 \times 10^{5}$ & Gaussian & LC-BLYP/6-31+G(d) & Ullah et al. (2019a) \\
\hline $\mathrm{Li}_{n}-\mathrm{H}-\left(\mathrm{CF}_{2}-\mathrm{CH}_{2}\right)_{3}-\mathrm{H}$ & $7.7 \times 10^{4}$ & Gaussian & $\begin{array}{l}\text { MP2/6-31+G(d) for }(C, H, F) \\
6-311+G(3 d f) \text { for } \mathrm{Li}\end{array}$ & H. L. Xu et al. (2007) \\
\hline $\mathrm{Li} @ \mathrm{~B}_{10} \mathrm{H}_{14}$ & $2.3 \times 10^{4}$ & Gaussian & $\mathrm{MP} 2 / 6-31+\mathrm{G}(\mathrm{d})$ & Muhammad et al. (2009) \\
\hline $\mathrm{Li}-\mathrm{H}_{3} \mathrm{C}_{4} \mathrm{~N}_{2} \cdots \mathrm{Ca}$ & $2.7 \times 10^{5}$ & Gaussian & MP2/6-311++G (3df, 2pd) & Y.-F. Wang et al. (2014) \\
\hline $\mathrm{Li}_{0} \mathrm{~F}_{6} \mathrm{C}_{6} \mathrm{H}_{6}$ & $7.1 \times 10^{5}$ & Gaussian & $\begin{array}{l}\mathrm{MP} 2 / \\
6-31+\mathrm{G}(\mathrm{d})\end{array}$ & N. Hou et al. (2018c) \\
\hline $\mathrm{C}_{6} \mathrm{Li}_{6}-\mathrm{K}$ & $5.4 \times 10^{5}$ & Gaussian & $\begin{array}{l}\text { CAM-B3LYP/ } \\
6-311+G(d)\end{array}$ & Srivastava, (2020) \\
\hline
\end{tabular}

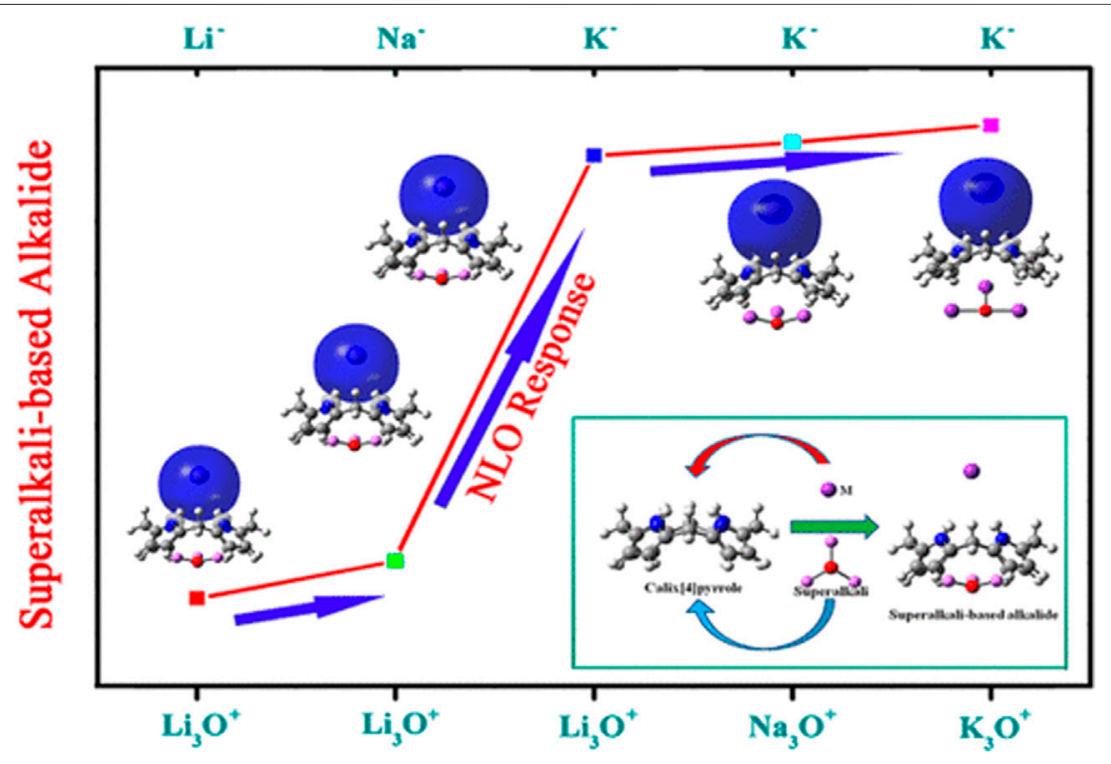

FIGURE 5 | Superalkali based alkalides of $\mathrm{Li}_{3} \mathrm{O}^{+}$(calix [4]pyrrole) $\mathrm{M}^{-}$and $\mathrm{M}_{3} \mathrm{O}^{+}$(calix [4]pyrrole) $\mathrm{K}^{-}$complexes. Reprinted from W. M. Sun et al., 2014 with permission from Copyright (2014) American Chemical Society.

2011), $\mathrm{M}^{+}\left(\mathrm{e} @ \mathrm{C}_{20} \mathrm{~F}_{20}\right)^{-}$(J.-J. Wang et al., 2012), and $\left(\mathrm{M}_{3} \mathrm{O}\right)^{+}(\mathrm{e} @$ $\left.\mathrm{C}_{20} \mathrm{~F}_{20}\right)^{-}$and chain-like $\mathrm{Li}_{n}-\mathrm{H}-\left(\mathrm{CF}_{2}-\mathrm{CH}_{2}\right)_{3}-\mathrm{H}(n=1,2)$ (H.-L. $\mathrm{Xu}$ et al., 2007), and so on. Some of these electrides are listed in Table 1.

\section{Alkalides}

Alkalides are novel excess electron compounds obtained when another metal atom is placed on the opposite side of electrides. Complexants' excess electrons are wrapped around a second metal atom to form a metal anion. Due to its low electron affinity, the excess electrons of anionic metal atoms are loosely bound with a dispersive nature. The first alkalide was successfully synthesized by Dye and co-workers in 1974 (Dye et al., 1974; Tehan et al., 1974). Later on, two stable alkalides $\mathrm{K}^{+}\left(\mathrm{Me}_{6} \mathrm{Aza} 222\right)$ $\mathrm{Na}^{-}$and $\mathrm{K}^{+}\left(\mathrm{Me}_{6} \mathrm{Aza} 22\right) \mathrm{K}^{-}$were synthesized by the same group which opened up the possibility of alkalide applications (Kim et al., 1999). Theoretical studies of room temperature stable alkalides $\mathrm{Li}^{+}$(calix [4] pyrrole) $\mathrm{M}^{-}$with a greater NLO response 
TABLE 2 | Nonlinear optical response (hyperpolarizability) of excess electron based alkalide complexes.

\begin{tabular}{|c|c|c|c|c|}
\hline Complex & Hyperpolarizability (au) & Software & Level of theory & References \\
\hline $\mathrm{Li}^{+}$(calix [4]pyrrole) $\mathrm{K}^{-}$ & $2.4 \times 10^{4}$ & Gaussian & $\begin{array}{l}\text { B3LYP/6-311++G for }(\mathrm{C}, \mathrm{H}, \mathrm{N}) \\
6-311++\mathrm{G}(3 \mathrm{df}) \text { for }(\mathrm{Li}, \mathrm{Na} \text { and } \mathrm{K})\end{array}$ & Chen et al. (2006) \\
\hline$\left(\mathrm{K}+@ 2^{6} \mathrm{adz}\right) \mathrm{K}-$ & $3.2 \times 10^{5}$ & Gaussian & $\begin{array}{l}\text { B3LYP/6-311++G for }(\mathrm{C}, \mathrm{H}, \mathrm{N}) \\
6-311++\mathrm{G}(3 \mathrm{df}) \text { for }(\mathrm{Li}, \mathrm{Na} \text { and } \mathrm{K})\end{array}$ & F.-F. Wang et al. (2008) \\
\hline $\mathrm{Li}^{+}\left(\mathrm{NH}_{3}\right)_{4} \mathrm{M}^{-}$ & $1.8 \times 10^{5}$ & Gaussian & $\begin{array}{l}\text { MP2/6-311++G for }(\mathrm{N}, \mathrm{H}) \\
6-311++\mathrm{G}(3 \mathrm{df}) \text { for }(\mathrm{Li}, \mathrm{Na} \text { and } \mathrm{K})\end{array}$ & Jing et al. (2006) \\
\hline $\mathrm{Ca}\left(\mathrm{NH}_{3}\right)_{6} \mathrm{NaCl}$ & $1.2 \times 10^{5}$ & Gaussian & CAM-B3LYP/6-311++G (d,p) & W.-M. Sun et al. (2015) \\
\hline $\mathrm{K}_{3} \mathrm{O}^{+}$(calix [4]pyrrole) $\mathrm{K}^{-}$ & $3.4 \times 10^{4}$ & Gaussian & $\begin{array}{l}\text { CAM-B3LYP/ } \\
6-311++G(d, p)\end{array}$ & W. M. Sun et al. (2014) \\
\hline $\mathrm{OLi}_{3}-\mathrm{K}-\mathrm{OLi} \mathrm{i}_{3}$ & $1.9 \times 10^{4}$ & Gaussian & $\mathrm{MP} 2 / 6-311+\mathrm{G}(\mathrm{d})$ & Srivastava and Misra, (2017) \\
\hline
\end{tabular}

opened a fresh approach for developing innovative alkalides (W. Chen et al., 2005a). The alkalide complexes of $\mathrm{Li}^{+}$(calix [4] pyrrole) $\mathrm{K}^{-}$(W. Chen et al., 2006; Sun et al., 2013) and ( $\mathrm{M}^{+} @$ $\left.\mathrm{n}^{6} \mathrm{adz}\right) \mathrm{M}^{\prime-}\left(\mathrm{n}=2,3, \mathrm{M}, \mathrm{M}^{\prime}=\mathrm{Li}, \mathrm{Na}\right.$ and $\left.\mathrm{K}\right)$ (F.-F. Wang et al., 2008) with larger NLO response have been reported. Similarly, theoretical studies on smaller alkalides $\mathrm{Li}^{+}\left(\mathrm{NH}_{3}\right)_{4} \mathrm{M}^{-}$were explored (Jing et al., 2006). It was observed that the NLO response of smaller alkalides was four times larger than larger organic $\mathrm{Li}^{+}$(calix [4]pyrrole) $\mathrm{M}^{-}$alkalides (Jing et al., 2006). A series of alkaline earth based alkalides $\mathrm{M}\left(\mathrm{NH}_{3}\right)_{6} \mathrm{NaCl}$ and $\mathrm{M}\left(\mathrm{NH}_{3}\right)_{6} \mathrm{Na}_{2}{ }^{-}(\mathrm{M}=\mathrm{Mg}$ and $\mathrm{Ca})$, with the highest hyperpolarizability up to 123,050 au have been explored theoretically (W.-M. Sun et al., 2015). Theoretical exploration of the NLO response of a new series of superalkali based alkalides $\mathrm{Li}_{3}{ }^{+}$(calix [4]pyrrole) $\mathrm{M}^{-}, \quad \mathrm{Li}_{3} \mathrm{O}^{+}$(calix [4]pyrrole) $\mathrm{M}^{-}$, and $\mathrm{M}_{3} \mathrm{O}^{+}$(calix [4] pyrrole) $\mathrm{K}^{-}(\mathrm{M}=\mathrm{Li}, \mathrm{Na}$, and $\mathrm{K})$ has been carried out via DFT calculations with the highest first hyperpolarizability up to 34,718 au (W. M. Sun et al., 2014). The superalkali based alkalides are shown in Figure 5.

Similarly, superalkali $\left(\mathrm{Li}_{2} \mathrm{~F}, \mathrm{Li}_{3} \mathrm{O}, \mathrm{Li}_{4} \mathrm{~N}\right.$, and $\left.\mathrm{Li}_{3}\right)$ doped (aza222)K alkalides with enhanced NLO response have been investigated theoretically (W.-M. Sun et al., 2016b). Coinage metal ( $\mathrm{Cu}, \mathrm{Ag}$, and $\mathrm{Au})$ based alkalides of (M@3 $\left.{ }^{6} \mathrm{adz}\right) \mathrm{M}^{\prime}$ have been investigated via DFT calculations and exhibit enhanced NLO responses (W. M. Sun et al., 2017a). A theoretical investigation of $\mathrm{Li}_{2} \mathrm{~F}$ superalkali based alkalides $\mathrm{FLi}_{2}-\mathrm{M}-\mathrm{Li}_{2} \mathrm{~F}$ $(\mathrm{M}=\mathrm{Li}, \mathrm{Na}$, and $\mathrm{K}$ ) has been carried out (Srivastava and Misra, 2015b). The negative charge on the sandwiched alkali metal atoms confirmed their alkalide nature. The mean polarizabilities of these stable superalkali based alkalides are up to $10^{3}$ au and hence may serve as better NLO candidates. The NLO response of $\mathrm{Li}_{3} \mathrm{O}$ based alkalides $\mathrm{OLi}_{3}-\mathrm{M}-\mathrm{OLi}_{3}(\mathrm{M}=\mathrm{Li}$, $\mathrm{Na}$, and $\mathrm{K}$ ) have been observed theoretically for the first time (Srivastava and Misra, 2017). The sandwiched Li, Na, and K metal atoms bear a negative charge donated by excess electrons of superalkalis. The highest NLO response of $1.9 \times 10^{4}$ au is observed for $\mathrm{OLi}_{3}-\mathrm{K}-\mathrm{OLi}_{3}$ at $\mathrm{C}_{2 V}$ symmetry.

Recently, a series of novel alkalides $\mathrm{M}^{+} \cdot \mathbf{1} \cdot \mathrm{M}^{\prime-}\left(\mathrm{M}, \mathrm{M}^{\prime}=\mathrm{Li}, \mathrm{Na}\right.$, $\mathrm{K})$ of a facially polar $\mathrm{C}_{6} \mathrm{H}_{6} \mathrm{~F}_{6}$ molecule $\left(\mathrm{C}_{6} \mathrm{H}_{6} \mathrm{~F}_{6}=1\right.$, all-cis1,2,3,4,5,6-hexafluorocyclohexane) has been investigated theoretically (Sun et al., 2017b). These alkalides show remarkable NLO response with the highest hyperpolarizability of $1.45 \times 10^{6} \mathrm{au}$. These findings were a tour de force of NLO materials and paved the way to new possibilities for designing stable alkalides. The NLO response (hyperpolarizability) of some excess electron based alkalides are listed in Table 2.

\section{Alkaline Earthides}

Alkaline earthides are novel excess electron compounds in which electron acceptors are alkaline earth metals (alkaline earth anion) in place of alkali metals. They show very large NLO response and have partial p-electrons participation in excess electron formation, unlike alkalides in which partial s-electrons participate. Development of negative charge on alkaline earth metals in the presence of alkali metals is more difficult due to their $n s^{2}$ (closed shell) electronic configuration and their weak electron affinity. As a result, selecting the right complexant to stabilize the alkali metal cation and alkaline earth metal anion at the same time is critical. One such alkaline earthide organic system $\mathrm{Li}^{+-} \mathbf{1 - M}(\mathbf{1}=$ $\mathrm{C}_{6} \mathrm{H}_{6} \mathrm{~F}_{6}$ (all-cis-1,2,3,4,5,6-hexafluorocyclohexane) with $\mathrm{Be}, \mathrm{Mg}$, and $\mathrm{Ca}$ as an electron acceptor has been reported (Hou J. et al., 2018). Sajjad et al. carried out theoretical investigation of thermally stable alkaline earthides of $\mathrm{M}^{+}-\mathbf{1}-\mathrm{M}^{\prime}\left(\mathbf{1}=\mathrm{C}_{6} \mathrm{H}_{6} \mathrm{~F}_{6}\right.$ (all-cis-1,2,3,4,5,6-hexafluorocyclohexane). These complexes have large NLO response with the highest hyperpolarizability up to $4.14 \times 10^{9}$ au (Sajjad et al., 2020).

Ahsan et al. theoretically investigated the NLO response of two series of a novel organic $\mathrm{M}^{+}\left(2^{6} \mathrm{Adz}\right) \mathrm{M}^{-}\left(\mathrm{M}^{-}=\mathrm{Be}, \mathrm{Mg}\right.$ and $\left.\mathrm{Ca}\right)$ alkaline earthides. These complexes show remarkable NLO response up to $1.0 \times 10^{6}$ au (Ahsan and Ayub, 2020a). Zhu et al. reported alkaline-earthides of $\mathrm{Li}\left(\mathrm{NH}_{3}\right)_{4} \mathrm{M}(\mathrm{M}=\mathrm{Be}, \mathrm{Mg}, \mathrm{Ca})$ based on a cage-like complexant. These complexes have an $\mathrm{Li}^{+}$ cation near the center of the complexant and the alkaline-earth anion is present outside. These alkaline earthides exhibit larger NLO response up to $8.01 \times 10^{6}$ au and could be considered as novel NLO molecules (Zhu et al., 2019). Another example of alkaline earthide complexes based on hexaammine complexant $\mathrm{M}^{+}\left(\mathrm{NH}_{3}\right)_{6} \mathrm{M}^{-}\left(\mathrm{M}^{+}=\mathrm{Li}, \mathrm{Na}, \mathrm{K} ; \mathrm{M}^{-}=\mathrm{Be}, \mathrm{Mg}, \mathrm{Ca}\right)$ that show larger NLO have been investigated by Ahsan et al. (Ahsan and Ayub, 2020 b). These complexes have remarkable NLO response up to $6.4 \times 10^{5}$ au and were thermodynamically stable. Recently, the NLO response of superalkali containing alkaline earthides $\mathrm{M}_{3} \mathrm{O}^{+}$1-M'- $\left(1=\mathrm{C}_{6} \mathrm{H}_{6} \mathrm{~F}_{6} ; \mathrm{M}^{\prime}=\mathrm{Be}, \mathrm{Mg}\right.$, $\mathrm{Ca}$ and $\mathrm{M}=\mathrm{Li}, \mathrm{Na}$, and $\left.\mathrm{K}\right)$ has been explored. The highest first hyperpolarizability is up to $5.2 \times$ $10^{6} \mathrm{au}$ and shows that designed complexes would have potential applications in optoelectronics (Bano et al., 2022). 


\section{Coinage Metalides}

Coinage metalides are new representatives of excess electron compounds in which coinage metal atoms [copper $(\mathrm{Cu})$, silver $(\mathrm{Ag})$, and gold $(\mathrm{Au})]$ serve as excess electron acceptors. The $n s^{1}$ valence-electron configurations and higher electron affinities (EA) were main features of coinage metal atoms than alkali metal atoms. Therefore, it is highly expected that the coinage metal atoms would be used to produce a new type of stable NLO material. In this regard, designing of a series of all-cis-1,2,3,4,5,6hexafluorocyclohexane based $\mathrm{M}^{+}-1-\mathrm{M}^{\prime-}\left(1=\mathrm{C}_{6} \mathrm{H}_{6} \mathrm{~F}_{6}, \mathrm{M}^{\prime}=\mathrm{Cu}\right.$, $\mathrm{Ag}$, and $\mathrm{Au}$ and $\mathrm{M}=\mathrm{Li}, \mathrm{Na}$, and $\mathrm{K}$ ) complexes have been investigated, theoretically. These complexes were thermodynamically stable due to stronger electrostatic interactions. All these coinage metalides possess remarkably enhanced NLO response up to 90,220 au (X.-H. Li et al., 2020a).

\section{Superalkalides}

The excess electron compounds in which a superalkali bears the anionic site are termed superalkalides. The larger volume of superalkalides than alkalides results in loosely binding of excess electrons to the superalkali core. It results in a more diffuse and readily polarized electron density distribution of complexes. Therefore, superalkalides might be responsible for the enhancement of NLO response. It is more difficult to locate an acceptable complexant to synthesize superalkalides due to the more loosely bounded nature of excess electron in superalkalis. The complexant in superalkalides must be highly resistive toward reduction. In 2015, the designing of the first superalkalides $\mathrm{M}^{+}(\mathrm{en}){ }_{3} \mathrm{M}_{3} \mathrm{O}^{-}$(en = ethylenediamine; $\mathrm{M}, \mathrm{M}^{\prime}=\mathrm{Li}, \mathrm{Na}$, and $\left.\mathrm{K}\right)$ was carried out by the aid of $a b$ initio calculations. These superalkalides were stabilized by the presence of hydrogen bonds and have remarkable NLO response (Mai et al., 2015). Similarly, designing superalkalides $\mathbf{L}-\mathrm{M}-\mathbf{L}-\mathrm{M}_{3}^{\prime} \mathrm{O}\left(\mathbf{L}, \mathrm{C}_{6} \mathrm{H}_{6} \mathrm{~F}_{6}\right)$ has been investigated theoretically (B. Li et al., 2018). It was observed that designed superalkalides L-M-L- $\mathrm{M}_{3}^{\prime} \mathrm{O}$ were thermodynamically more stable than their respective alkalides. Moreover, these superalkalides possess larger NLO response up to $1.31 \times 10^{6}$ au for $\mathbf{L}-\mathrm{Li}-\mathrm{L}-\mathrm{Li}_{3} \mathrm{O}$ complex and would be useful candidates for high performance NLO materials.

\section{Supersalts}

Superalkalis in combination with superhalogens result in the formation of supersalts such as $\mathrm{Li}_{3} \mathrm{O}, \mathrm{Cs}_{2} \mathrm{NO}_{3}$, and $\mathrm{Cs}_{2} \mathrm{Cl}$ (superalkalis) in combination with $\mathrm{BeF}_{4}, \mathrm{BeF}_{3}$, and $\mathrm{NO}_{3}$ (superhalogens) constitute supersalts (Giri et al., 2014). Wang et al. theoretically observed superhalides of $\left(\mathrm{Li}_{3}\right)^{+}(\mathrm{SH})^{-}(\mathrm{SH}=$ $\mathrm{LiF}_{2}, \mathrm{BeF}_{3}$, and $\mathrm{BF}_{4}$ ). These superalkali-superhalogen compounds have special characteristics of low vertical ionization energy, delocalized $\sigma$ bonding orbital on the $\mathrm{Li}_{3}$ ring and are electrides or alkalides in nature (F. Wang et al., 2006). The theoretically calculated bond energies of $\mathrm{Li}_{6} \mathrm{~B}-\mathrm{X}\left(\mathrm{X}=\mathrm{F}, \mathrm{LiF}_{2}, \mathrm{BeF}_{3}, \mathrm{BF}_{4}\right)$ supersalts are up to $220.6 \mathrm{kcal} / \mathrm{mol}$ with enhanced NLO response ranging from 5166.5 to 17,791 au (Li et al., 2008). Similarly, the supersalts of $\mathrm{BF}_{4}-\mathrm{M}\left(\mathrm{M}=\mathrm{Li}, \mathrm{FLi}_{2}, \mathrm{OLi}_{3}, \mathrm{NLi}_{4}\right)$ have been investigated theoretically (Yang et al., 2012). The NLO response and binding energies of these ionic compounds are also higher than pure superalkalis.

\section{EXCESS ELECTRON BASED SYSTEMS IN NONLINEAR OPTICS}

Many organic and inorganic excess electron based NLO materials have been designed theoretically. Doping is an efficient approach to enhance the NLO response of various systems including cyclacene (Xu et al., 2009), calix [4] pyrrole (W. Chen et al., 2006), organic and inorganic fullerenes (Ahsan et al., 2021; S.; Liu et al., 2019; Shakerzadeh et al., 2016a; Ullah et al., 2020b), phosphorenes, $\mathrm{B}_{10} \mathrm{H}_{14}$ baskets (Muhammad et al., 2009), cyclic polyamines (Li et al., 2009a), fluorocarbons (H. L. Xu et al., 2007), and so forth.

\section{Fullerenes}

Kroto et al. invented fullerene, a third allotropic form of carbon, in 1985 and were awarded the Nobel prize in 1996 for fullerene discovery (Kroto et al., 1985; Lopez et al., 2011). Fullerenes are sp $^{2}$ hybridized polyhedral carbon cages with resonating $\pi$ electrons (Haymet, 1985; Haddon et al., 1986). Fullerenes exist in a variety of shapes, including hollow spheres, ellipsoids, and tubes depending on the amount of carbon atoms in them, for example, $\mathrm{C}_{20}, \mathrm{C}_{60}$, and $\mathrm{C}_{70}$ (Wakabayashi and Achiba, 1992; Ortíz-Saavedra et al., 1993; Fripertinger, 1996). Bucky balls, also known as spherical fullerene $\left(\mathrm{C}_{60}\right)$, is a stable carbon cluster with 20 hexagons and 12 pentagons that resemble a soccer ball (Hawkins et al., 1991). It has a hollow sphere like geometry with a diameter of $7 \AA ̊$. It is stabilized by electron resonance and can tolerate extreme temperature and pressure conditions (Chuvilin et al., 2010). Fullerenes have attracted extensive attention in various fields including optoelectronics (Tutt and Kost, 1992), information technology (Senftleben et al., 2009), biomedical (Q. Liu et al., 2014; Markovic and Trajkovic, 2008; Stoilova et al., 2007), etc. In the area of nonlinear optics, various classes of fullerene family such as endohedral fullerenes, exohedral fullerenes, and substituted fullerenes have been explored as in Figure 6.

Exohedral fullerenes are the most versatile fullerenes. They are formed by the doping of atoms to the outside of the fullerene cage. In this regard, $\mathrm{LaC}_{60}$ has been synthesized and theoretically investigated (Rosen and Wästberg, 1989; Rosen and Waestberg, 1988). The exohedral nature of fullerenes was also observed in superconductive alkali fullerides general formula $\mathrm{M}_{3} \mathrm{C}_{60}(\mathrm{M}=\mathrm{K}, \mathrm{Rb}, \mathrm{Cs})$ (Erwin and Pickett, 1991; Pauling, 1991; Sparn et al., 1991; Novikov et al., 1992). Endohedral metallofullerenes are formed by inside doping of metal atoms to a fullerene cage. Endohedral metallofullerenes were first predicted in 1985 by the encapsulation of the $\mathrm{La}^{+}$(lanthanum ion) in $\mathrm{C}_{60}$ (Heath et al., 1985). After the macroscopic manufacture of fullerenes in 1990, rapid research of its unique features became available (Krätschmer et al., 1990a; Krätschmer et al., 1990b). Polar endohedral metallofullerenes Li@C ${ }_{60}$ have emerged as novel nanomaterials from its first synthesis reported in 1996 (Tellgmann et al., 1996). Later on, two of its salts [ $\mathrm{Li}^{+} @$ $\left.\mathrm{C}_{60}\right] \mathrm{PF}_{6}{ }^{-}$and $\left[\mathrm{Li}^{+} @ \mathrm{C}_{60}\right] \mathrm{SbCl}_{6}{ }^{-}$have been synthesized and were confirmed by crystallographic analysis (Okada et al., 2012). A theoretical investigation on $\left[\mathrm{Li} @ \mathrm{C}_{60}\right] \mathrm{PF}_{6}$ endofullerene complex has been carried out and its spectral properties match well with 


\section{कर- \\ Buckminster Fullerene $\left(\mathrm{C}_{60}\right)$}

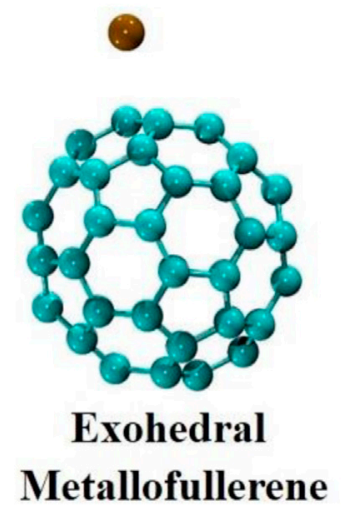

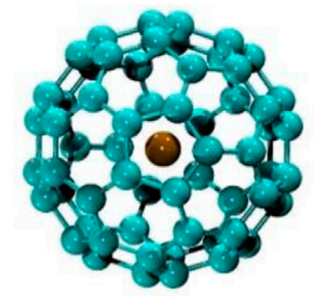

Endohedral Metallofullerene

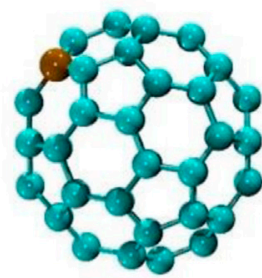

Substituted

Fullerene

FIGURE 6 | Fullerene $\left(\mathrm{C}_{60}\right)$ and its three main types of fullerenes.

the experimental data (Srivastava et al., 2016a). The endohedral metallofullerene complex of $\mathrm{Li} @ \mathrm{C}_{60}-\mathrm{PF}_{6}$ is resulted by the interaction of $\mathrm{Li} @ \mathrm{C}_{60}$ with $\mathrm{PF}_{6}$ superhalogen and shows a remarkable NLO response up to 1500 au. Similarly, NLO response of stable $\mathrm{Li} @ \mathrm{C}_{60}-\mathrm{BX}_{4}(\mathrm{X}=\mathrm{F}, \mathrm{Cl}, \mathrm{Br})$ complexes have been explored theoretically (S.-J. Wang et al., 2013). Superalkali $\left(\mathrm{Li}_{2} \mathrm{~F}, \mathrm{Li}_{3} \mathrm{O}, \mathrm{Li}_{4} \mathrm{~N}\right)$ entrapped $\mathrm{C}_{60}$ endofullerenes have been investigated theoretically and a comparison of their electronic properties with $\mathrm{Li} @ \mathrm{C}_{60}$ has been carried out (Srivastava et al., 2016). These superalkali@ $\mathrm{C}_{60}$ endofullerenes are stabilized by charge transfer from superalkali toward $\mathrm{C}_{60}$ fullerenes and have large polarizabilities. Superalkali endofullerenes on interaction with superhalogens $\mathrm{SA} @ \mathrm{C}_{60}-\mathrm{X}\left(\mathrm{SA}=\mathrm{Li}_{2} \mathrm{~F}, \mathrm{Li}_{3} \mathrm{O}, \mathrm{Li}_{4} \mathrm{~N}, \mathrm{X}=\mathrm{BF}_{4}\right.$, $\mathrm{BCl}_{4}$, and $\mathrm{BBr}_{4}$ ) form stable endofullerene complexes (Srivastava et al., 2017). The nonlinear optical response has been computed for these complexes and the highest NLO response up to $3.2 \times 10^{4}$ au for $\mathrm{Li}_{2} \mathrm{~F} @ \mathrm{C}_{60}-\mathrm{BBr}_{4}$ has been computed. Fullerenes with encapsulated metal atoms have unique features that are not present in pristine fullerenes (A. A. Popov et al., 2013). Endohedral fullerene complexes have prospective applications in MRI contrast agents (Anilkumar et al., 2011; Zhang et al., 2007), radiotracers (Kobayashi et al., 1995), polymeric solar cells (PSCs) (Ross et al., 2009), lasers (Yakigaya et al., 2007), optoelectronics (B. Wu et al., 2015; Lee et al., 2002), and in quantum computers (Benjamin et al., 2006).

Substituted fullerenes, also known as hetero-fullerenes, have one or more carbon atom of fullerene replaced by heteroatoms. The first heterofullerene $\mathrm{C}_{59} \mathrm{~B}$ was synthesized by Gou et al., in 1991 (Guo et al., 1991). Similarly, synthesis and electronic structure of five stable metallocarbohedrenes $\mathrm{M}_{8} \mathrm{C}_{12}((\mathrm{M}=\mathrm{Ti}$,
Zr, Hf, V) have been achieved by using anion photoelectron spectroscopy (S. Li et al., 1997). Since then, a variety of hybrid or non-carbon fullerene-like structures with varied numbers of substituted metal atoms $\left(\mathrm{Al}_{12} \mathrm{~N}_{12}, \mathrm{~B}_{12} \mathrm{~N}_{12}, \mathrm{Al}_{12} \mathrm{P}_{12}, \mathrm{~B}_{12} \mathrm{P}_{12}\right.$ etc. has also been reported (Akasaka et al., 1999; Billas et al., 2000; Liu et al., 2019; Paul et al., 2017) and is shown in Figure 7.

The replacement of $\mathrm{C}=\mathrm{C}$ double bonds with $\mathrm{X}-\mathrm{Y}$ hetero bonds is a viable technique for the development of stable heterofullerenes. The geometric, stability and electronic properties of $\mathrm{C}_{20}$ analogous-heterofullerenes $\mathrm{X}_{4} \mathrm{Y}_{4} \mathrm{C}_{12}(\mathrm{X}=\mathrm{B}$, $\mathrm{Al}, \mathrm{Ga}, \mathrm{Si}$ and $\mathrm{Y}=\mathrm{N}, \mathrm{P}, \mathrm{As}, \mathrm{Ge}$ ) have been investigated theoretically (Koohi et al., 2018). The homonuclear noncarbon nanocages may include gold (Gao et al., 2014; Zheng et al., 2018a) and boron nanocages (Z. Wang et al., 2020) while nitrides and phosphides of group III and carbides of group IV are included in heteronuclear non-carbon nanocages (Tahmasebi et al., 2016). The relative stabilities of different sized nanocages have been the subject of several theoretical investigations. Fowler et al. theoretically investigated that $\mathrm{B}_{12} \mathrm{~N}_{12}$ is the most stable nanocage among $\mathrm{B}_{12} \mathrm{~N}_{12}, \mathrm{~B}_{16} \mathrm{~N}_{16}$, and $\mathrm{B}_{28} \mathrm{~N}_{28}$ nanoclusters (Seifert et al., 1997). The first synthesis of $\mathrm{B}_{12} \mathrm{~N}_{12}$ nanocluster was carried out by Oku et al. and was detected by laser desorption time-off-light mass spectrometry (Oku et al., 2004). Wu et al. explored a series of $(\mathrm{AlN})_{\mathrm{n}}(\mathrm{n}=2-41)$ nanocages and concluded that $\mathrm{Al}_{12} \mathrm{~N}_{12}$ inorganic fullerene is the most stable and served as a suitable NLO substrate (H.-S. Wu et al., 2003). Similarly, Beheshtian et al. explored the geometric and electronic properties of $\mathrm{Al}_{12} \mathrm{~N}_{12}$, $\mathrm{B}_{12} \mathrm{~N}_{12}, \mathrm{Al}_{12} \mathrm{P}_{12}$, and $\mathrm{B}_{12} \mathrm{P}_{12}$ fullerenes like structure via DFT simulations (Beheshtian et al., 2012). These nanostructures are 


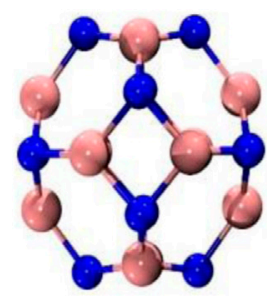

$\mathrm{Al}_{12} \mathbf{N}_{12}$
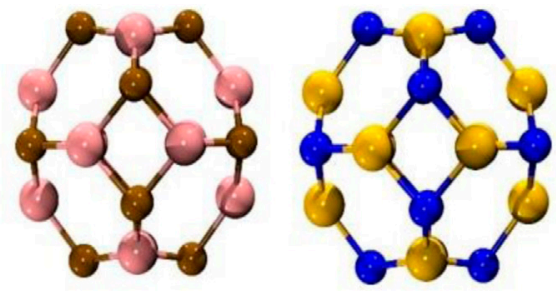

$\mathbf{B}_{12} \mathbf{N}_{12}$

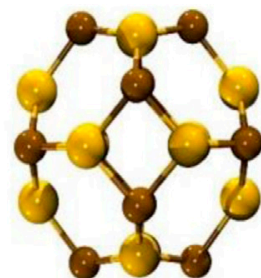

$\mathbf{B}_{12} \mathbf{P}_{12}$

FIGURE 7 | Non-carbon fullerene like nanoclusters of $\mathrm{Al}_{12} \mathrm{~N}_{12}, \mathrm{Al}_{12} \mathrm{P}_{12}, \mathrm{~B}_{12} \mathrm{~N}_{12}$, and $\mathrm{B}_{12} \mathrm{P}_{12}$.

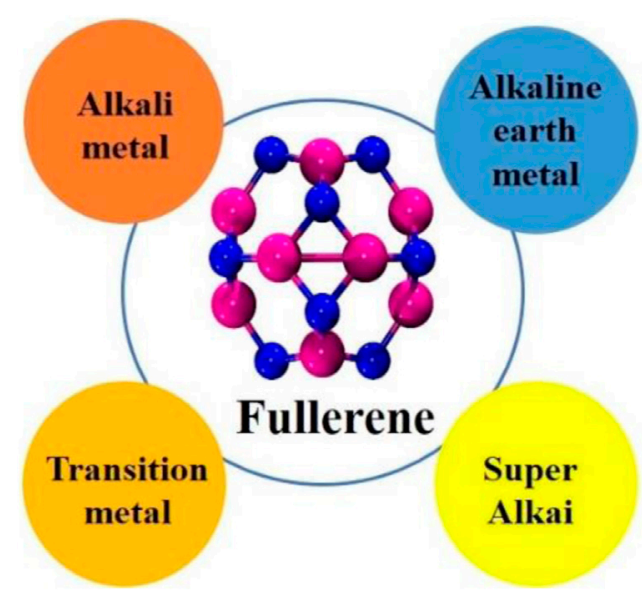

FIGURE 8 | Excess electron-based dopants for fullerenes.

semiconductor materials with a wide energy gap. Group III nitrides and phosphides with fullerene like properties come in a variety of sizes. The geometrical, electrical, and nonlinear optical properties of these fullerene-like structures were altered on heteroatom introduction. These nanocages can be doped by various electron-based systems as shown in Figure 8.

\section{Alkali Metal Doped Nanocages}

Introduction of diffuse excess electron is an efficient approach to improve the NLO response of various systems. Alkali metals can donate excess electrons easily due to low ionization potential (Redko et al., 2005). Fullerene like nanostructures of group II-VI and III-V $\left(\mathrm{Al}_{12} \mathrm{~N}_{12}, \mathrm{~B}_{12} \mathrm{~N}_{12}, \mathrm{Al}_{12} \mathrm{P}_{12}, \mathrm{~B}_{12} \mathrm{P}_{12}, \mathrm{Be}_{12} \mathrm{O}_{12}, \mathrm{Mg}_{12} \mathrm{O}_{12}\right.$, $\mathrm{Ca}_{12} \mathrm{O}_{12}, \mathrm{Si}_{12} \mathrm{C}_{12}$, etc.) are important sources of nanoscale materials due to their potential applications as solar cells, optoelectronics quantum devices, hydrogen storage, photocatalysts, and in biomedicine ( $\mathrm{Rad}$ and Ayub, 2018a; Zheng et al., 2018b; Ravaei et al., 2019; Zhou et al., 2019). The geometrical, electrical, and optical properties of these nanocages will be altered on the introduction of alkali metal. Niu et al. observed the alkali metal doping at various position of M@ $x-\mathrm{Al}_{12} \mathrm{~N}_{12}\left(x=b_{66}, b_{64}\right.$, and $\left.r_{6}\right)$. Diffuse excess electrons of alkali metals have lowered the energy gap that led to an enhancement in NLO response of $\mathrm{Al}_{12} \mathrm{~N}_{12}$. The highest $\beta_{0}$ of $8.89 \times 10^{5}$ au has been obtained for $\mathrm{Li} @ \mathrm{r}_{6}-\mathrm{Al}_{12} \mathrm{~N}_{12}$. It reflects that designed complexes will be applicable in hi-tech NLO materials and electronic nanodevices (Niu et al., 2014). Alkali metal doping at various position $\left(b_{64}\right.$, and $\left.r_{6}\right)$ of $\mathrm{Al}_{12} \mathrm{~N}_{12}$ nanocage is shown in Figure 9.

Alkali metal doping on $\mathrm{Be}_{12} \mathrm{O}_{12}$ and $\mathrm{Mg}_{12} \mathrm{O}_{12}$, the most viable clusters of group II-VI, has been reported. Their results show that alkali metal interaction with $\mathrm{Be}_{12} \mathrm{O}_{12}$ and $\mathrm{Mg}_{12} \mathrm{O}_{12}$ tuned up their structural and optoelectronic properties. A more pronounced NLO response was observed by exohedral doping and was larger than encapsulated ones for these metal oxide nanoclusters (Shakerzdeh et al., 2015). First synthesis of $\mathrm{B}_{12} \mathrm{~N}_{12}$ nanocage and its detection by laser desorption mass spectrometry by $\mathrm{Oku}$ et al. opened new research perspectives in various fields (Oku et al., 2004). Theoretical investigation of alkali metals doped $\mathrm{MB}_{12} \mathrm{~N}_{11}$ and $\mathrm{MB}_{11} \mathrm{~N}_{12}$ has been carried out for their potential applications in nonlinear optics. The highest NLO response of 1.3 $\times 10^{4}$ au for $\mathrm{KB}_{12} \mathrm{~N}_{11}$ was obtained (Maria et al., 2016). In another work, structural stability, boundary crossing barriers, and NLO properties of alkali metals encapsulated $\mathrm{X}_{12} \mathrm{Y}_{12}$ nanocages $(\mathrm{X}=\mathrm{B}$, $\mathrm{Al}$ and $\mathrm{Y}=\mathrm{N}, \mathrm{P}$ ) have been studied. A correlation existed between the size of alkali metal with adsorption energies of complexes and diameter of nanocages with the distortion energies. It was concluded that the nonlinear optical properties of alkali metal encapsulated phosphide nanocages $\left(\mathrm{B}_{12} \mathrm{P}_{12}\right)$ were two to three times larger than those of corresponding nitride nanocages. The highest NLO response was obtained for $\mathrm{K} @ \mathrm{~B}_{12} \mathrm{P}_{12}$ nanocage, i.e., $5.7 \times 10^{5}$ au due to its very low excitation energy $(0.5 \mathrm{eV})$ (Ayub, 2016). In 2016, Hou et al. studied the structural and NLO response of alkali metal atoms doped $\mathrm{B}_{12} \mathrm{~N}_{12}$ electrides via DFT simulations. It was observed that HOMO-LUMO energy gap of designed electrides was lowered by the introduction of excess electrons of alkali metals. The highest nonlinear optical response of 18,889 au was observed in $\mathrm{B}_{12} \mathrm{~N}_{12}-\mathrm{Na}$ isomer. The decrease in transition energy values in the range of $1.4-2.3 \mathrm{eV}$ has caused the enhancement in NLO response (N. Hou et al., 2016).

Shakerzadeh and co-workers observed the electro-optical properties of $\mathrm{Li}$ complexation with $\mathrm{B}_{12} \mathrm{~N}_{12}$ and $\mathrm{B}_{16} \mathrm{~N}_{16}$ nanoclusters theoretically. It was concluded that $\mathrm{Li}$ complexation with boron nitride nanoclusters has significantly tuned up the nonlinear optical response with the reduction in 


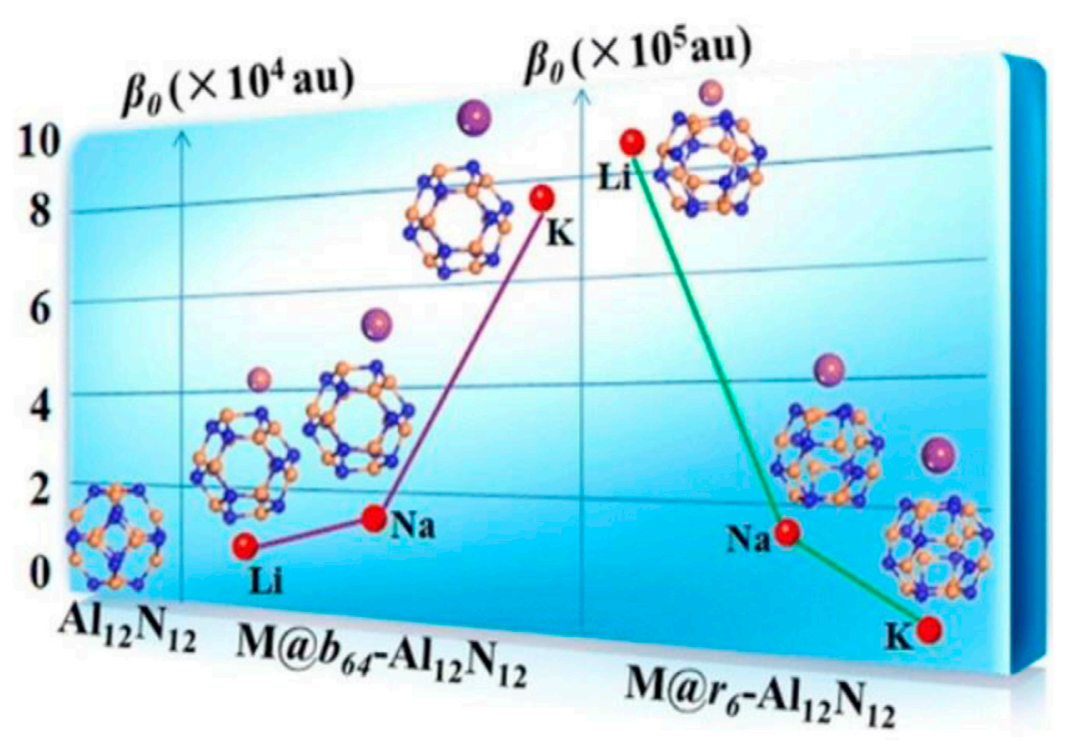

FIGURE 9 | Alkali metal doping at various positions of $\mathrm{M} @ x-\mathrm{Al}_{12} \mathrm{~N}_{12}$ nanocage $\left(x=b_{64}\right.$, and $\left.r_{6}\right)$. Reprinted with permission from Niu et al., 2014. Copyright (2014) American Chemical Society.

HOMO-LUMO energy gap. Large NLO response in the range of 2975-130,837 au reflected that the Li complexed boron nitride clusters could serve as innovative electro-optical materials (Shakerzadeh et al., 2016b). The same group observed the optoelectronic effect of alkali metals ( $\mathrm{Li}, \mathrm{Na}$, and $\mathrm{K}$ ) encapsulation on $\mathrm{B}_{12} \mathrm{~N}_{12}, \mathrm{Al}_{12} \mathrm{~N}_{12}, \mathrm{Ga}_{12} \mathrm{~N}_{12}, \mathrm{C}_{24}, \mathrm{Si}_{12} \mathrm{C}_{12}$, and $\mathrm{Ge}_{12} \mathrm{C}_{12}$ nanoclusters of group III nitrides and group IV carbides. Nitride nanoclusters show remarkable NLO response than that of corresponding carbides. Optoelectronic properties of $\mathrm{B}_{12} \mathrm{~N}_{12}$ complexes especially hyperpolarizabilities were remarkably

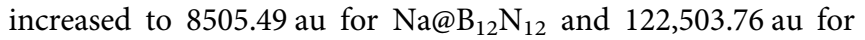
$\mathrm{K} @ \mathrm{~B}_{12} \mathrm{~N}_{12}$ (Tahmasebi et al., 2016).

Alkali metal substituted $\mathrm{MX}_{12} \mathrm{P}_{11}$ and $\mathrm{MX}_{11} \mathrm{P}_{12}(\mathrm{X}=\mathrm{B}, \mathrm{Al})$ nanocages were also explored for geometric, electronic, and NLO properties investigation. Diffuse excess electrons of alkali metals $(\mathrm{M}=\mathrm{Li}, \mathrm{Na}$, and $\mathrm{K})$ have boosted up the NLO response of phosphide nanocages by the decrease in HOMO-LUMO energy gap (Maria et al., 2017). In the same year, Song et al. computed the optoelectronic properties of alkali metal doped $\mathrm{C}_{24} \mathrm{~N}_{24}$ nanocage by using DFT calculations. Alkali metals were doped outside $(\mathrm{M}=$ $\mathrm{Li}, \mathrm{Na}$, and $\mathrm{K})$ and inside $(\mathrm{M}=\mathrm{Na}$ and $\mathrm{K})$ the nanocage at various doping positions. Alkali metal doping altered the electronic properties and orbital energy gap have lowered in both cases in contrast to pristine $\mathrm{C}_{24} \mathrm{~N}_{24}$. The highest first hyperpolarizabilities obtained for $\mathrm{M}_{\text {out }} @ \mathrm{C}_{24} \mathrm{~N}_{24}$ and $\mathrm{M}_{\mathrm{int}} @$ $\mathrm{C}_{24} \mathrm{~N}_{24}$ were 1242 au and 4772 au, respectively (Song et al., 2017). Stable $\mathrm{Si}_{12} \mathrm{C}_{12}$ nanocage has been observed theoretically and has many applications in optical communication, optical data storage, laser devices, and optical computing (Pochet et al., 2010; Javan, 2013; Duan and Burggraf, 2015). Theoretical investigation of alkali metals $(\mathrm{M}=\mathrm{Li}, \mathrm{Na}$, and $\mathrm{K}$ ) doping on $\mathrm{Si}_{12} \mathrm{C}_{12}$ nanocage was carried out. There was a remarkable enhancement in nonlinear optical response of $\mathrm{M} @ \mathrm{Si}_{12} \mathrm{C}_{12}$ complexes as compared to pristine $\mathrm{Si}_{12} \mathrm{C}_{12}$ (Solimannejad et al., 2017).

Exploring novel NLO materials is an area of scientific investigation of our recent era. In this regard, $\mathrm{Zn}_{12} \mathrm{O}_{12}$ nanocage served as a stable motif with a potential for cluster materials (Reber et al., 2006). In a recent work, endohedral and exohedral doping of alkali metals on $\mathrm{Zn}_{12} \mathrm{O}_{12}$ clusters at all possible sites have been carried out. The DFT results manifest that most of $\mathrm{M} @ \mathrm{Zn}_{12} \mathrm{O}_{12}$ complexes were electride in nature and thermodynamically stable. Alkali metal doped $\mathrm{Zn}_{12} \mathrm{O}_{12}$ nanocages have prominent features of exothermic encapsulation superior to other inorganic nanocages with endothermic encapsulation. The energy gaps were significantly reduced with the enhancement in NLO response. The highest NLO response of $1.0 \times 10^{5}$ au was observed for $\mathrm{K} @ \mathrm{r}_{6}-\mathrm{Zn}_{12} \mathrm{O}_{12}$ complex. Third order NLO response was also computed for the designed M@ $\mathrm{Zn}_{12} \mathrm{O}_{12}$ electrides (S. Khan et al., 2021b). Similarly, geometric, electronic, and NLO response of endohedral and exohedral alkali metal doped $\mathrm{Ca}_{12} \mathrm{O}_{12}$ electrides have been studied. The excess electrons of alkali metals have caused reduction in energy gaps of these complexes. The highest NLO response of the order of $1.0 \times 10^{6}$ au was obtained for endohedral electrides (endo-K@ $\mathrm{Ca}_{12} \mathrm{O}_{12}$ ) (Ahsan et al., 2021).

Recently, a DFT investigation of bi-alkali metals $\left(\mathrm{Li}_{2}, \mathrm{Na}_{2}, \mathrm{~K}_{2}\right)$ doped $\mathrm{B}_{12} \mathrm{P}_{12}$ nanocages has proved to be an effective approach. These bi-alkali metals doped complexes were thermodynamically stable with enhanced NLO response of the order of $4.0 \times 10^{4}$ au. Non-covalent interactions and atoms in molecules analyses reflected their bonding phenomenon (Baloach et al., 2021). In other work, bi-alkali metal doped $\mathrm{Al}_{12} \mathrm{~N}_{12}$ nanoclusters were explored with greater stability. A remarkable enhancement in the NLO response with the reduction in HOMO-LUMO energy gap was observed. The highest hyperpolarizability of $1.2 \times 10^{5}$ au 
TABLE 3 | Alkali metal doped complexes with enhanced nonlinear optical responses.

\begin{tabular}{|c|c|c|c|c|}
\hline Complex & Hyperpolarizability (au) & Software & Level of theory & References \\
\hline $\mathrm{Li} @ \mathrm{r}_{6}-\mathrm{Al}_{12} \mathrm{~N}_{12}$ & $8.8 \times 10^{5}$ & Gaussian & $\begin{array}{l}\text { MP2/ } \\
6-31+G(d)\end{array}$ & Niu et al. (2014) \\
\hline $\mathrm{Li} @ \mathrm{Be}_{12} \mathrm{O}_{12}$ & $9.4 \times 10^{3}$ & Gaussian & $\begin{array}{l}\text { CAM-B3LYP/ } \\
6-311+G(d)\end{array}$ & Shakerzdeh et al. (2015) \\
\hline $\mathrm{Li} @ \mathrm{Mg}_{12} \mathrm{O}_{12}$ & $2.7 \times 10^{4}$ & Gaussian & $\begin{array}{l}\text { CAM-B3LYP/ } \\
6-311+G(d)\end{array}$ & Shakerzdeh et al. (2015) \\
\hline $\mathrm{K}-\mathrm{B}_{12} \mathrm{~N}_{11}$ & $1.3 \times 10^{4}$ & Gaussian & $\begin{array}{l}\text { CAM-B3LYP/ } \\
6-31+G(d)\end{array}$ & Maria et al. (2016) \\
\hline $\mathrm{K} @ \mathrm{~B}_{12} \mathrm{P}_{12}$ & $5.7 \times 10^{5}$ & Gaussian & $\begin{array}{l}\text { CAMB3LYP/ } \\
6-311+G(d)\end{array}$ & Ayub, (2016) \\
\hline $\mathrm{Na} @ \mathrm{~B}_{12} \mathrm{~N}_{12}$ & $1.8 \times 10^{4}$ & Gaussian & $\begin{array}{l}\mathrm{MP} 2 / \\
6-31+\mathrm{G}(\mathrm{d})\end{array}$ & N. Hou et al. (2016) \\
\hline $\begin{array}{l}\mathrm{Na} @ \mathrm{Si}_{12} \mathrm{C}_{12} \\
\mathrm{~K} @ \mathrm{Ca}_{12} \mathrm{O}_{12}\end{array}$ & $\begin{array}{l}5.7 \times 10^{3} \\
1.0 \times 10^{6}\end{array}$ & $\begin{array}{l}\text { Gaussian } \\
\text { Gaussian }\end{array}$ & $\begin{array}{l}\text { MP2/6-31+G(d) } \\
\omega B 97 X D / \\
6-31 G(d, p)\end{array}$ & $\begin{array}{l}\text { Solimannejad et al. (2017) } \\
\text { Ahsan et al. (2021) }\end{array}$ \\
\hline
\end{tabular}

for $\mathrm{K}_{2} @ \mathrm{~N}_{\text {top }}-\mathrm{Al}_{12} \mathrm{~N}_{12}$ reflected that these bi-alkali metal doped complexes proved as potential candidates in high-tech NLO materials (Sohail et al., 2021). The highest nonlinear optical response of some alkali metal doped nanocages is listed in Table 3.

\section{Alkaline Earth Metal Doped Nanocages}

Alkaline earth metals ( $\mathrm{Be}, \mathrm{Mg}, \mathrm{Ca}, \mathrm{Sr}, \mathrm{Ba}$, and $\mathrm{Ra}$ ) are also a good source of excess electrons for complexes. In this regard, alkaline earth metal oxides especially $\mathrm{BeO}$ and $\mathrm{MgO}$ are wurtzite insulators, with very high thermal conductivity and melting points (Duman et al., 2009). Nonlinear optical response of alkaline earth metals doped $\mathrm{Be}_{12} \mathrm{O}_{12}$ and $\mathrm{Mg}_{12} \mathrm{O}_{12}$ nanocluster was studied. Excess electrons of alkaline earth metals have profoundly enhanced the $\mathrm{NLO}$ response of $\mathrm{Be}_{12} \mathrm{O}_{12}$ and $\mathrm{Mg}_{12} \mathrm{O}_{12}$ nanocages and their HOMO-LUMO gaps were lowered. The highest hyperpolarizability of the order of $4.72 \times$ $10^{4} \mathrm{au}$ was obtained for endo- $\mathrm{Ca} @ \mathrm{Mg}_{12} \mathrm{O}_{12}$. Hyperpolarizability trend was rationalized by two-level model calculations and $\beta_{\text {vec }}$ was also computed (Kosar et al., 2020a). In another work, alkaline earth metals doping on $(\mathrm{XY})_{12}(\mathrm{X}=\mathrm{Al}, \mathrm{B}$, and $\mathrm{Y}=\mathrm{P})$ based phosphide nanoclusters of group III has been observed theoretically. Excess electrons of alkaline earth metals have lowered the HOMO-LUMO gaps of designed complexes and enhanced NLO response. The highest hyperpolarizability of the order of $7.8 \times 10^{4}$ au was observed in this case (Ullah et al., 2020b). Similarly alkaline earth metals doping on $\mathrm{Al}_{12} \mathrm{~N}_{12}$ nanocages was carried out by using DFT calculations. It was observed that designed complexes were thermodynamically stable, and their energy gaps $\left(\mathrm{G}_{\mathrm{H}-\mathrm{L}}\right)$ were significantly reduced. These designed complexes have the ability to serve as potential NLO candidates as they have large NLO response of 7769 au as compared to pristine $\mathrm{Al}_{12} \mathrm{~N}_{12}$ (0 au) (Ullah et al., 2020c). Further exploration of NLO materials by single and multi-doping of odd number alkaline earth metals on $\mathrm{C}_{20}$ fullerenes was carried out. The stable complex $\mathrm{Ca}_{5} @ \mathrm{C}_{20}$ has the highest hyperpolarizability of $6.5 \times 10^{7}$ au with the energy gap of $1.40 \mathrm{eV}$. These multialkaline earth metals doped complexes would be an ideal choice to obtain novel nanomaterials in optoelectronics (Tahir et al.,
2020). In other work, theoretical investigation of $\mathrm{Be}, \mathrm{Mg}$, and $\mathrm{Ca}$ (even number $=2,4,6$ ) doped $\mathrm{C}_{20}$ nanocluster have been carried out. The complexes were thermodynamically stable and the highest binding energy of $-241.18 \mathrm{kcalmol}^{-1}$ was observed for $\mathrm{Be}_{6} @ \mathrm{C}_{20}$. Their energy gap $\left(\mathrm{G}_{\mathrm{H}-\mathrm{L}}\right)$ was effectively reduced for all complexes with the lowest value of $0.82 \mathrm{eV}$ for $\mathrm{Ca}_{6} @ \mathrm{C}_{20}$ nanocluster. Their NLO response was also enhanced significantly but was lower than odd alkaline earth metal doped $\mathrm{C}_{20}$ (Kosar et al., 2021b). Single and multi-alkaline earth metal atoms doping on $\mathrm{C}_{24}$ fullerene have been carried out. The $\mathrm{Be}_{4} @ \mathrm{C}_{24}$ has the highest stabilization energy of $-182.87 \mathrm{kcal} \mathrm{mol}^{-1}$ which reflected that designed complexes are thermodynamically stable. The lowest energy gap $\left(\mathrm{G}_{\mathrm{H}-\mathrm{L}}\right)$ of $0.83 \mathrm{eV}$ for $\mathrm{Mg}_{4} @ \mathrm{C}_{24}$ has reflected its conductive nature. Newly generated HOMO orbitals (due to excess electrons) have dramatically enhanced the NLO response up to $3.62 \times 10^{6}$ au in the case of $\mathrm{Mg}_{4} @ \mathrm{C}_{24}$. These results have paved the way to synthesize highly efficient optoelectronic materials (Kosar et al., 2021c).

\section{Transition Metal Doped Nanocages}

DFT investigation of second row transition metal atoms (zirconium $(\mathrm{Zr})$, ruthenium $(\mathrm{Ru})$, molybdenum $(\mathrm{Mo})$, and palladium $(\mathrm{Pd})$ ) substituted $\mathrm{C}_{20}$ fullerene was carried out. The results manifest that charge distribution of $\mathrm{C}_{20}$ was altered by substitution. The HOMO-LUMO energy gap was lowered in the case of $\mathrm{Zr}$ and Mo atoms while it was increased on $\mathrm{Ru}$ and $\mathrm{Pd}$ substitution. Their nonlinear optical properties including polarizability and hyperpolarizabilities were improved. Their first hyperpolarizabilities were 2795, 2775, 1304, and 66,669 au for $\mathrm{Zr}, \mathrm{Mo}, \mathrm{Ru}$, and $\mathrm{Pd}$ substituted $\mathrm{C}_{20}$ nanocluster ( $\mathrm{Rad}$ and Ayub, 2017). Scandium (Sc) doped $\mathrm{Be}_{12} \mathrm{O}_{12}, \mathrm{Mg}_{12} \mathrm{O}_{12}$, and $\mathrm{Ca}_{12} \mathrm{O}_{12}$ nanocages were explored to study the effect of Sc doping on structure, stability, and optoelectronic properties. Reduction in energy gaps of designed complexes has enhanced conductance of Sc doped complexes. NLO response of all designed complexes was increased and the highest NLO was obtained for Sc-doped $\mathrm{Ca}_{12} \mathrm{O}_{12}$. TD-DFT calculations also confirmed that the highest hyperpolarizability was observed 
for Sc-doped $\mathrm{Ca}_{12} \mathrm{O}_{12}$ nanoclusters with the smallest transition energy values $(\Delta \mathrm{E})$. Sc-doped nanoclusters would be an ideal candidate for optoelectronic devices (Omidi et al., 2017). Exohedral doping of the first row transition metal doping at various sites $\left(\mathrm{x}=\mathrm{b}_{64}, \mathrm{~b}_{66}, \mathrm{r}_{6}\right.$, and $\left.\mathrm{r}_{4}\right)$ of $\mathrm{Al}_{12} \mathrm{~N}_{12}$ nanocage was carried out. The geometric, electronic, and optoelectronic properties were computed for all $\mathrm{M} @ \mathrm{x}-\mathrm{Al}_{12} \mathrm{~N}_{12}$ complexes and their spin state stability was also computed. Transition metal doping resulted in chemisorption and a remarkable reduction in energy gap up to $40 \%$ were observed in this case. Their NLO response was comparable to their alkali metal doped $\mathrm{Al}_{12} \mathrm{~N}_{12}$ analogs and the highest NLO response of $1.85 \times 10^{4}$ au was observed for $\mathrm{Cu} @ \mathrm{r}_{6}-\mathrm{Al}_{12} \mathrm{~N}_{12}$ (Arshad et al., 2018).

Gilani et al. have carried out exohedral and endohedral doping of copper on $\mathrm{Al}_{12} \mathrm{~N}_{12}$ nanocages. It was concluded that the $\mathrm{Cu} @$ $\mathrm{r}_{6}-\mathrm{Al}_{12} \mathrm{~N}_{12}$ (copper at the center of the six-membered ring of $\mathrm{Al}_{12} \mathrm{~N}_{12}$ ) has the highest reduction in energy gap $\left(\mathrm{E}_{\mathrm{g}}\right)$ up to $52 \%$. Excess electrons have generated a new HOMO orbital between the original Frontier molecular orbitals as revealed from total and partial densities of states. The highest NLO response of $1.8 \times$ $10^{4}$ au was observed for $\mathrm{Cu} @ \mathrm{r}_{6}-\mathrm{Al}_{12} \mathrm{~N}_{12}$ as in the case of previous studies. TD-DFT simulations were performed to obtain crucial excited states. Two level model-based verification of hyperpolarizability was also carried out. These striking results reflect that the designed copper doped complexes would have potential applications in nonlinear optics (Gilani et al., 2018). Ali et al. have explored the exohedral doping of nickel metal (Ni) on inorganic $\mathrm{Mg}_{12} \mathrm{O}_{12}$ nanocluster by using DFT simulations. Different energy changes including zero-point energies (ZPE), thermal enthalpies $(\Delta \mathrm{H})$, thermal energies $(\Delta \mathrm{E})$, and thermal Gibbs free energies $(\Delta \mathrm{G})$ were also computed and compared with interaction energies of $\mathrm{Ni@} \mathrm{Mg}_{12} \mathrm{O}_{12}$ nanocluster. A remarkably enhanced nonlinear optical response on doping was observed as compared to pristine $\mathrm{Mg}_{12} \mathrm{O}_{12}$ ( $\mathrm{Rad}$ and Ayub, 2018b). In another work, $\mathrm{Rad}$ et al. carried out substitutional doping of transition metal $(\mathrm{Cr}, \mathrm{Ni}$, and $\mathrm{Ti})$ at $\mathrm{C}_{20}$ fullerene theoretically. Transition metals substitution has altered the charge distribution of $\mathrm{C}_{20}$ with the highest charge distribution for $\mathrm{TiC}_{19}$. The nonlinear optical properties were enhanced significantly and the highest hyperpolarizability $2.5 \times 10^{3}$ au observed in the case of $\mathrm{TiC}_{19}$ complex (Rad and Ayub, 2018c).

In 2019, the same group also performed the substitutional doping of transition metal ( $\mathrm{Sc}, \mathrm{Fe}, \mathrm{Cu}$, and $\mathrm{Zn}$ ) at $\mathrm{C}_{20}$ fullerene via DFT simulations. Replacement of carbon by a transition metal has enhanced the optoelectronic properties and the highest hyperpolarizability of 2224.5 au was observed for $\mathrm{Sc}-\mathrm{C}_{19}$. Furthermore, the results of reactivity descriptors reflected iron-substituted fullerene $\left(\mathrm{Fe}-\mathrm{C}_{19}\right)$ as the softest metal. These results showed that designed transition metal substituted fullerene would have promising applications in optoelectronics (Rad and Ayub, 2019). The optoelectronic effect of the first row transition metal doping $\mathrm{C}_{24} \mathrm{~N}_{24}$ cavernous nitride fullerene has been performed via DFT simulation. Transition metal atoms were doped in the N4 cavity of the nanocage. Spin state analysis reflected that spin state stability increases to sextet up to Mn@ $\mathrm{C}_{24} \mathrm{~N}_{24}$ and then gradually decreases to singlet for $\mathrm{Zn@C} \mathrm{C}_{24} \mathrm{~N}_{24}$ system. Transition metal atoms have decreased the HOMO-
LUMO energy gap up to $63 \%$. The NLO response was enhanced for all $\mathrm{M} @ \mathrm{C}_{24} \mathrm{~N}_{24}$ cavernous nitride complexes and reflected that designed complexes would be better candidates for high performance NLO materials (Shakerzadeh et al., 2020a). The first experimental synthesis of novel all-boron fullerene $\mathrm{B}_{40}$ has opened new research avenues for its potential application in various fields (Zhai et al., 2014).

Optoelectronic properties of the first row transition metal decorated at hexagonal and heptagonal rings of $\mathrm{B}_{40}$ fullerene have been computed. Obtained complexes were stable with the reduced HOMO-LUMO energy gaps and work functions. The highest hyperpolarizability of $1.35 \times 10^{5}$ au was observed for cobalt (Co) doped $B_{40}$ fullerene (Shakerzadeh et al., 2020b). Ullah et al. investigated the structural and optoelectronic effect of first row transition metals decorated $\mathrm{Al}_{12} \mathrm{P}_{12}$ heterofullerene. Thermally stable $\mathrm{M} @ \mathrm{Al}_{12} \mathrm{P}_{12}$ complexes have reduced energy gaps due to excess electrons of transition metal atoms. Nonlinear optical properties were enhanced and the highest hyperpolarizability up to $5.9 \times 10^{6}$ au was obtained (Ullah et al., 2021). Similarly, optoelectronic properties of transition metal doped $\mathrm{B}_{12} \mathrm{P}_{12}$ nanocage at different doping sites have been explored via DFT simulations. Adsorption of the first row transition metals at $\mathrm{B} 12 \mathrm{P} 12$ have significantly enhanced the thermodynamic stability with the highest interaction energy of $-74.42 \mathrm{kcal} \mathrm{mol}^{-1}$ for $\mathrm{Ni} @ \mathrm{r}_{4}-\mathrm{B}_{12} \mathrm{P}_{12}$ nanocluster. Their NLO response has improved remarkably up to $4.4 \times 10^{4}$ au due to excess electron of transition metals. Furthermore, SHG and EOPE values of $1.1 \times 10^{5}$ and $4.4 \times 10^{5}$ au for $\mathrm{Sc} @ \mathrm{~B}_{12} \mathrm{P}_{12}$ showed that designed $\mathrm{M} @ \mathrm{~B}_{12} \mathrm{P}_{12}$ have a tendency to serve as NLO materials (Irshad et al., 2021). Recently, Khaliq et al. investigated the NLO properties of lanthanum metal doping on $\mathrm{Al}_{12} \mathrm{~N}_{12}$ and $\mathrm{Al}_{12} \mathrm{P}_{12}$ nanoclusters. Interaction energy analysis indicated that designed complexes were stable and exohedral doping was more favorable than endohedral doping. Lanthanum doping has uplifted the NLO responses of complexes up to $4.43 \times 10^{4}$ au and will serve as a high-tech NLO material in optoelectronics (Khaliq et al., 2021a). The highest nonlinear optical response of some alkali metal doped nanocages is listed in Table 4.

\section{Superalkali Doped Nanocages}

Superalkalis have low ionization potential than alkali metals and have a better tendency to donate excess electrons toward the system (Gutsev and Boldyrev, 1982). This enables them to form a wide range of unique molecules with intriguing features while the structural integrity of superalkalis remains intact on interaction with other atoms. In this regard, superalkalis $\left(\mathrm{Li}_{2} \mathrm{~F}, \mathrm{Li}_{3} \mathrm{O}\right.$, and $\mathrm{Li}_{4} \mathrm{~N}$ ) (Rehm et al., 1992), hyperlithiated superalkali clusters $\mathrm{Li}_{n} \mathrm{~F}$ ( $\mathrm{n}=2-5$ ) (Srivastava and Misra, 2015c), and hypervalent superalkalis $\mathrm{M}_{2} \mathrm{X}(\mathrm{M}=\mathrm{Li}, \mathrm{Na} ; \mathrm{X}=\mathrm{F}, \mathrm{Cl})$ (Srivastava and Misra, 2016c) served as potential superalkali subunits. These superalkali clusters on interaction with metal atoms resulted in the formation of hyperalkalized superalkali-metal (SA-M) species (Srivastava and Misra, 2016b). These species possess remarkable NLO response and the highest NLO up to $3.6 \times 10^{4}$ au is observed for $\mathrm{NLi}_{4}-\mathrm{Na}$. The gas phase basicities of superalkali hydroxides FLinOH $(n=2-5)$ have been computed theoretically and are 
TABLE 4 | Transition metal doped nanocages with enhanced nonlinear optical responses.

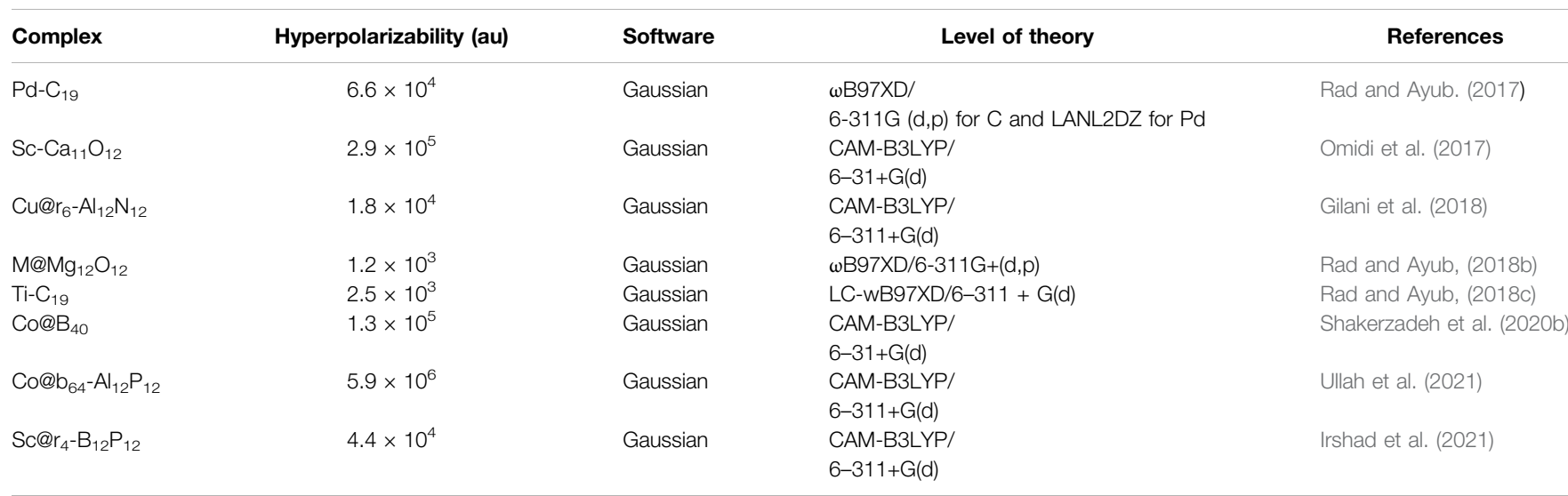

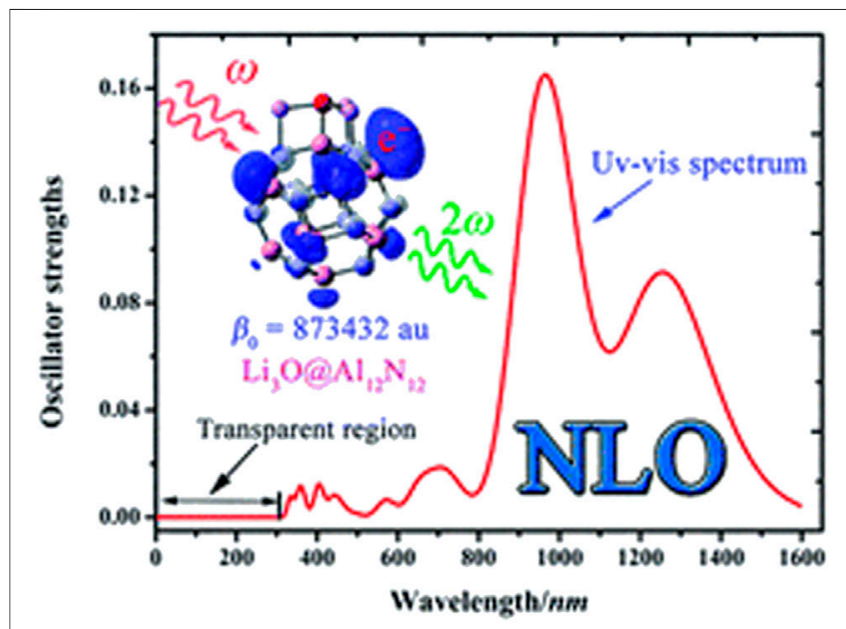

FIGURE 10 | Superalkali $\mathrm{Li}_{3} \mathrm{O}$ doped $\mathrm{Al}_{12} \mathrm{~N}_{12}$ nanocage with NLO response and UV-visible spectrum. Reprinted from W. M. Sun et al., 2016a with permission of Royal Society of Chemistry.

comparable to those of strong alkali hydroxides such as $\mathrm{LiOH}$ and some of them may act as superbases (Srivastava and Misra, 2015a). These superalkali hydroxides have several unusual and intriguing features, one of which is their enhanced NLO responses. The hydrogenated superalkalis $\left(\mathrm{SAHs}=\mathrm{FLi}_{2} \mathrm{H}\right.$, $\mathrm{OLi}_{3} \mathrm{H}$, and $\mathrm{NLi}_{4} \mathrm{H}$ ) with enhanced $\mathrm{NLO}$ response have also been investigated theoretically (Srivastava and Misra, 2016a).

These superalkali clusters donate their excess electrons on interaction with nanocages to form high performance NLO materials. In 2016, Sun et al. carried out theoretical investigation of superalkali $\mathrm{M}_{3} \mathrm{O}(\mathrm{M}=\mathrm{Li}, \mathrm{Na}, \mathrm{K})$ doping on $\mathrm{Al}_{12} \mathrm{~N}_{12}$ nanocage for the first time (W. M. Sun et al., 2016a). Diffuse excess electrons of superalkalis have enhanced the hyperpolarizability of complexes up to $1.86 \times 10^{7} \mathrm{au}$. Moreover, NLO response of $\mathrm{Li}_{3} \mathrm{O}$ superalkali on other nanocages has been investigated systematically. These electrides have high deep ultraviolet transparency and larger NLO response. These superalkali doped nanocages would be potential precursors for high-performance NLO materials as shown in Figure 10.

The optoelectronic properties of superalkali $\mathrm{M}_{n} \mathrm{O}(\mathrm{M}=\mathrm{Li}, \mathrm{Na}$, $\mathrm{K} ; n=2,3,4)$ doped $\mathrm{Mg}_{12} \mathrm{O}_{12}$ nanocages have been investigated theoretically. Superalkali excess electrons have reduced the energy gap and remarkable increment in the NLO response was observed for $\mathrm{M}_{3} \mathrm{O}$ superalkali doped nanocluster series. These complexes were potential candidates in the field of nonlinear optics with the highest hyperpolarizability of $\beta \approx$ 600,000 au for $\mathrm{K}_{3} \mathrm{O} @ \mathrm{Mg}_{12} \mathrm{O}_{12}$ complex (Hesari et al., 2016). In another work, $\mathrm{Li}_{3} \mathrm{O}, \mathrm{Na}_{3} \mathrm{O}$, and $\mathrm{K}_{3} \mathrm{O}$ doped $\mathrm{Si}_{12} \mathrm{C}_{12}$ nanocages have been explored via DFT simulations. It was observed that energy gap (HOMO-LUMO) was reduced monotonically with the size of superalkali subunits. Doping of superalkalis $\mathrm{Li}_{3} \mathrm{O} @ \mathrm{Si}_{12} \mathrm{C}_{12}(3.750 \mathrm{eV}), \mathrm{Na}_{3} \mathrm{O} @ \mathrm{Si}_{12} \mathrm{C}_{12}(2.984 \mathrm{eV})$, and $\mathrm{K}_{3} \mathrm{O} @ \mathrm{Si}_{12} \mathrm{C}_{12}(2.634 \mathrm{eV})$ has transformed the pristine $\mathrm{Si}_{12} \mathrm{C}_{12}$ nanocage $(5.452 \mathrm{eV})$ to $n$-type semiconductors. A reduction in HOMO-LUMO gap has strikingly enhanced the NLO response with the highest hyperpolarizability of 21,695 au for $\mathrm{K}_{3} \mathrm{O} @$ $\mathrm{Si}_{12} \mathrm{C}_{12}$. These superalkali doped $\mathrm{Si}_{12} \mathrm{C}_{12}$ nanocages would have a major role in optoelectronic devices due to their semiconducting nature (Lin et al., 2017). Nonlinear optical properties of superalkali doped $\mathrm{C}_{20}$ fullerene like nanocluster have been investigated theoretically. A decrement in energy gap was observed and indicated that superalkalis have enhanced the optoelectronic properties of $\mathrm{C}_{20}$ fullerene. A large NLO response was observed with the highest hyperpolarizability for $\mathrm{Na}_{3} \mathrm{O} @ \mathrm{C}_{20}$ nanocluster (Noormohammadbeigi and Shamlouei, 2018). Inorganic boron-based nanosystem of all-boron fullerene $\mathrm{B}_{40}$ has also been doped with superalkali subunits $\left(\mathrm{M}_{3} \mathrm{O}\right)_{\mathrm{n}}(\mathrm{M}=\mathrm{Li}$ and $\mathrm{K}, \mathrm{n}=1$ and 2) to investigate the geometrical, stability, and optoelectronic properties. Excess electrons of superalkalis have significantly enhanced the NLO response and narrowed the HOMO-LUMO energy gap $(0.61-1.11 \mathrm{eV})$ as compared to pristine $\mathrm{B}_{40}(2.86 \mathrm{eV})$. The increment in the first hyperpolarizability and second hyperpolarizability was up to $2.46 \times 10^{5}$ and $4.85 \times 10^{8} \mathrm{au}$, respectively. These complexes were structurally stable due to formation of $\mathrm{B}-\mathrm{O}$ bond and have binding energies in the range of $57.0-99.8 \mathrm{kcal} / \mathrm{mol}$. Their fascinating results reflect that superalkali doped $B_{40}$ 
nanocage would be beneficial for modern electronic nanodevices (Noormohammadbeigi and Shamlouei, 2018).

In 2019, Ullah et al. carried out three superalkalis doping on $\mathrm{Li}_{2} \mathrm{~F}, \mathrm{Li}_{3} \mathrm{O}$, and $\mathrm{Li}_{4} \mathrm{~N}$ on fullerene like $\mathrm{B}_{12} \mathrm{P}_{12}$ inorganic nanocage to investigate the NLO response of designed complexes. Doping at various sites resulted in different isomers with excess electrons and were thermodynamically stable. Nonlinear optical response of complexes has been enhanced with the highest hyperpolarizability of $3.48 \times 10^{5}$ au. These superalkali doped $\mathrm{B}_{12} \mathrm{P}_{12}$ nanoclusters have deep ultraviolet transparency and would have potential applications in high-performance NLO devices (Ullah et al., 2019a). In the same year, theoretical investigation of $\mathrm{Li}_{2} \mathrm{~F}, \mathrm{Li}_{3} \mathrm{O}$, and $\mathrm{Li}_{4} \mathrm{~N}$ doping on $\mathrm{B}_{12} \mathrm{P}_{12}$ nanocage have been carried out to observe their geometric, electronic, and NLO properties. All the designed complexes were electride in nature due to diffuse excess electrons of superalkali subunits. These complexes were highly stable as indicated by their interaction energies $\left(-105.13 \mathrm{kcal} \mathrm{mol}^{-1}\right)$. These stable inorganic electrides have narrowed HOMOLUMO energy gap with an increment in NLO response up to $6.25 \times 10^{4}$ au for $\mathrm{Li}_{4} \mathrm{~N} @ \mathrm{Al}_{12} \mathrm{P}_{12}$ (Ullah et al., 2019b). Ullah et al. also explored the superalkali $\left(\mathrm{Li}_{2} \mathrm{~F}, \mathrm{Li}_{3} \mathrm{O}\right.$, and $\left.\mathrm{Li}_{4} \mathrm{~N}\right)$ doping on $\mathrm{Si}_{12} \mathrm{C}_{12}$ nanocage at various positions via DFT calculations. Superalkali doping has altered the electronic properties of $\mathrm{Si}_{12} \mathrm{C}_{12}$ from insulator to n-type semiconductor. These complexes have static first hyperpolarizability up to 19,864 au. Furthermore, frequency dependent hyperpolarizability calculations were also performed in the region $400-1600 \mathrm{~nm}$ to check their practical applicability. The designed complexes were transparent in deep UV regions and would be applicable in the deep UV transparent NLO materials (Ullah et al., 2020d). In a recent work, $\mathrm{Li}_{3} \mathrm{O}, \mathrm{Na}_{3} \mathrm{O}$, and $\mathrm{K}_{3} \mathrm{O}$ superalkalis doping at various doping sites of $\mathrm{Zn}_{12} \mathrm{O}_{12}$ nanocage have been carried out theoretically. Excess electrons of superalkalis have enhanced the $\mathrm{NLO}$ response of $\mathrm{Zn}_{12} \mathrm{O}_{12}$ nanocluster and were $\mathrm{UV}$ transparent under workable laser conditions. The NLO increased monotonically and the highest NLO response of 394,217 au was observed for $\mathrm{K}_{3} \mathrm{O} @ \mathrm{Zn}_{12} \mathrm{O}_{12}$. These $n$-type semiconductor complexes have reduced the energy gap up to $70 \%$ as compared to pristine $\mathrm{Zn}_{12} \mathrm{O}_{12}$. These designed complexes will be applicable in the high performance NLO materials (Kosar et al., 2020b).

A theoretical investigation of superalkali doping on structural and optoelectronic properties of $\mathrm{C}_{24}$ fullerene has been carried out via DFT simulations. The density of states analysis was carried out to confirm the alteration in HOMO-LUMO energy gap on superalkalis doping. The excess electrons of superalkalis have remarkably enhanced the NLO response especially polarizability and hyperpolarizability of $\mathrm{C}_{24}$ fullerene-based nanostructures (Omidi et al., 2020). $\mathrm{Li}_{3} \mathrm{O}$ super alkali doping at various positions of $\mathrm{B}_{12} \mathrm{~N}_{12}$ reflected that designed complexes were thermodynamically stable and chemisorbed. A remarkable reduction in HOMO-LUMO energy gap $(0.42-3.94 \mathrm{eV})$ has transferred the designed complexes to n-type semiconductor as compared to pristine insulator nanocage $(6.84 \mathrm{eV})$. Nonlinear optical response of superalkali doped $\mathrm{B}_{12} \mathrm{~N}_{12}$ nanocluster was increased from 1045 au to 126,261 au. These complexes were transparent in the UV region as reflected by TDDFT investigations and would have practical applications as optoelectronic materials (Raza Ayub et al., 2020). In a recent work, $\mathrm{Li}_{4} \mathrm{~N}$ and $\mathrm{Li}_{4} \mathrm{O}$ doped $\mathrm{Al}_{12} \mathrm{~N}_{12}$ nanoclusters have been explored for their NLO properties (Khaliq et al., 2021b). These $\mathrm{Li}_{4} \mathrm{~N}$ and $\mathrm{Li}_{4} \mathrm{O}$ based $\mathrm{Al}_{12} \mathrm{~N}_{12}$ nanoclusters were thermodynamically stable and have deep UV transparency. Smaller excitation energies of $1.27-2.73 \mathrm{eV}$ have a major role in tuning up the NLO response of designed complexes. A remarkable enhancement in NLO response with the highest hyperpolarizability of $5.7 \times 10^{4}$ au was achieved for $\mathrm{Li}_{4} \mathrm{~N} @$ $\mathrm{Al}_{12} \mathrm{~N}_{12}$ isomer (Figure 11). These $\mathrm{Li}_{4} \mathrm{~N}$ and $\mathrm{Li}_{4} \mathrm{O}$ based $\mathrm{Al}_{12} \mathrm{~N}_{12}$ nanoclusters would be potential precursors in designing high-performance NLO materials.

\section{Excess Electron Based Organic Complexes}

Besides inorganic nanoclusters, superalkali doping on many other organic clusters has been carried out for their potential applications in nonlinear optics (X. Li and Li, 2019) (P. Khan et al., 2021a). Organic NLO materials have extended $\pi$ conjugation, high laser damage thresholds, and smaller dielectric constants (Kang et al., 2019). Most of these organic NLO materials are electrides, alkalides, alkaline earthides, coinage metalides, and superalkalides and have been described in the above sections. However, some other superalkali doped organic NLO materials have attracted much attention in recent years. In this regard, the NLO response of $\mathrm{M}_{3} \mathrm{O}$ and $\mathrm{M}_{3} \mathrm{~S}(\mathrm{M}=\mathrm{Li}, \mathrm{Na}$, and $\mathrm{K})$, single and double superalkali $\mathrm{M}_{3} \mathrm{O}$ doped graphdiyne nanoclusters have been explored (N. Hou et al., 2021; Kosar et al., 2020b; X. Li et al., 2020b). Similarly, Shehzadi et al. observed a remarkable increase in the NLO response of superalkali doped graphdiyne nanoclusters $\left(\mathrm{M}_{2} \mathrm{X} @ \mathrm{GDY} \mathrm{X}=\mathrm{F}, \mathrm{Cl}, \mathrm{Br}\right.$ and $\left.\mathrm{M}=\mathrm{Li}, \mathrm{Na}, \mathrm{K}\right)$ with the highest response $\left(7.7 \times 10^{4} \mathrm{au}\right)$ for $\mathrm{Na}_{2} \mathrm{~F} @ G D Y$ (Shehzadi et al., 2019). Such novel carbon material graphynes (GYs) on combination with superalkalis results in the formation of stable complexes. These GY superalkali complexes $\mathrm{OM}_{3}{ }^{+} @(\mathrm{GY} / \mathrm{GDY} / \mathrm{GTY})^{-}$possess exceptionally large NLO response of $6.5 \times 10^{5}$ au for $\mathrm{Li}_{3} \mathrm{O} @ \mathrm{GTY}$ (GTY = graphtrigne). The NLO properties of doping of alkali metal atoms and superalkali at pyridinic vacancy graphene (3NG) have been studied theoretically. The highest NLO response of $1.6 \times 10^{4}$ was observed for $\mathrm{K}_{3} \mathrm{O} @ 3 \mathrm{NG}$ (Song et al., 2018b). A theoretical exploration of superalkali doped boron substituted biphenalenyl diradical dimer $\left(\mathrm{BC}_{25} \mathrm{H}_{18}\right)$ was carried out by Song et al. and the highest $\mathrm{NLO}$ response was for $\mathrm{K}_{3} \mathrm{O} @ \mathrm{BC}_{25} \mathrm{H}_{18}$ (Song et al., 2018a). Superalkali doping on cyclic conjugated ring systems especially cyclic oligofuran (CF) and hexathiophene ring (6CT) has been carried out theoretically to evaluate their NLO response (Sajid et al., 2020; Sajid et al., 2021). The highest NLO response of some organic complexes is listed in Table 5.

\section{NONLINEAR OPTICAL RESPONSE: EXPERIMENTAL VS. THEORETICAL}

The corroboration between theoretical and experimental data is useful for designing and synthesis of novel NLO materials. In this regard, various NLO systems have been synthesized and their 


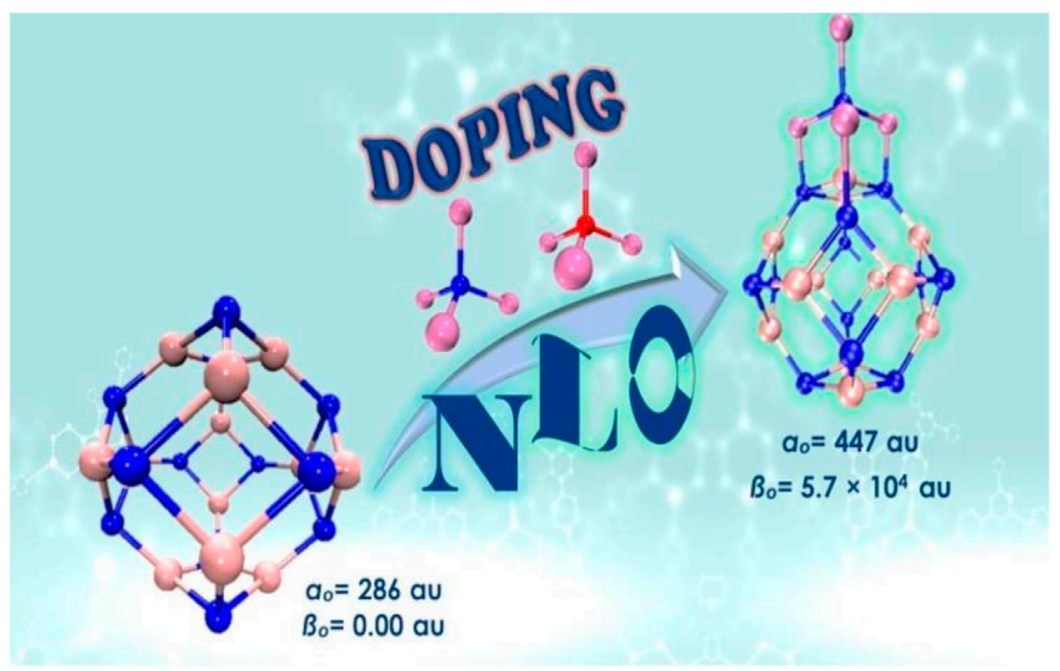

FIGURE 11 | Li ${ }_{4} \mathrm{~N} @ \mathrm{Al}_{12} \mathrm{~N}_{12}$ complex with the highest hyperpolarizability of $5.7 \times 10^{4}$ au. Reprinted from Khaliq et al., 2021b with permission from Elsevier.

TABLE 5 | Some superalkali doped organic complexes with enhanced nonlinear optical response.

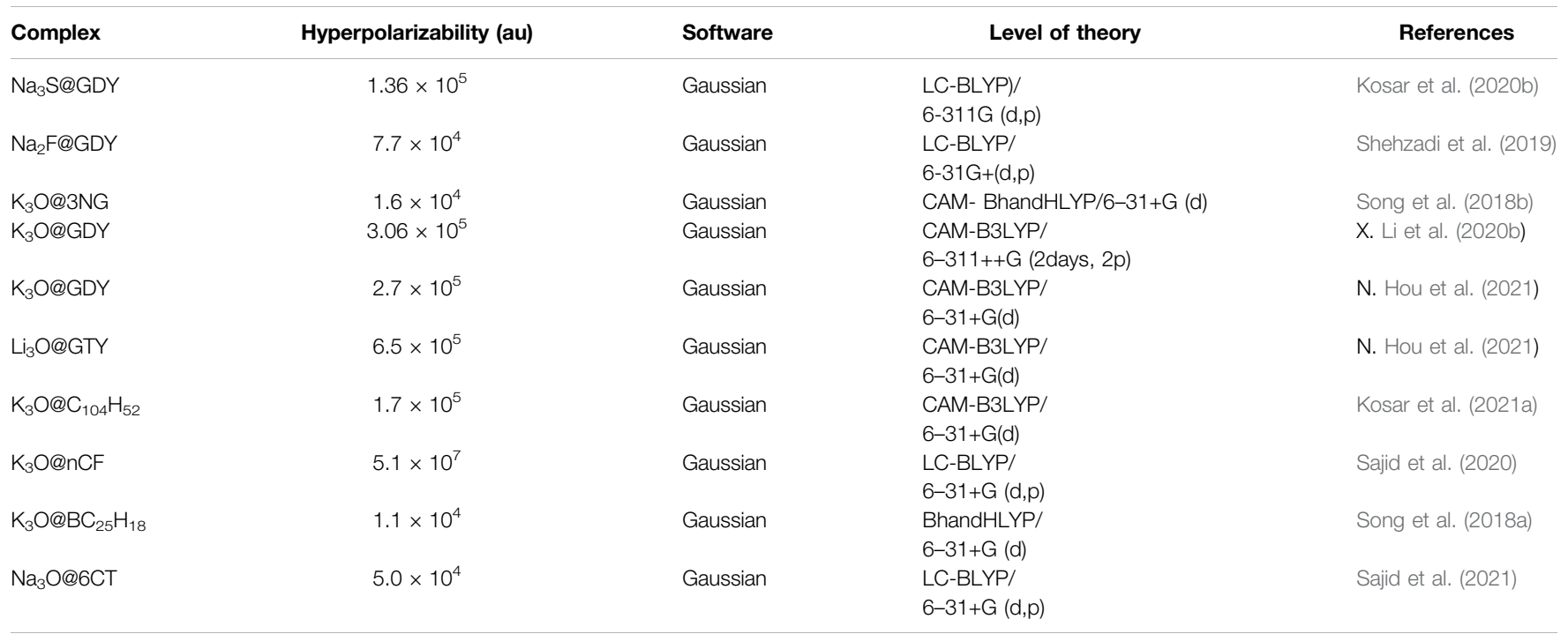

NLO responses have been investigated theoretically and experimentally. The linear and NLO susceptibilities of single crystals of potassium titanyl phosphate $\mathrm{KTiOPO}_{4}$ have been studied experimentally and theoretically (Reshak et al., 2010). Using DFT calculations, the theoretically predicted band gap $(3.1 \mathrm{eV})$ of $\mathrm{KTiOPO}_{4}$ shows excellent agreement with the experimental data $(3.2 \mathrm{eV})$ at WIEN2K code. Furthermore, the computed second harmonic generation (SHG) susceptibility coefficients are matched with single crystal SHG response. The experimental and theoretical NLO studies of synthesized $\mathrm{LiBaB}_{9} \mathrm{O}_{15}$ crystals have been carried out (Reshak et al., 2013). The electronic properties especially band gap energies $(5.11 \mathrm{eV})$ by using DFT simulations match well with the experimental values $(5.17 \mathrm{eV})$. The calculated second order NLO susceptibility especially second harmonic generation $(\mathrm{SHG})$ was $\beta_{333}=0.291 \times$ $10^{-30}$ esu at $1064 \mathrm{~nm}$. This computed value correlated with the experimental one $\left(0.467 \times 10^{-30} \mathrm{esu}\right)$ at $1064 \mathrm{~nm}$ by using $\mathrm{Nd}$ : YAG laser. Single crystals of $\mathrm{LiNaB}_{4} \mathrm{O}_{7}$ have been synthesized and confirmed by X-ray crystallography. The results of DFT calculations for electronic properties by using LDA, GGA, EVGGA, and $\mathrm{mBJ}$ methods demonstrate that these crystals have a substantial band gap of about 2.80, 2.91, 3.21, and $3.81 \mathrm{eV}$, respectively. These results match well with the experimental band gap of $3.88 \mathrm{eV}$. The calculated absorption spectrum of $\mathrm{LiNaB}_{4} \mathrm{O}_{7}$ crystals also matched well with the experimental one. The second order hyperpolarizabilities of these crystals were $0.306 \times 10^{-30}$ esu (static) and $0.332 \times$ $10^{-30} \mathrm{esu}$ at $1064 \mathrm{~nm}$ (Reshak et al., 2012). The first and 
second hyperpolarizabilities of substituted dimesityl boranes have been explored both theoretically (AM1 semi-empirical level, MOPAC program) and experimentally (at $1907 \mathrm{~nm}$ under NdYAG laser). The theoretical results were in concurrence with the experimentally measured data for these complexes (Yuan et al., 2006). The nonlinear optical crystals of strontium borate $\mathrm{Sr}_{2} \mathrm{~B}_{5} \mathrm{O}_{9}(\mathrm{OH}) \mathrm{H}_{2} \mathrm{O}$ have been synthesized. The DFT calculations of SHG response, nonlinear refractive index, and birefringence computed by using CASTEP package were consistent with experimentally measured values (Zhang et al., 2015). These studies show that theoretical strategies for calculating NLO response show a good agreement with the available experimental data. Therefore, theoretically predicted high performance NLO materials could be a good starting point for the experimentalists.

\section{CONCLUSION AND OUTLOOK}

The current review establishes a systematic array of different studies for the theoretical designing of NLO materials. NLO materials have covered a large area of science and technology owning to their potential applications in optoelectronics. In material research, computational design and experimental synthesis of NLO materials with higher order nonlinearities come into vogue. Several strategies including metal ligand framework, push pull mechanism, diradical character, and so on have been elaborated for the enhancement of NLO response of materials. Role of diffuse excess electron in developing noncentrosymmetric materials for nonlinear optics have been discussed. A theoretical design from the simplest NLO material to

\section{REFERENCES}

Ahsan, A., and Ayub, K. (2020a). Adamanzane Based Alkaline Earthides with Excellent Nonlinear Optical Response and Ultraviolet Transparency. Opt. Laser Tech. 129 (April), 106298. doi:10.1016/j.optlastec.2020.106298

Ahsan, A., and Ayub, K. (2020b). Extremely Large Nonlinear Optical Response and Excellent Electronic Stability of True Alkaline Earthides Based on Hexaammine Complexant. J. Mol. Liquids 297, 111899. doi:10.1016/j.molliq.2019.111899

Ahsan, A., Khan, S., Gilani, M. A., and Ayub, K. (2021). Endohedral Metallofullerene Electrides of Ca12O12 with Remarkable Nonlinear Optical Response. RSC Adv. 11 (3), 1569-1580. doi:10.1039/d0ra08571e

Akasaka, T., Okubo, S., Wakahara, T., Yamamoto, K., Kobayashi, K., Nagase, S., et al. (1999). Endohedrally Metal-Doped Heterofullerenes: La@C81N and La2@ C79N. Chem. Lett. 28 (9), 945-946. doi:10.1246/cl.1999.945

Anilkumar, P., Lu, F., Cao, L., G. Luo, P. P., Liu, J.-H., Sahu, S., et al. (2011). Fullerenes for Applications in Biology and Medicine. Cmc 18 (14), 2045-2059. doi:10.2174/092986711795656225

Arivuoli, D. (2001). Fundamentals of Nonlinear Optical Materials. Pramana J. Phys. 57 (5-6), 871-883. doi:10.1007/s12043-001-0004-1

Armstrong, J. A., Bloembergen, N., Ducuing, J., and Pershan, P. S. (1962). Interactions between Light Waves in a Nonlinear Dielectric. Phys. Rev. 127 (6), 1918-1939. doi:10.1103/physrev.127.1918

Arshad, Y., Khan, S., Hashmi, M. A., and Ayub, K. (2018). Transition Metal Doping: a New and Effective Approach for Remarkably High Nonlinear Optical Response in Aluminum Nitride Nanocages. New J. Chem. 42 (9), 6976-6989. doi:10.1039/c7nj04971d

Ayub, K. (2016). Are Phosphide Nano-Cages Better Than Nitride Nano-Cages? A Kinetic, Thermodynamic and Non-linear Optical Properties Study of Alkali the complex alkali, alkaline earth, transition, and superalkali doped nanoclusters is summarized in the present review. Excess electrons of the nanoclusters have played a pivotal role in enhancing the NLO properties of various systems especially hyperpolarizabilities. These excess electron-based systems may help to increase the second hormonic generation (SHG) efficiency and electro-optical Pockels effect (EOPE). These insights are essential for the development of new NLO materials. These findings also provide an intriguing area for future research into potential building blocks and structure-directing constituents that may help to promote the synthesis of these theoretically designed NLO materials. It is expected that the present review will provide a better understanding of the NLO responses of nanoclusters, paving the way for the development of high-tech NLO materials.

\section{AUTHOR CONTRIBUTIONS}

K.A., M.G., and T.M. contributed to the design and outlines of the review. R.B. and M.A. collected the literature and wrote the first draft. R.Z. revised the first draft and corrected its language. J.I. and S.T. wrote some sections of the review. All authors contributed to manuscript revision, read, and approved the submitted version.

\section{FUNDING}

This project was financially supported by the Higher Education Commission, Pakistan under HEC-NRPU project (7853).

Metal Encapsulated X12Y12 Nano-Cages. J. Mater. Chem. C 4 (46), 10919-10934. doi:10.1039/c6tc04456e

Baloach, R., Ayub, K., Mahmood, T., Asif, A., Tabassum, S., and Gilani, M. A. (2021). A New Strategy of Bi-alkali Metal Doping to Design Boron Phosphide Nanocages of High Nonlinear Optical Response with Better Thermodynamic Stability. J. Inorg. Organomet. Polym. 31 (7), 3062-3076. doi:10.1007/s10904021-02000-6

Bano, R., Arshad, M., Mahmood, T., Ayub, K., Sharif, A., Perveen, S., et al. (2022). Face Specific Doping of Janus All-Cis-1,2,3,4,5,6-Hexafluorocyclohexane with Superalkalis and Alkaline Earth Metals Leads to Enhanced Static and Dynamic NLO Responses. J. Phys. Chem. Sol. 160, 110361. doi:10.1016/j.jpcs.2021.110361

Becker, P. (1998). Borate Materials in Nonlinear Optics. Adv. Mater. 10 (13), 979-992. doi:10.1002/(sici)1521-4095(199809)10:13<979:aid-adma979>3.0.co; $2-n$

Beheshtian, J., Bagheri, Z., Kamfiroozi, M., and Ahmadi, A. (2012). A Comparative Study on the B12N12, Al12N12, B12P12 and Al12P12 Fullerene-like Cages. J. Mol. Model. 18 (6), 2653-2658. doi:10.1007/s00894-011-1286-y

Benjamin, S. C., Ardavan, A., Briggs, G. A. D., Britz, D. A., Gunlycke, D., Jefferson, J., et al. (2006). Towards a Fullerene-Based Quantum Computer. J. Phys. Condens. Matter 18 (21), S867-S883. doi:10.1088/0953-8984/18/21/s12

Bezi Javan, M. (2013). Optical Properties of SiC Nanocages: Ab Initio Study. Appl. Phys. A. 113 (1), 105-113. doi:10.1007/s00339-013-7633-3

Billas, I. M. L., Massobrio, C., Boero, M., Parrinello, M., Branz, W., Tast, F., et al. (2000). First Principles Calculations of Iron-Doped Heterofullerenes. Comput. Mater. Sci. 17 (2-4), 191-195. doi:10.1016/s0927-0256(00)00022-7

Biswal, B. P., Valligatla, S., Wang, M., Banerjee, T., Saad, N. A., Mariserla, B. M. K., et al. (2019). Nonlinear Optical Switching in Regioregular Porphyrin Covalent Organic Frameworks. Angew. Chem. 131, 6970-6974. doi:10.1002/ ange.201814412 
Bogani, L., and Wernsdorfer, W. (2010). "Molecular Spintronics Using SingleMolecule Magnets," in Nanoscience and Technology: A Collection of Reviews from Nature Journals (Singapore: World Scientific), 194-201.

Boyd, R. W. (2020). Nonlinear Optics. Cambridge: Academic Press.

Buckingham, A. D., and Orr, B. J. (1967). Molecular Hyperpolarisabilities. Q. Rev. Chem. Soc. 21 (2), 195-212. doi:10.1039/qr9672100195

Burland, D. (1994). Optical Nonlinearities in Chemistry: Introduction. Chem. Rev. 94 (1), 1-2. doi:10.1021/cr00025a600

Chen, J., Krasavin, A., Ginzburg, P., Zayats, A. V., Pullerits, T., and Karki, K. J. (2018). Evidence of High-Order Nonlinearities in Supercontinuum white-light Generation from a Gold Nanofilm. ACS Photon. 5 (5), 1927-1932. doi:10.1021/ acsphotonics.7b01125

Chen, W., Li, Z.-R., Wu, D., Gu, F.-L., Hao, X.-Y., Wang, B.-Q., et al. (2004). The Static Polarizability and First Hyperpolarizability of the Water Trimer anion:Ab Initiostudy. J. Chem. Phys. 121 (21), 10489-10494. doi:10.1063/ 1.1811609

Chen, W., Li, Z.-R., Wu, D., Li, R.-Y., and Sun, C.-C. (2005b). Theoretical Investigation of the Large Nonlinear Optical Properties of (HCN)n Clusters with Li Atom. J. Phys. Chem. B 109 (1), 601-608. doi:10.1021/jp0480394

Chen, W., Li, Z.-R., Wu, D., Li, Y., Sun, C.-C., Gu, F. L., et al. (2006). Nonlinear Optical Properties of Alkalides Li+(calix[4]pyrrole) M- $(\mathrm{M}=\mathrm{Li}, \mathrm{Na}$, and $\mathrm{K})$ : Alkali Anion Atomic Number Dependence. J. Am. Chem. Soc. 128 (4), 1072-1073. doi:10.1021/ja056314+

Chen, W., Li, Z.-R., Wu, D., Li, Y., Sun, C.-C., and Gu, F. L. (2005a). The Structure and the Large Nonlinear Optical Properties of Li@Calix[4]pyrrole. J. Am. Chem. Soc. 127 (31), 10977-10981. doi:10.1021/ja050601w

Cheng, L. T., Tam, W., Stevenson, S. H., Meredith, G. R., Rikken, G., and Marder, S. R. (1991). Experimental Investigations of Organic Molecular Nonlinear Optical Polarizabilities. 1. Methods and Results on Benzene and Stilbene Derivatives. J. Phys. Chem. 95 (26), 10631-10643. doi:10.1021/j100179a026

Chuvilin, A., Kaiser, U., Bichoutskaia, E., Besley, N. A., and Khlobystov, A. N. (2010). Direct Transformation of Graphene to Fullerene. Nat. Chem 2 (6), 450-453. doi:10.1038/nchem.644

Cirilo, E. R., Natti, P. L., Romeiro, N. M. L., Natti, E. R. T., and de Oliveira, C. F. (2010). Solitons in Ideal Optical Fibers-A Numerical Development. Semina: Ciências Exatas e Tecnológicas 31, 57-68. doi:10.5433/16790375.2010v31n1p57

Dawes, S. B., Ward, D. L., Huang, R. H., and Dye, J. L. (1986). First Electride crystal Structure. J. Am. Chem. Soc. 108 (12), 3534-3535. doi:10.1021/ja00272a073

Delaire, J. A., and Nakatani, K. (2000). Linear and Nonlinear Optical Properties of Photochromic Molecules and Materials. Chem. Rev. 100 (5), 1817-1846. doi: $10.1021 / \mathrm{cr} 980078 \mathrm{~m}$

Duan, X. F., and Burggraf, L. W. (2015). Theoretical Investigation of Stabilities and Optical Properties of Si12C12 Clusters. J. Chem. Phys. 142 (3), 034303. doi:10.1063/1.4905542

Ducuing, J., and Bloembergen, N. (1964). Statistical Fluctuations in Nonlinear Optical Processes. Phys. Rev. 133 (6A), A1493-A1502. doi:10.1103/ physrev.133.a1493

Duman, S., Sütlü, A., Bağcl, S., Tütüncü, H. M., and Srivastava, G. P. (2009). Structural, Elastic, Electronic, and Phonon Properties of Zinc-Blende and Wurtzite BeO. J. Appl. Phys. 105 (3), 033719. doi:10.1063/1.3075814

Dye, J. L., Ceraso, J. M., Lok, M., Barnett, B. L., and Tehan, F. J. (1974). Crystalline Salt of the Sodium Anion (Na-). J. Am. Chem. Soc. 96 (2), 608-609. doi:10.1021/ ja00809a060

Ellaboudy, A., Dye, J. L., and Smith, P. B. (1983). Cesium 18-crown-6 Compounds. A Crystalline Ceside and a Crystalline Electride. J. Am. Chem. Soc. 105 (21), 6490-6491. doi:10.1021/ja00359a022

Erwin, S. C., and Pickett, W. E. (1991). Theoretical Fermi-Surface Properties and Superconducting Parameters for K 3 C 60. Science 254 (5033), 842-845. doi:10.1126/science. 254.5033 .842

Fan, X., Pan, S., Hou, X., Tian, X., Han, J., Haag, J., et al. (2010). Growth and Properties of Single Crystals of Noncentrosymmetric Na3VO2B6O11. Cryst. Growth Des. 10 (1), 252-256. doi:10.1021/cg900877h

Franken, P. A., Hill, A. E., Peters, C. W., and Weinreich, G. (1961). Generation of Optical Harmonics. Phys. Rev. Lett. 7 (4), 118-119. doi:10.1103/ physrevlett.7.118

Fripertinger, H. (1996). The Cycle index of the Symmetry Group of the Fullerene C60. MATCH Commun. Math. Comput. Chem. 33, 121-138.
Gao, Y., Dai, X., Kang, S. G., Jimenez-Cruz, C. A., Xin, M., Meng, Y., et al. (2014). Structural and Electronic Properties of Uranium-Encapsulated Au14 Cage. Sci. Rep. 4 (1), 5862-5866. doi:10.1038/srep05862

Gibbs, H. M., McCall, S. L., and Venkatesan, T. N. C. (1976). Differential Gain and Bistability Using a Sodium-Filled Fabry-Perot Interferometer. Phys. Rev. Lett. 36 (19), 1135-1138. doi:10.1103/physrevlett.36.1135

Gilani, M. A., Tabassum, S., Gul, U., Mahmood, T., Alharthi, A. I., Alotaibi, M. A., et al. (2018). Copper-doped Al12N12 Nano-Cages: Potential Candidates for Nonlinear Optical Materials. Appl. Phys. A. 124 (1), 1-14. doi:10.1007/s00339017-1425-0

Giri, S., Behera, S., and Jena, P. (2014). Superalkalis and Superhalogens as Building Blocks of Supersalts. J. Phys. Chem. A. 118, 638-645. doi:10.1021/ jp4115095

Girisun, T. C. S., Somayaji, R. M., Priyadarshani, N., and Rao, S. V. (2017). Femtosecond Third Order Optical Nonlinearity and Optical Limiting Studies of ( $\gamma$ and $\beta$ )-Barium Borate Nanostructures. Mater. Res. Bull. 87, 102-108. doi:10.1016/j.materresbull.2016.11.022

Grote, J. G., Zetts, J. S., Nelson, R. L., Diggs, D. E., Hopkins, F. K., Yaney, P. P., et al. (2002). Nonlinear Optic Polymer Electro-Optic Modulators for Space Applications. Photon. Space Environments VIII, 6-18. doi:10.1117/12.453494

Guo, T., Jin, C., and Smalley, R. E. (1991). Doping Bucky: Formation and Properties of boron-doped Buckminsterfullerene. J. Phys. Chem. 95 (13), 4948-4950. doi:10.1021/j100166a010

Gutsev, G. L., and Boldyrev, A. I. (1982). DVM Xa Calculations on the Electronic Structure of "superalkali" Cations. Chem. Phys. Lett. 92 (3), 262-266. doi:10.1016/0009-2614(82)80272-8

Haddon, R. C., Brus, L. E., and Raghavachari, K. (1986). Electronic Structure and Bonding in Icosahedral C60. Chem. Phys. Lett. 125 (5-6), 459-464. doi:10.1016/ 0009-2614(86)87079-8

Hawkins, J. M., Meyer, A., Lewis, T. A., Loren, S., and Hollander, F. J. (1991). Crystal Structure of Osmylated C 60 : Confirmation of the Soccer Ball Framework. Science 252 (5003), 312-313. doi:10.1126/science.252.5003.312

Haymet, A. D. J. (1985). C120 and C60: Archimedean Solids Constructed from Sp2 Hybridized Carbon Atoms. Chem. Phys. Lett. 122 (5), 421-424. doi:10.1016/ 0009-2614(85)87239-0

Heath, J. R., O’Brien, S. C., Zhang, Q., Liu, Y., Curl, R. F., Tittel, F. K., et al. (1985). Lanthanum Complexes of Spheroidal Carbon Shells. J. Am. Chem. Soc. 107 (25), 7779-7780. doi:10.1021/ja00311a102

Hesari, A. M., Shamlouei, H. R., and Raoof Toosi, A. (2016). Effects of the Adsorption of Alkali Metal Oxides on the Electronic, Optical, and Thermodynamic Properties of the Mg12O12nanocage: a Density Functional Theory Study. J. Mol. Model. 22 (8), 1-8. doi:10.1007/s00894-016-3044-7

Hou, D., Nissimagoudar, A. S., Bian, Q., Wu, K., Pan, S., Li, W., et al. (2018a). Prediction and Characterization of $\mathrm{NaGaS2}$, a High thermal Conductivity Midinfrared Nonlinear Optical Material for High-Power Laser Frequency Conversion. Inorg. Chem. 58 (1), 93-98. doi:10.1021/acs.inorgchem.8b01174

Hou, J., Linsheng, Zhu., Zhu, D., Jiang, D., Qin, J., and Duan, Q. (2018b). Alkalineearthide: A New Class of Excess Electron Compounds Li-C6h6f6-M ( $\mathrm{M}=\mathrm{Be}$, $\mathrm{Mg}$ and $\mathrm{Ca}$ ) with Extremely Large Nonlinear Optical Responses. Chem. Phys. Lett. 711 (July), 55-59. doi:10.1016/j.cplett.2018.09.023

Hou, N., Du, F., Feng, R., Wu, H., and Li, Z. (2021). Effects of the Atomic Number of Alkali Atom and Pore Size of Graphyne on the Second-order Nonlinear Optical Response of Superalkali Salts of Graphynes OM3+@ GYs- $-(\mathrm{M}=\mathrm{Li}, \mathrm{Na}$, and K). Int. J. Quan. Chem. 121 (4), e26477. doi:10.1002/qua.26477

Hou, N., Wu, Y.-Y., and Liu, J.-Y. (2016). Theoretical Studies on Structures and Nonlinear Optical Properties of Alkali Doped Electrides B12N12-M $(\mathrm{M}=\mathrm{Li}$, Na, K). Int. J. Quan. Chem. 116 (17), 1296-1302. doi:10.1002/qua.25177

Hou, N., Wu, Y.-Y., Wang, B.-Q., and Wu, H.-S. (2018c). Investigation on the Electronic Structures and Nonlinear Optical Properties of Alkali Metal Atom Doped All-Cis 1,2,3,4,5,6-hexafluorocyclohexane. Int. J. Quan. Chem 118 (15), e25619. doi:10.1002/qua.25619

Huff, T. B., Shi, Y., Fu, Y., Wang, H., and Cheng, J.-X. (2008). Multimodal Nonlinear Optical Microscopy and Applications to central Nervous System Imaging. IEEE J. Select. Top. Quan. Electron. 14 (1), 4-9. doi:10.1109/ jstqe.2007.913419

Hutchinson, G. D., and Milburn, G. J. (2004). Nonlinear Quantum Optical Computing via Measurement. J. Mod. Opt. 51 (8), 1211-1222. doi:10.1080/ 09500340408230417 
Iliopoulos, K., Krupka, O., Gindre, D., and Sallé, M. (2010). Reversible Two-Photon Optical Data Storage in Coumarin-Based Copolymers. J. Am. Chem. Soc. 132 (41), 14343-14345. doi:10.1021/ja1047285

Irshad, S., Ullah, F., Khan, S., Ludwig, R., Mahmood, T., and Ayub, K. (2021). First Row Transition Metals Decorated boron Phosphide Nanoclusters as Nonlinear Optical Materials with High Thermodynamic Stability and Enhanced Electronic Properties; A Detailed Quantum Chemical Study. Opt. Laser Tech. 134, 106570. doi:10.1016/j.optlastec.2020.106570

Ivonina, M. V., Orimoto, Y., and Aoki, Y. (2020). Nonlinear Optical Properties of Push-Pull Systems Containing [2.2]paracyclophane: Theoretical Study via Elongation Method. Chem. Phys. Lett. 755, 137760. doi:10.1016/ j.cplett.2020.137760

Jing, Y.-Q., Li, Z.-R., Wu, D., Li, Y., Wang, B.-Q., Gu, F. L., et al. (2006). Effect of the Complexant Shape on the Large First Hyperpolarizability of Alkalides Li+(NH3)4M-. ChemPhysChem 7 (8), 1759-1763. doi:10.1002/ cphc.200600157

Kachynski, A. V., Pliss, A., Kuzmin, A. N., Ohulchanskyy, T. Y., Baev, A., Qu, J., et al. (2014). Photodynamic Therapy by In Situ Nonlinear Photon Conversion. Nat. Photon 8 (6), 455-461. doi:10.1038/nphoton.2014.90

Kamada, K., Ohta, K., Kubo, T., Shimizu, A., Morita, Y., Nakasuji, K., et al. (2007). Strong Two-Photon Absorption of Singlet Diradical Hydrocarbons. Angew. Chem. Int. Ed. 46 (19), 3544-3546. doi:10.1002/anie.200605061

Kang, L., Liang, F., Jiang, X., Lin, Z., and Chen, C. (2019). First-Principles Design and Simulations Promote the Development of Nonlinear Optical Crystals. Acc. Chem. Res. 53, 209-217. doi:10.1021/acs.accounts.9b00448

Kanis, D. R., Ratner, M. A., and Marks, T. J. (1992). Calculation and Electronic Description of Quadratic Hyperpolarizabilities. Toward a Molecular Understanding of NLO Responses in Organotransition Metal Chromophores. J. Am. Chem. Soc. 114 (26), 10338-10357. doi:10.1021/ ja00052a035

Kanis, D. R., Ratner, M. A., and Marks, T. J. (1994). Design and Construction of Molecular Assemblies with Large Second-Order Optical Nonlinearities. Quantum Chemical Aspects. Chem. Rev. 94 (1), 195-242. doi:10.1021/ cr00025a007

Kerr, J. (1879). Electro-optic Observation on Various Liquids. Lond. Edinb. Dublin Philos. Mag. J. Sci. 8 (47), 85-102. doi:10.1080/14786447908639658

Khalid, M., Hussain, R., Hussain, A., Ali, B., Jaleel, F., Imran, M., et al. (2019). Electron Donor and Acceptor Influence on the Nonlinear Optical Response of Diacetylene-Functionalized Organic Materials (DFOMs): Density Functional Theory Calculations. Molecules 24 (11), 2096. doi:10.3390/molecules24112096

Khaliq, F., Ayub, K., Mahmood, T., Muhammad, S., Tabassum, S., and Gilani, M. A. (2021a). First Example of Lanthanum as Dopant on Al12N12 and Al12P12 Nanocages for Improved Electronic and Nonlinear Optical Properties with High Stability. Mater. Sci. Semiconductor Process. 135 (July), 106122. doi:10.1016/j.mssp.2021.106122

Khaliq, F., Mahmood, T., Ayub, K., Tabassum, S., and Gilani, M. A. (2021b). Exploring Li4N and Li4O Superalkalis as Efficient Dopants for the Al12N12 Nanocage to Design High Performance Nonlinear Optical Materials with High Thermodynamic Stability. Polyhedron 200, 115145. doi:10.1016/ j.poly.2021.115145

Khan, P., Mahmood, T., Ayub, K., Tabassum, S., and Amjad Gilani, M. (2021a). Turning Diamondoids into Nonlinear Optical Materials by Alkali Metal Substitution: A DFT Investigation. Opt. Laser Tech. 142 (April), 107231. doi:10.1016/j.optlastec.2021.107231

Khan, S., Gilani, M. A., Munsif, S., Muhammad, S., Ludwig, R., and Ayub, K. (2021b). Inorganic Electrides of Alkali Metal Doped Zn12O12 Nanocage with Excellent Nonlinear Optical Response. J. Mol. Graphics Model. 106 (May), 107935. doi:10.1016/j.jmgm.2021.107935

Kim, J., Ichimura, A. S., Huang, R. H., Redko, M., Phillips, R. C., Jackson, J. E., et al. (1999). Crystalline Salts of Na- and K- (Alkalides) that Are Stable at Room Temperature. J. Am. Chem. Soc. 121 (45), 10666-10667. doi:10.1021/ja992667v

Kishida, H., Hibino, K., Nakamura, A., Kato, D., and Abe, J. (2010). Third-order Nonlinear Optical Properties of a $\pi$-conjugated Biradical Molecule Investigated by Third-Harmonic Generation Spectroscopy. Thin Solid Films 519 (3), 1028-1030. doi:10.1016/j.tsf.2010.08.037

Kobayashi, K., Kuwano, M., Sueki, K., Kikuchi, K., Achiba, Y., Nakahara, H., et al. (1995). Activation and Tracer Techniques for Study of Metallofullerenes. J. Radioanal. Nucl. Chem. Articles 192 (1), 81-89. doi:10.1007/bf02037739
Koohi, M., Soleimani-Amiri, S., and Shariati, M. (2018). Novel X- and Y-Substituted Heterofullerenes X4Y4C12 Developed from the Nanocage $\mathrm{C} 20$, where $\mathrm{X}=\mathrm{B}, \mathrm{Al}, \mathrm{Ga}, \mathrm{Si}$ and $\mathrm{Y}=\mathrm{N}, \mathrm{P}$, as, Ge: a Comparative Investigation on Their Structural, Stability, and Electronic Properties at DFT. Struct. Chem. 29 (3), 909-920. doi:10.1007/s11224-017-1071-3

Kosar, N., Ayub, K., and Mahmood, T. (2021a). Surface Functionalization of Twisted Graphene C32H15 and C104H52 Derivatives with Alkalis and Superalkalis for NLO Response; a DFT Study. J. Mol. Graphics Model. 102, 107794. doi:10.1016/j.jmgm.2020.107794

Kosar, N., Gul, S., Ayub, K., Bahader, A., Gilani, M. A., Arshad, M., et al. (2020a). Significant Nonlinear Optical Response of Alkaline Earth Metals Doped Beryllium and Magnesium Oxide Nanocages. Mater. Chem. Phys. 242, 122507. doi:10.1016/j.matchemphys.2019.122507

Kosar, N., Shehzadi, K., Ayub, K., and Mahmood, T. (2020b). Theoretical Study on Novel Superalkali Doped Graphdiyne Complexes: Unique Approach for the Enhancement of Electronic and Nonlinear Optical Response. J. Mol. Graphics Model. 97, 107573. doi:10.1016/j.jmgm.2020.107573

Kosar, N., Tahir, H., Ayub, K., Gilani, M. A., Arshad, M., and Mahmood, T. (2021b). Impact of Even Number of Alkaline Earth Metal Doping on the NLO Response of C20 Nanocluster; a DFT Outcome. Comput. Theor. Chem. 1204, 113386. doi:10.1016/j.comptc.2021.113386

Kosar, N., Tahir, H., Ayub, K., Gilani, M. A., and Mahmood, T. (2021c). Theoretical Modification of C24 Fullerene with Single and Multiple Alkaline Earth Metal Atoms for Their Potential Use as NLO Materials. J. Phys. Chem. Sol. 152, 109972. doi:10.1016/j.jpcs.2021.109972

Krätschmer, W., Fostiropoulos, K., and Huffman, D. R. (1990a). The Infrared and Ultraviolet Absorption Spectra of Laboratory-Produced Carbon Dust: Evidence for the Presence of the C60 Molecule. Chem. Phys. Lett. 170 (2-3), 167-170. doi:10.1016/0009-2614(90)87109-5

Krätschmer, W., Lamb, L. D., Fostiropoulos, K., and Huffman, D. R. (1990b). Solid C 60: a New Form of Carbon. Nature 347 (6291), 354-358. doi:10.1038/ $347354 \mathrm{a} 0$

Kroto, H. W., Heath, J. R., O’Brien, S. C., Curl, R. F., and Smalley, R. E. (1985). C60: Buckminsterfullerene. Nature 318 (6042), 162-163. doi:10.1038/318162a0

Kumar, R. A., Vizhi, R. E., Vijayan, N., and Babu, D. R. (2010a). Growth, Optical and Mechanical Properties of Nonlinear Optical Alpha-Lithium Iodate Single crystal. Sch. Res. Lib. 2 (5), 247-254.

Kumar, R. A., Vizhi, R. E., Vijayan, N., Bhagavannarayana, G., and Babu, D. R. (2010b). Growth, Crystalline Perfection and Z-Scan Studies of Nonlinear Optical Alpha-Lithium Iodate Single crystal. J. Pure Appl. Ind. Phys. 1 (1), $1-106$.

Kumbhakar, P., and Kobayashi, T. (2007). Ultra-broadband Optical Parametric Amplification in KBe2BO3F2 crystal. Opt. Commun. 277 (1), 205-208. doi:10.1016/j.optcom.2007.04.061

Lee, J., Kim, H., Kahng, S.-J., Kim, G., Son, Y.-W., Ihm, J., et al. (2002). Bandgap Modulation of Carbon Nanotubes by Encapsulated Metallofullerenes. Nature 415 (6875), 1005-1008. doi:10.1038/4151005a

Lettow, J. S., and Martin, C. (2010). Graphene in NLO Devices for High Laser Energy Protection. Jessup, MD: VORBECK MATERIALS CORP.

Li, B., Peng, D., Gu, F. L., and Zhu, C. (2018). Facially Polarized Molecule for Alkalides and Superalkalides with Considerable Nonlinear Optical Response. ChemistrySelect 3, 12782-12790. doi:10.1002/slct.201802769

Li, S., Wu, H., and Wang, L.-S. (1997). Probing the Electronic Structure of Metallocarbohedrenes: M8C12 ( $\mathrm{M}=\mathrm{Ti}, \mathrm{V}, \mathrm{Cr}, \mathrm{Zr}, \mathrm{Nb}) . J$. Am. Chem. Soc. 119 (32), 7417-7422. doi:10.1021/ja9710159

Li, W., Chen, B., Meng, C., Fang, W., Xiao, Y., Li, X., et al. (2014). Ultrafast AllOptical Graphene Modulator. Nano Lett. 14 (2), 955-959. doi:10.1021/ nl $404356 \mathrm{t}$

Li, X.-H., Zhang, X.-L., Chen, Q.-H., Zhang, L., Chen, J.-H., Wu, D., et al. (2020a). Coinage Metalides: a New Class of Excess Electron Compounds with High Stability and Large Nonlinear Optical Responses. Phys. Chem. Chem. Phys. 22 (16), 8476-8484. doi:10.1039/c9cp06894e

Li, X., and Li, S. (2019). Investigations of Electronic and Nonlinear Optical Properties of Single Alkali Metal Adsorbed Graphene, Graphyne and Graphdiyne Systems by First-Principles Calculations. J. Mater. Chem. C 7 (6), 1630-1640. doi:10.1039/c8tc05392h

Li, X., Zhang, Y., and Lu, J. (2020b). Remarkably Enhanced First Hyperpolarizability and Nonlinear Refractive index of Novel Graphdiyne- 
Based Materials for Promising Optoelectronic Applications: A First-Principles Study. Appl. Surf. Sci. 512 (December 2019), 145544. doi:10.1016/ j.apsusc.2020.145544

Li, Y., Heng, W.-K., Lee, B. S., Aratani, N., Zafra, J. L., Bao, N., et al. (2012). Kinetically Blocked Stable Heptazethrene and Octazethrene: Closed-Shell or Open-Shell in the Ground State? J. Am. Chem. Soc. 134 (36), 14913-14922. doi:10.1021/ja304618v

Li, Y., Li, Z.-R., Wu, D., Li, R.-Y., Hao, X.-Y., and Sun, C.-C. (2004). An Ab Initio Prediction of the Extraordinary Static First Hyperpolarizability for the Electron-Solvated Cluster (FH)2\{e\}(HF). J. Phys. Chem. B 108 (10), 3145-3148. doi:10.1021/jp036808y

Li, Y., Wu, D., and Li, Z.-R. (2008). Compounds of Superatom Clusters: Preferred Structures and Significant Nonlinear Optical Properties of the BLi6-X (X = F, LiF2, BeF3, BF4) Motifs. Inorg. Chem. 47 (21), 9773-9778. doi:10.1021/ ic $800184 \mathrm{z}$

Li, Z.-J., Li, Z.-R., Wang, F.-F., Luo, C., Ma, F., Wu, D., et al. (2009a). A Dependence on the Petal Number of the Static and Dynamic First Hyperpolarizability for Electride Molecules: Many-petal-shaped Li-Doped Cyclic Polyamines. J. Phys. Chem. A. 113 (12), 2961-2966. doi:10.1021/jp8109012

Li, Z.-J., Wang, F.-F., Li, Z.-R., Xu, H.-L., Huang, X.-R., Wu, D., et al. (2009b). Large Static First and Second Hyperpolarizabilities Dominated by Excess Electron Transition for Radical Ion Pair Salts M2+TCNQ-(M = Li, Na, K). Phys. Chem. Chem. Phys. 11 (2), 402-408. doi:10.1039/b809161g

Lin, Z., Lu, T., and Ding, X.-L. (2017). A Theoretical Investigation on Doping Superalkali for Triggering Considerable Nonlinear Optical Properties of Si12 C12 Nanostructure. J. Comput. Chem. 38 (18), 1574-1582. doi:10.1002/ jcc. 24796

Liu, Q., Cui, Q., Li, X. J., and Jin, L. (2014). The Applications of Buckminsterfullerene C60and Derivatives in Orthopaedic Research. Connect. Tissue Res. 55 (2), 71-79. doi:10.3109/03008207.2013.877894

Liu, S., Gao, F.-W., Xu, H.-L., and Su, Z.-M. (2019). Transition Metals Doped Fullerenes: Structures - NLO Property Relationships. Mol. Phys. 117 (6), 705-711. doi:10.1080/00268976.2018.1538540

Liu, X., Guo, Q., and Qiu, J. (2017). Emerging Low-Dimensional Materials for Nonlinear Optics and Ultrafast Photonics. Adv. Mater. 29 (14), 1605886. doi:10.1002/adma.201605886

Luo, M., Liang, F., Song, Y., Zhao, D., Xu, F., Ye, N., et al. (2018). M2B10O14F6 (M $=\mathrm{Ca}, \mathrm{Sr})$ : Two Noncentrosymmetric Alkaline Earth Fluorooxoborates as Promising Next-Generation Deep-Ultraviolet Nonlinear Optical Materials. J. Am. Chem. Soc. 140 (11), 3884-3887. doi:10.1021/jacs.8b01263

Luo, Z., Li, Y., Zhong, M., Huang, Y., Wan, X., Peng, J., et al. (2015). Nonlinear Optical Absorption of Few-Layer Molybdenum Diselenide (MoSe_2) for Passively Mode-Locked Soliton Fiber Laser [Invited]. Photon. Res. 3 (3), A79-A86. doi:10.1364/PRJ.3.000A79

Mai, J., Gong, S., Li, N., Luo, Q., and Li, Z. (2015). A novel class of compoundssuperalkalides: $\mathrm{M}+(\mathrm{en}) 3 \mathrm{M}^{\prime} \mathrm{O}-\left(\mathrm{M}, \mathrm{M}^{\prime}=\mathrm{Li}, \mathrm{Na}\right.$, and $\mathrm{K}$; en = ethylenediamine $)$ with excellent nonlinear optical properties and high stabilities. Phys. Chem. Chem. Phys. 17 (43), 28754-28764. doi:10.1039/c5cp03635f

Maiman, T. H. (1960). Stimulated Optical Radiation in Ruby. Nature 187 (4736), 493-494. doi:10.1038/187493a0

Majumdar, S., Singha, T., Dhibar, S., Mandal, A., Datta, P. K., and Dey, B. (2020). Protein-Based Self-Healing $\mathrm{Cu}(\mathrm{II})$-Metallohydrogels: Efficient Third-Order Nonlinear Optical Materials in Terms of an Intensity-dependent Refractive Index and Two-Photon Absorption. ACS Appl. Electron. Mater. 2 (11), 3678-3685. doi:10.1021/acsaelm.0c00728

Manykin, E. A. (2002). Multiphoton Processes in Systems of Rydberg Atoms. Moscow: Russian Research Center Moscow Kurchatov Inst.

Maria, Iqbal, J., and Ayub, K. (2016). Enhanced Electronic and Non-linear Optical Properties of Alkali Metal ( $\mathrm{Li}, \mathrm{Na}, \mathrm{K}$ ) Doped boron Nitride Nano-Cages. J. Alloys Comp. 687, 976-983. doi:10.1016/j.jallcom.2016.06.121

Maria, Iqbal, J., Ludwig, R., and Ayub, K. (2017). Phosphides or Nitrides for Better NLO Properties? A Detailed Comparative Study of Alkali Metal Doped Nano-Cages. Mater. Res. Bull. 92, 113-122. doi:10.1016/ j.materresbull.2017.03.065

Markovic, Z., and Trajkovic, V. (2008). Biomedical Potential of the Reactive Oxygen Species Generation and Quenching by Fullerenes (C60). Biomaterials 29 (26), 3561-3573. doi:10.1016/j.biomaterials.2008.05.005
Miller, M. J., Wei, S. H., Parker, I., and Cahalan, M. D. (2002). Two-photon Imaging of Lymphocyte Motility and Antigen Response in Intact Lymph Node. Science 296 (5574), 1869-1873. doi:10.1126/science.1070051

Mollenauer, L. F., Stolen, R. H., and Gordon, J. P. (1980). Experimental Observation of Picosecond Pulse Narrowing and Solitons in Optical Fibers. Phys. Rev. Lett. 45 (13), 1095-1098. doi:10.1103/physrevlett.45.1095

Montellano López, A., Mateo-Alonso, A., and Prato, M. (2011). Materials Chemistry of Fullerene C60derivatives. J. Mater. Chem. 21 (5), 1305-1318. doi:10.1039/c0jm02386h

Muhammad, S., Ito, S., Nakano, M., Kishi, R., Yoneda, K., Kitagawa, Y., et al. (2015). Diradical Character and Nonlinear Optical Properties of Buckyferrocenes: Focusing on the Use of Suitably Modified Fullerene Fragments. Phys. Chem. Chem. Phys. 17 (8), 5805-5816. doi:10.1039/ c4cp05175k

Muhammad, S., Minami, T., Fukui, H., Yoneda, K., Minamide, S., Kishi, R., et al. (2013). Comparative Study of Diradical Characters and Third-Order Nonlinear Optical Properties of Linear/cyclic Acenes versus Phenylenes. Int. J. Quan. Chem. 113 (4), 592-598. doi:10.1002/qua.24032

Muhammad, S., Xu, H., Liao, Y., Kan, Y., and Su, Z. (2009). Quantum Mechanical Design and Structure of the Li@B10H14 Basket with a Remarkably Enhanced Electro-Optical Response. J. Am. Chem. Soc. 131 (33), 11833-11840. doi:10.1021/ja9032023

Munsif, S., Maria, Khan, S., Ali, A., Gilani, M. A., Iqbal, J., et al. (2018). Remarkable Nonlinear Optical Response of Alkali Metal Doped Aluminum Phosphide and boron Phosphide Nanoclusters. J. Mol. Liquids 271, 51-64. doi:10.1016/ j.molliq.2018.08.121

Nakano, M., Kishi, R., Ohta, S., Takebe, A., Takahashi, H., Furukawa, S., et al. (2006b). Origin of the Enhancement of the Second Hyperpolarizability of Singlet Diradical Systems with Intermediate Diradical Character. J. Chem. Phys. 125 (7), 074113. doi:10.1063/1.2213974

Nakano, M., Minami, T., Fukui, H., Kishi, R., Shigeta, Y., and Champagne, B. (2012). Full Configuration Interaction Calculations of the Second Hyperpolarizabilities of the H4 Model Compound: Summation-Over-States Analysis and Interplay with Diradical Characters. J. Chem. Phys. 136 (2), 024315. doi:10.1063/1.3675684

Nakano, M., Kishi, R., Nakagawa, N., Ohta, S., Takahashi, H., Furukawa, S.-i., et al. (2006a). Second Hyperpolarizabilities $(\gamma)$ of Bisimidazole and Bistriazole Benzenes: Diradical Character, Charged State, and Spin State Dependences. J. Phys. Chem. A. 110 (12), 4238-4243. doi:10.1021/jp056672z

Nakano, M., Kishi, R., Nitta, T., Kubo, T., Nakasuji, K., Kamada, K., et al. (2005). Second Hyperpolarizability $(\gamma)$ of Singlet Diradical System: Dependence of $\gamma$ on the Diradical Character. J. Phys. Chem. A. 109 (5), 885-891. doi:10.1021/ jp046322x

Nakano, M., Kishi, R., Ohta, S., Takahashi, H., Kubo, T., Kamada, K., et al. (2007). Relationship between Third-Order Nonlinear Optical Properties and Magnetic Interactions in Open-Shell Systems: a New Paradigm for Nonlinear Optics. Phys. Rev. Lett. 99 (3), 33001. doi:10.1103/physrevlett.99.033001

Nakano, M., Nagai, H., Fukui, H., Yoneda, K., Kishi, R., Takahashi, H., et al. (2008). Theoretical Study of Third-Order Nonlinear Optical Properties in Square Nanographenes with Open-Shell Singlet Ground States. Chem. Phys. Lett. 467 (1-3), 120-125. doi:10.1016/j.cplett.2008.10.084

Nakano, M., Nitta, T., Yamaguchi, K., Champagne, B., and Botek, E. (2004). Spin Multiplicity Effects on the Second Hyperpolarizability of an Open-Shell Neutral

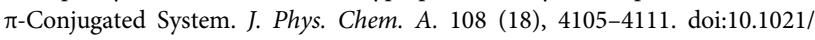
jp0496371

Ni, B., Cai, X., Lin, J., Li, Y., Huang, S., Li, Z., et al. (2019). Tailoring the Linear and Second-Order Nonlinear Optical Responses of the Titanium-MIL-125 MetalOrganic Framework through Ligand Functionalization: A First Principles Study. J. Phys. Chem. C 123 (1), 653-664. doi:10.1021/acs.jpcc.8b08008

Ni, B., Sun, W., Kang, J., and Zhang, Y. (2020). Understanding the Linear and Second-Order Nonlinear Optical Properties of UiO-66-Derived Metal-Organic Frameworks: A Comprehensive DFT Study. J. Phys. Chem. C 124 (21), 11595-11608. doi:10.1021/acs.jpcc.0c01580

Niu, M., Yu, G., Yang, G., Chen, W., Zhao, X., and Huang, X. (2014). Doping the Alkali Atom: An Effective Strategy to Improve the Electronic and Nonlinear Optical Properties of the Inorganic Al12N12 Nanocage. Inorg. Chem. 53 (1), 349-358. doi:10.1021/ic4022917 
Noormohammadbeigi, M., and Shamlouei, H. R. (2018). The Effect of Superalkali $\mathrm{M} 3 \mathrm{O}(\mathrm{M}=\mathrm{Li}, \mathrm{Na}$ and $\mathrm{K})$ on Structure, Electrical and Nonlinear Optical Properties of C20 Fullerene Nanocluster. J. Inorg. Organomet. Polym. 28 (1), 110-120. doi:10.1007/s10904-017-0730-6

Novikov, D. L., Gubanov, V. A., and Freeman, A. J. (1992). Electronic Structure, Electron-Phonon Interaction and Superconductivity in $\mathrm{K} 3 \mathrm{C} 60, \mathrm{Rb} 3 \mathrm{C} 60$ and Cs3C60. Physica C: Superconductivity 191 (3-4), 399-408. doi:10.1016/09214534(92)90936-7

Ohta, S., Nakano, M., Kubo, T., Kamada, K., Ohta, K., Kishi, R., et al. (2007). Theoretical Study on the Second Hyperpolarizabilities of Phenalenyl Radical Systems Involving Acetylene and Vinylene Linkers: Diradical Character and Spin Multiplicity Dependences. J. Phys. Chem. A. 111 (18), 3633-3641. doi:10.1021/jp0713662

Okada, H., Komuro, T., Sakai, T., Matsuo, Y., Ono, Y., Omote, K., et al. (2012). Preparation of Endohedral Fullerene Containing Lithium (Li@C60) and Isolation as Pure Hexafluorophosphate Salt ([Li+@C60][PF6-]). RSC Adv. 2 (28), 10624-10631. doi:10.1039/c2ra21244g

Oku, T., Nishiwaki, A., and Narita, I. (2004). Formation and Atomic Structure of B12N12nanocage Clusters Studied by Mass Spectrometry and Cluster Calculation. Sci. Tech. Adv. Mater. 5 (5-6), 635-638. doi:10.1016/ j.stam.2004.03.017

Omidi, M., Sabzehzari, M., and Shamlouei, H. R. (2020). Influence of Superalkali Oxides on Structural, Electrical and Optical Properties of C24 Fullerene Nanocluster: A Theoretical Study. Chin. J. Phys. 65, 567-578. doi:10.1016/ j.cjph.2020.02.032

Omidi, M., Shamlouei, H. R., and Noormohammadbeigi, M. (2017). The Influence of Sc Doping on Structural, Electronic and Optical Properties of Be12O12, Mg12O12 and Ca12O12 Nanocages: a DFT Study. J. Mol. Model. 23 (3), 82. doi:10.1007/s00894-017-3243-x

Orbelli Biroli, A., Tessore, F., Pizzotti, M., Biaggi, C., Ugo, R., Caramori, S., et al. (2011). A Multitechnique Physicochemical Investigation of Various Factors Controlling the Photoaction Spectra and of Some Aspects of the Electron Transfer for a Series of Push-Pull $\mathrm{Zn}(\mathrm{II})$ Porphyrins Acting as Dyes in DSSCs. J. Phys. Chem. C 115 (46), 23170-23182. doi:10.1021/ jp2030363

Orbelli Biroli, A., Tessore, F., Righetto, S., Forni, A., Macchioni, A., Rocchigiani, L., et al. (2017). Intriguing Influence of $-\mathrm{COOH}$-Driven Intermolecular Aggregation and Acid-Base Interactions with N,N-Dimethylformamide on the Second-Order Nonlinear-Optical Response of 5,15 Push-Pull Diarylzinc(II) Porphyrinates. Inorg. Chem. 56 (11), 6438-6450. doi:10.1021/ acs.inorgchem.7b00510

Ortíz-Saavedra, J., Aguilera-Granja, F., Dorantes-Dávila, J., and Morán-López, J. L. (1993). The S and P Character of the Electronic Structure of C20, C60 and C70. Solid State. Commun. 85 (9), 767-771. doi:10.1016/0038-1098(93) 90668-D

Paul, D., Deb, J., Bhattacharya, B., and Sarkar, U. (2017). Density Functional Theory Study of Pristine and Transition Metal Doped Fullerene. AIP Conf. Proc. 1832 (1), 50107. doi:10.1063/1.4980340

Pauling, L. (1991). The Structure of K3C60 and the Mechanism of Superconductivity. Proc. Natl. Acad. Sci. 88 (20), 9208-9209. doi:10.1073/ pnas.88.20.9208

Pochet, P., Genovese, L., Caliste, D., Rousseau, I., Goedecker, S., and Deutsch, T. (2010). First-principles Prediction of Stable SiC Cage Structures and Their Synthesis Pathways. Phys. Rev. B 82 (3), 35431. doi:10.1103/physrevb.82.035431

Popov, A. A., Yang, S., and Dunsch, L. (2013). Endohedral Fullerenes. Chem. Rev. 113 (8), 5989-6113. doi:10.1021/cr300297r

Popov, A. K., and Shalaev, V. M. (2006). Compensating Losses in Negative-index Metamaterials by Optical Parametric Amplification. Opt. Lett. 31 (14), 2169-2171. doi:10.1364/ol.31.002169

Qiu, Y.-Q., Fan, H.-L., Sun, S.-L., Liu, C.-G., and Su, Z.-M. (2008). Theoretical Study on the Relationship between Spin Multiplicity Effects and Nonlinear Optical Properties of the Pyrrole Radical (C4H4N.). J. Phys. Chem. A. 112 (1), 83-88. doi:10.1021/jp073907t

Rad, A. S., and Ayub, K. (2017). Substitutional Doping of Zirconium-, Molybdenum-, Ruthenium-, and Palladium: an Effective Method to Improve Nonlinear Optical and Electronic Property of C20 Fullerene. Comput. Theor. Chem. 1121, 68-75. doi:10.1016/j.comptc.2017.10.015
Rad, A. S., and Ayub, K. (2019). Change in the Electronic and Nonlinear Optical Properties of Fullerene through its Incorporation with Sc-, Fe-, Cu-, and $\mathrm{Zn}$ Transition Metals. Appl. Phys. A 125 (6), 1-9. doi:10.1007/s00339-019-2721-7

Rad, A. S., and Ayub, K. (2018a). How Can Nickel Decoration Affect H 2 Adsorption on B 12 P 12 Nano-Heterostructures? J. Mol. Liquids 255, 168-175. doi:10.1016/j.molliq.2018.01.149

Rad, A. S., and Ayub, K. (2018c). Nonlinear Optical and Electronic Properties of Cr-, Ni-, and Ti- Substituted C 20 Fullerenes: A Quantum-Chemical Study. Mater. Res. Bull. 97 (September 2017), 399-404. doi:10.1016/ j.materresbull.2017.09.036

Rad, A. S., and Ayub, K. (2018b). Nonlinear Optical, IR and Orbital Properties of Ni Doped MgO Nanoclusters: A DFT Investigation. Comput. Theor. Chem. 1138, 39-47. doi:10.1016/j.comptc.2018.06.003

Ravaei, I., Haghighat, M., and Azami, S. M. (2019). A DFT, AIM and NBO Study of Isoniazid Drug Delivery by MgO Nanocage. Appl. Surf. Sci. 469 (November 2018), 103-112. doi:10.1016/j.apsusc.2018.11.005

Ray, P. C. (2010). Size and Shape Dependent Second Order Nonlinear Optical Properties of Nanomaterials and Their Application in Biological and Chemical Sensing. Chem. Rev. 110 (9), 5332-5365. doi:10.1021/cr900335q

Raza Ayub, A., Aqil Shehzad, R., Alarfaji, S. S., and Iqbal, J. (2020). Super Alkali (OLi3) Doped boron Nitride with Enhanced Nonlinear Optical Behavior. J. Nonlinear Optic. Phys. Mat. 29 (01n02), 2050004. doi:10.1142/ s0218863520500046

Reber, A. C., Khanna, S. N., Hunjan, J. S., and Beltrán, M. R. (2006). Cobalt Doped Rings and Cages of $\mathrm{ZnO}$ Clusters: Motifs for Magnetic Cluster-Assembled Materials. Chem. Phys. Lett. 428 (4-6), 376-380. doi:10.1016/ j.cplett.2006.07.045

Redko, M. Y., Jackson, J. E., Huang, R. H., and Dye, J. L. (2005). Design and Synthesis of a Thermally Stable Organic Electride. J. Am. Chem. Soc. 127 (35), 12416-12422. doi:10.1021/ja053216f

Rehm, E., Boldyrev, A. I., and Schleyer, P. v. R. (1992). Ab Initio study of Superalkalis. First Ionization Potentials and Thermodynamic Stability. Inorg. Chem. 31 (23), 4834-4842. doi:10.1021/ic00049a022

Reshak, A. H., Chen, X., Auluck, S., and Kamarudin, H. (2012). Linear and Nonlinear Optical Susceptibilities and Hyperpolarizability of Borate LiNaB4O7 Single Crystals: Theory and experiment. J. Appl. Phys. 112 (5), 53526. doi:10.1063/1.4749409

Reshak, A. H., Chen, X., Auluck, S., Kamarudin, H., Chyský, J., Wojciechowski, A., et al. (2013). Linear and Nonlinear Optical Susceptibilities and the Hyperpolarizability of Borate LiBaB9O15 single-crystal: Theory and experiment. J. Phys. Chem. B 117 (45), 14141-14150. doi:10.1021/jp4077905

Reshak, A. H., Kityk, I. V., and Auluck, S. (2010). Investigation of the Linear and Nonlinear Optical Susceptibilities of KTiOPO4 Single Crystals: Theory and experiment. J. Phys. Chem. B 114 (50), 16705-16712. doi:10.1021/jp1072878

Rosen, A., and Waestberg, B. (1988). First-principle Calculations of the Ionization Potentials and Electron Affinities of the Spheroidal Molecules Carbon (C60) and Lanthanum Carbude (LaC60). J. Am. Chem. Soc. 110 (26), 8701-8703. doi:10.1021/ja00234a024

Rosén, A., and Wästberg, B. (1989). Electronic Structure of Spheroidal Metal Containing Carbon Shells: Study of the LaC60 and C60 Clusters and Their Ions within the Local Density Approximation. Z. Für Physik D Atoms, Mol. Clusters 12 (1), 387-390. doi:10.1007/978-3-642-74913-1_86

Ross, R. B., Cardona, C. M., Swain, F. B., Guldi, D. M., Sankaranarayanan, S. G., Van Keuren, E., et al. (2009). Tuning Conversion Efficiency in Metallo Endohedral Fullerene-Based Organic Photovoltaic Devices. Adv. Funct. Mater. 19 (14), 2332-2337. doi:10.1002/adfm.200900214

Sajid, H., Ayub, K., and Mahmood, T. (2020). Exceptionally High NLO Response and Deep Ultraviolet Transparency of Superalkali Doped Macrocyclic Oligofuran Rings. New J. Chem. 44, 2609-2618. doi:10.1039/c9nj05065e

Sajid, H., Ullah, F., Khan, S., Ayub, K., Arshad, M., and Mahmood, T. (2021). Remarkable Static and Dynamic NLO Response of Alkali and Superalkali Doped Macrocyclic [hexa-]thiophene Complexes; a DFT Approach. RSC Adv. 11 (7), 4118-4128. doi:10.1039/d0ra08099c

Sajjad, S., Ali, A., Mahmood, T., and Ayub, K. (2020). Janus Alkaline Earthides with Excellent NLO Response from Sodium and Potassium as Source of Excess Electrons; a First Principles Study. J. Mol. Graphics Model. 100, 107668. doi:10.1016/j.jmgm.2020.107668 
Seifert, G., Fowler, P. W., Mitchell, D., Porezag, D., and Frauenheim, T. (1997). Boron-nitrogen Analogues of the Fullerenes: Electronic and Structural Properties. Chem. Phys. Lett. 268 (5-6), 352-358. doi:10.1016/s00092614(97)00214-5

Senftleben, O., Stimpel-Lindner, T., Iskra, P., Eisele, J., and Baumgärtner, H. (2009). C60Nanostructures for Applications in Information Technology. Adv. Eng. Mater. 11 (4), 278-284. doi:10.1002/adem.200800293

Shakerzadeh, E., Biglari, Z., and Tahmasebi, E. (2016a). M@B40 (M = Li, Na, K) Serving as a Potential Promising Novel NLO Nanomaterial. Chem. Phys. Lett. 654, 76-80. doi:10.1016/j.cplett.2016.05.014

Shakerzadeh, E., Mashak Shabavi, Z., and Anota, E. C. (2020a). Enhanced Electronic and Nonlinear Optical Responses of C24N24 Cavernous Nitride Fullerene by Decoration with First Row Transition Metals; A Computational Investigation. Appl. Organomet. Chem. 34 (8), e5694. doi:10.1002/aoc.5694

Shakerzadeh, E., Tahmasebi, E., and Biglari, Z. (2016b). A Quantum Chemical Study on the Remarkable Nonlinear Optical and Electronic Characteristics of boron Nitride Nanoclusters by Complexation via Lithium Atom. J. Mol. Liquids 221, 443-451. doi:10.1016/j.molliq.2016.05.090

Shakerzadeh, E., Yousefizadeh, M., and Bamdad, M. (2020b). Electronic and Nonlinear Optical Features of First Row Transition Metals-Decorated Allboron B40 Fullerene: A Promising Route to Remarkable Electro-Optical Response. Inorg. Chem. Commun. 112 (November 2019), 107692. doi:10.1016/j.inoche.2019.107692

Shakerzdeh, E., Tahmasebi, E., and Shamlouei, H. R. (2015). The Influence of Alkali Metals ( $\mathrm{Li}, \mathrm{Na}$ and $\mathrm{K}$ ) Interaction with $\mathrm{Be} 12 \mathrm{O} 12$ and $\mathrm{Mg} 12 \mathrm{O} 12$ Nanoclusters on Their Structural, Electronic and Nonlinear Optical Properties: A Theoretical Study. Synth. Met. 204, 17-24. doi:10.1016/ j.synthmet.2015.03.008

Shehzadi, K., Ayub, K., and Mahmood, T. (2019). Theoretical Study on Design of Novel Superalkalis Doped Graphdiyne: A New Donor-Acceptor (D- $\pi-A$ ) Strategy for Enhancing NLO Response. Appl. Surf. Sci. 492, 255-263. doi:10.1016/j.apsusc.2019.06.221

Shelton, D. P., and Rice, J. E. (1994). Measurements and Calculations of the Hyperpolarizabilities of Atoms and Small Molecules in the Gas Phase. Chem. Rev. 94 (1), 3-29. doi:10.1021/cr00025a001

Shen, Y.-R. (1984). The Principles of Nonlinear Optics. NJ, USA: Wiley.

Shen, Y. R. (1989). Surface Properties Probed by Second-Harmonic and SumFrequency Generation. Nature 337 (6207), 519-525. doi:10.1038/337519a0

Sohail, M., Khaliq, F., Mahmood, T., Ayub, K., Tabassum, S., and Gilani, M. A. (2021). Influence of Bi-alkali Metals Doping over Al12N12 Nanocage on Stability and Optoelectronic Properties: A DFT Investigation. Radiat. Phys. Chem. 184 (November 2020), 109457. doi:10.1016/j.radphyschem.2021.109457

Solimannejad, M., Rahimi, R., and Kamalinahad, S. (2017). Nonlinear Optical (NLO) Response of Si12C12 Nanocage Decorated with Alkali Metals $(\mathrm{M}=\mathrm{Li}$, $\mathrm{Na}$ and K): A Theoretical Study. J. Inorg. Organomet. Polym. 27 (5), 1234-1242. doi:10.1007/s10904-017-0570-4

Song, Y.-D., Wang, L., and Wang, Q.-T. (2018a). Effect of (Super) Alkali Doping and boron Substitution on the Nonlinear Optical Property of Biphenalenyl Diradical $\pi$ Dimer: A Theoretical Study. Optik 165, 319-331. doi:10.1016/ j.ijleo.2018.03.124

Song, Y.-D., Wang, L., and Wang, Q.-T. (2018b). Structures and Nonlinear Optical Properties of Alkali Atom/superalkali Doped Pyridinic Vacancy Graphene. Optik 154, 411-420. doi:10.1016/j.ijleo.2017.10.100

Song, Y.-D., Wang, L., and Wu, L.-M. (2017). How the Alkali Metal Atoms Affect Electronic Structure and the Nonlinear Optical Properties of C24N24 Nanocage. Optik 135, 139-152. doi:10.1016/j.ijleo.2017.01.096

Sparn, G., Thompson, J. D., Huang, S.-M., Kaner, R. B., Diederich, F., Whetten, R. L., et al. (1991). Pressure Dependence of Superconductivity in Single-phase K 3 C 60. Science 252 (5014), 1829-1831. doi:10.1126/science.252.5014.1829

Srivastava, A. K. (2020). Enormously High Second-Order Nonlinear Optical Response of Single Alkali Atom Decorated Hexalithiobenzene. J. Mol. Liquids 298, 112187. doi:10.1016/j.molliq.2019.112187

Srivastava, A. K., Kumar, A., and Misra, N. (2016a). Structure and Properties of Li@ C 60 -PF 6 Endofullerene Complex. Physica E: Low-Dimensional Syst. Nanostructures 84, 524-529. doi:10.1016/j.physe.2016.06.021

Srivastava, A. K., Kumar, A., and Misra, N. (2017). Superalkali@ C60-superhalogen: Structure and Nonlinear Optical Properties of a New
Class of Endofullerene Complexes. Chem. Phys. Lett. 682, 20-25. doi:10.1016/j.cplett.2017.05.070

Srivastava, A. K., and Misra, N. (2015a). Ab Initio investigations on the Gas Phase Basicity and Nonlinear Optical Properties of FLinOH Species $(\mathrm{N}=2-5)$. RSC Adv. 5 (91), 74206-74211. doi:10.1039/c5ra14735b

Srivastava, A. K., and Misra, N. (2015b). Ab Initio prediction of Novel Alkalides FLi2-M-Li2F (M = Li, Na and K). Chem. Phys. Lett. 639, 307-309. doi:10.1016/ j.cplett.2015.09.046

Srivastava, A. K., and Misra, N. (2017). Competition between Alkalide Characteristics and Nonlinear Optical Properties in OLi3 $7 \mathrm{M} \mid \mathrm{Li} 3 \mathrm{O}(\mathrm{M}=\mathrm{Li}$, $\mathrm{Na}$, and $\mathrm{K})$ Complexes $\rceil \mathrm{M}\rceil \mathrm{Li} 3 \mathrm{O}(\mathrm{M}=\mathrm{Li}, \mathrm{Na}$, and $\mathrm{K})$ Complexes. Int. J. Quan. Chem. 117 (3), 208-212. doi:10.1002/qua.25313

Srivastava, A. K., and Misra, N. (2016a). Hydrogenated Superalkalis and Their Possible Applications. J. Mol. Model. 22 (6), 122. doi:10.1007/s00894-0162994-0

Srivastava, A. K., and Misra, N. (2016c). M2X (M= Li, Na; X= F, Cl): the Smallest Superalkali Clusters with Significant NLO Responses and Electride Characteristics. Mol. Simulation 42 (12), 981-985. doi:10.1080/ 08927022.2015.1132840

Srivastava, A. K., and Misra, N. (2015c). Nonlinear Optical Behavior of Li N F (N = 2-5) Superalkali Clusters. J. Mol. Model. 21 (12), 305. doi:10.1007/s00894-0152849-0

Srivastava, A. K., and Misra, N. (2016b). Remarkable NLO Responses of Hyperalkalized Species: the Size Effect and Atomic Number Dependence. New J. Chem. 40 (6), 5467-5472. doi:10.1039/c6nj00584e

Srivastava, A. K., Pandey, S. K., and Misra, N. (2016b). Prediction of superalkali@ C60 Endofullerenes, Their Enhanced Stability and Interesting Properties. Chem. Phys. Lett. 655-656, 71-75. doi:10.1016/j.cplett.2016.05.039

Stoilova, O., Jérôme, C., Detrembleur, C., Mouithys-Mickalad, A., Manolova, N., Rashkov, I., et al. (2007). C60-containing Nanostructured Polymeric Materials with Potential Biomedical Applications. Polymer 48 (7), 1835-1843. doi:10.1016/j.polymer.2007.02.026

Stucky, G. D., Phillips, M. L. F., and Gier, T. E. (1989). The Potassium Titanyl Phosphate Structure Field: a Model for New Nonlinear Optical Materials. Chem. Mater. 1 (5), 492-509. doi:10.1021/cm00005a008

Sun, W.-M., Fan, L.-T., Li, Y., Liu, J.-Y., Wu, D., and Li, Z.-R. (2014). On the Potential Application of Superalkali Clusters in Designing Novel Alkalides with Large Nonlinear Optical Properties. Inorg. Chem. 53 (12), 6170-6178. doi:10.1021/ic500655s

Sun, W.-M., Li, X.-H., Wu, D., Li, Y., He, H.-M., Li, Z.-R., et al. (2016b). A Theoretical Study on Superalkali-Doped Nanocages: Unique Inorganic Electrides with High Stability, Deep-Ultraviolet Transparency, and a Considerable Nonlinear Optical Response. Dalton Trans. 45 (17), 7500-7509. doi:10.1039/c6dt00342g

Sun, W.-M., Li, X.-H., Wu, J., Lan, J.-M., Li, C.-Y., Wu, D., et al. (2017a). Can Coinage Metal Atoms Be Capable of Serving as an Excess Electron Source of Alkalides with Considerable Nonlinear Optical Responses? Inorg. Chem. 56 (8), 4594-4600. doi:10.1021/acs.inorgchem.7b00183

Sun, W.-M., Li, Y., Li, X.-H., Wu, D., He, H.-M., Li, C.-Y., et al. (2016a). Stability and Nonlinear Optical Response of Alkalides that Contain a Completely Encapsulated Superalkali Cluster. ChemPhysChem 17 (17), 2672-2678. doi:10.1002/cphc.201600389

Sun, W.-M., Ni, B.-L., Wu, D., Lan, J.-M., Li, C.-Y., Li, Y., et al. (2017b). Designing Alkalides with Considerable Nonlinear Optical Responses and High Stability Based on the Facially Polarized Janus All-Cis-1,2,3,4,5,6Hexafluorocyclohexane. Organometallics 36 (17), 3352-3359. doi:10.1021/ acs.organomet.7b00491

Sun, W.-M., Wu, D., Li, Y., and Li, Z.-R. (2013). Substituent Effects on the Structural Features and Nonlinear Optical Properties of the Organic Alkalide $\mathrm{Li}+($ calix$[4]$ pyrrole)Li-. ChemPhysChem 14 (2), 408-416. doi:10.1002/ cphc.201200805

Sun, W.-M., Wu, D., Li, Y., Liu, J.-Y., He, H.-M., and Li, Z.-R. (2015). A Theoretical Study on Novel Alkaline Earth-Based Excess Electron Compounds: Unique Alkalides with Considerable Nonlinear Optical Responses. Phys. Chem. Chem. Phys. 17 (6), 4524-4532. doi:10.1039/c4cp04951a

Tahir, H., Kosar, N., Ayub, K., and Mahmood, T. (2020). Outstanding NLO Response of Thermodynamically Stable Single and Multiple Alkaline Earth 
Metals Doped C20 Fullerene. J. Mol. Liquids 305, 112875. doi:10.1016/ j.molliq.2020.112875

Tahmasebi, E., Shakerzadeh, E., and Biglari, Z. (2016). Theoretical Assessment of the Electro-Optical Features of the Group III Nitrides (B12N12, Al12N12 and Ga12N12) and Group IV Carbides (C24, Si12C12 and Ge12C12) Nanoclusters Encapsulated with Alkali Metals (Li, Na and K). Appl. Surf. Sci. 363, 197-208. doi:10.1016/j.apsusc.2015.12.001

Tehan, F. J., Barnett, B. L., and Dye, J. L. (1974). Alkali Anions. Preparation and crystal Structure of a Compound Which Contains the Cryptated Sodium Cation and the Sodium Anion. J. Am. Chem. Soc. 96 (23), 7203-7208. doi:10.1021/ ja00830a005

Tellgmann, R., Krawez, N., Lin, S.-H., Hertel, I. V., and Campbell, E. E. B. (1996). Endohedral Fullerene Production. Nature 382 (6590), 407-408. doi:10.1038/ $382407 \mathrm{a} 0$

Tessore, F., Biroli, A. O., Di Carlo, G., and Pizzotti, M. (2018). Porphyrins for Second Order Nonlinear Optics (NLO): An Intriguing History. Inorganics 6 (3), 81. doi:10.3390/inorganics6030081

Tutt, L. W., and Kost, A. (1992). Optical Limiting Performance of C60 and C70 Solutions. Nature 356 (6366), 225-226. doi:10.1038/356225a0

Ullah, F., Ayub, K., and Mahmood, T. (2020a). Remarkable Second and Third Order Nonlinear Optical Properties of Organometallic C6Li6-M3o Electrides. New J. Chem. 44 (23), 9822-9829. doi:10.1039/d0nj01670e

Ullah, F., Irshad, S., Khan, S., Hashmi, M. A., Ludwig, R., Mahmood, T., et al. (2021). Nonlinear Optical Response of First-Row Transition Metal Doped Al12P12 Nanoclusters; a First-Principles Study. J. Phys. Chem. Sol. 151, 109914. doi:10.1016/j.jpcs.2020.109914

Ullah, F., Kosar, N., Ali, A., Maria, T., Mahmood, T., and Ayub, K. (2020b). Design of Novel Inorganic Alkaline Earth Metal Doped Aluminum Nitride Complexes (AEM@Al12N12) with High Chemical Stability, Improved Electronic Properties and Large Nonlinear Optical Response. Optik 207, 163792. doi:10.1016/j.ijleo.2019.163792

Ullah, F., Kosar, N., Ali, A., MariaMahmood, T., Mahmood, T., and Ayub, K. (2020c). Alkaline Earth Metal Decorated Phosphide Nanoclusters for Potential Applications as High Performance NLO Materials; A First Principle Study. Physica E: Low-Dimensional Syst. Nanostructures 118 (October 2019), 113906. doi:10.1016/j.physe.2019.113906

Ullah, F., Kosar, N., Arshad, M. N., Gilani, M. A., Ayub, K., and Mahmood, T. (2020d). Design of Novel Superalkali Doped Silicon Carbide Nanocages with Giant Nonlinear Optical Response. Opt. Laser Tech. 122, 105855. doi:10.1016/ j.optlastec.2019.105855

Ullah, F., Kosar, N., Ayub, K., Gilani, M. A., and Mahmood, T. (2019a). Theoretical Study on a boron Phosphide Nanocage Doped with Superalkalis: Novel Electrides Having Significant Nonlinear Optical Response. New J. Chem. 43 (15), 5727-5736. doi:10.1039/C9NJ00225A

Ullah, F., Kosar, N., Ayub, K., and Mahmood, T. (2019b). Superalkalis as a Source of Diffuse Excess Electrons in Newly Designed Inorganic Electrides with Remarkable Nonlinear Response and Deep Ultraviolet Transparency: A DFT Study. Appl. Surf. Sci. 483, 1118-1128. doi:10.1016/j.apsusc.2019.04.042

Van Cleuvenbergen, S., Stassen, I., Gobechiya, E., Zhang, Y., Markey, K., De Vos, D. E., et al. (2016). ZIF-8 as Nonlinear Optical Material: Influence of Structure and Synthesis. Chem. Mater. 28 (9), 3203-3209. doi:10.1021/ acs.chemmater.6b01087

Van Steenwinckel, D., Hendrickx, E., Persoons, A., and Samyn, C. (2001). Large Dynamic Ranges in Photorefractive NLO Polymers and NLO-PolymerDispersed Liquid Crystals Using a Bifunctional Chromophore as a Charge Transporter. Chem. Mater. 13 (4), 1230-1237. doi:10.1021/cm001159d

Vijayakumar, T., Hubert Joe, I., Reghunadhan Nair, C. P., and Jayakumar, V. S. (2008). Efficient $\pi$ Electrons Delocalization in Prospective Push-Pull Nonlinear Optical Chromophore 4-[N,N-dimethylamino]-4'-nitro Stilbene (DANS): A Vibrational Spectroscopic Study. Chem. Phys. 343 (1), 83-99. doi:10.1016/j.chemphys.2007.10.033

Wakabayashi, T., and Achiba, Y. (1992). A Model for the C60 and C70 Growth Mechanism. Chem. Phys. Lett. 190 (5), 465-468. doi:10.1016/0009-2614(92) 85174-9

Wang, F.-F., Li, Z.-R., Wu, D., Sun, X.-Y., Chen, W., Li, Y., et al. (2006). Novel Superalkali Superhalogen Compounds ( $\mathrm{Li} 3)+(\mathrm{SH})-(\mathrm{SH}=\mathrm{LiF} 2, \mathrm{BeF} 3$, and $\mathrm{BF} 4)$ with Aromaticity: New Electrides and Alkalides. ChemPhysChem 7 (5), 1136-1141. doi:10.1002/cphc.200600014
Wang, F.-F., Li, Z.-R., Wu, D., Wang, B.-Q., Li, Y., Li, Z.-J., et al. (2008). Structures and Considerable Static First Hyperpolarizabilities: New Organic Alkalides $(\mathrm{M}+@ n 6 a d z) M^{\prime}-\left(M, M^{\prime}=\mathrm{Li}, \mathrm{Na}, \mathrm{K} ; \mathrm{N}=2,3\right)$ with Cation inside and Anion outside of the Cage Complexants. J. Phys. Chem. B 112 (4), 1090-1094. doi:10.1021/jp076790h

Wang, G., Higgins, S., Wang, K., Bennett, D., Milosavljevic, N., Magan, J. J., et al. (2018). Intensity-dependent Nonlinear Refraction of Antimonene Dispersions in the Visible and Near-Infrared Region. Appl. Opt. 57 (22), E147-E153. doi:10.1364/ao.57.00e147

Wang, H.-W., Langohr, I. M., Sturek, M., and Cheng, J.-X. (2009). Imaging and Quantitative Analysis of Atherosclerotic Lesions by CARS-Based Multimodal Nonlinear Optical Microscopy. Atvb 29 (9), 1342-1348. doi:10.1161/ atvbaha.109.189316

Wang, J.-J., Zhou, Z.-J., Bai, Y., Liu, Z.-B., Li, Y., Wu, D., et al. (2012). The Interaction between Superalkalis $(\mathrm{M} 3 \mathrm{O}, \mathrm{M}=\mathrm{Na}, \mathrm{K})$ and a C20F20 Cage Forming Superalkali Electride Salt Molecules with Excess Electrons inside the C20F20 Cage: Dramatic Superalkali Effect on the Nonlinear Optical Property. J. Mater. Chem. 22 (19), 9652-9657. doi:10.1039/c2jm15405f

Wang, S.-J., Li, Y., Wang, Y.-F., Wu, D., and Li, Z.-R. (2013). Structures and Nonlinear Optical Properties of the Endohedral Metallofullerene-Superhalogen Compounds Li@C60-BX4 (X = F, Cl, Br). Phys. Chem. Chem. Phys. 15 (31), 12903-12910. doi:10.1039/c3cp51443a

Wang, Y.-F., Huang, J., Jia, L., and Zhou, G. (2014). Theoretical Investigation of the Structures, Stabilities, and NLO Responses of Calcium-Doped Pyridazine: Alkaline-Earth-Based Alkaline Salt Electrides. J. Mol. Graphics Model. 47, 77-82. doi:10.1016/j.jmgm.2013.11.003

Wang, Z., Li, Y., Sheng-Jiang, G., Jing-Hui, L., Mei, X., and Rastegar, S. F. (2020). Quasi-planar B36 boron Cluster: a New Potential Basis for Ammonia Detection. J. Mol. Model. 26 (10), 263-268. doi:10.1007/s00894-020-04486-2

Wostyn, K., Binnemans, K., Clays, K., and Persoons, A. (2001). Hyper-Rayleigh Scattering in the Fourier Domain for Higher Precision: Correcting for Multiphoton Fluorescence with Demodulation and Phase Data. Rev. Scientific Instr. 72 (8), 3215-3220. doi:10.1063/1.1384429

Wu, B., Hu, J., Cui, P., Jiang, L., Chen, Z., Zhang, Q., et al. (2015). Visible-light Photoexcited Electron Dynamics of Scandium Endohedral Metallofullerenes: the Cage Symmetry and Substituent Effects. J. Am. Chem. Soc. 137 (27), 8769-8774. doi:10.1021/jacs.5b03612

Wu, H.-S., Zhang, F.-Q., Xu, X.-H., Zhang, C.-J., and Jiao, H. (2003). Geometric and Energetic Aspects of Aluminum Nitride Cages. J. Phys. Chem. A. 107 (1), 204-209. doi:10.1021/jp027300i

Xu, H.-L., Li, Z.-R., Wu, D., Ma, F., Li, Z.-J., and Gu, F. L. (2009). Lithiation and LiDoped Effects of [5]cyclacene on the Static First Hyperpolarizability. J. Phys. Chem. C 113 (12), 4984-4986. doi:10.1021/jp806864w

Xu, H.-L., Li, Z.-R., Wu, D., Wang, B.-Q., Li, Y., Gu, F. L., et al. (2007). Structures and Large NLO Responses of New Electrides: Li-Doped Fluorocarbon Chain. J. Am. Chem. Soc. 129 (10), 2967-2970. doi:10.1021/ja068038k

Xu, H.-L., Sun, S.-L., Muhammad, S., and Su, Z.-M. (2011). Three-propeller-bladeshaped Electride: Remarkable Alkali-Metal-Doped Effect on the First Hyperpolarizability. Theor. Chem. Acc. 128 (2), 241-248. doi:10.1007/ s00214-010-0837-0

Yakigaya, K., Takeda, A., Yokoyama, Y., Ito, S., Miyazaki, T., Suetsuna, T., et al. (2007). Superconductivity of Doped Ar@C60. New J. Chem. 31 (6), 973-979. doi:10.1039/b700726d

Yang, H., Li, Y., Wu, D., and Li, Z.-r. (2012). Structural Properties and Nonlinear Optical Responses of Superatom Compounds BF4 -M (M = Li, FLi2 , OLi3 , NLi4 ). Int. J. Quan. Chem. 112 (3), 770-778. doi:10.1002/qua.23053

Yu, G., Huang, X.-R., Chen, W., and Sun, C.-C. (2011). Alkali Metal AtomAromatic Ring: A Novel Interaction Mode Realizes Large First Hyperpolarizabilities of $\mathrm{M} @ \mathrm{AR}(\mathrm{M}=\mathrm{Li}, \mathrm{Na}$, and $\mathrm{K}, \mathrm{AR}=$ Pyrrole, Indole, Thiophene, and Benzene). J. Comput. Chem. 32 (9), 2005-2011. doi:10.1002/ jcc. 21789

Yuan, Z., Entwistle, C. D., Collings, J. C., Albesa-Jové, D., Batsanov, A. S., Howard, J. A. K., et al. (2006). Synthesis, Crystal Structures, Linear and Nonlinear Optical Properties, and Theoretical Studies of (P-R-Phenyl)-, (P-R-Phenylethynyl)-, and (E)-[2-(p-R-Phenyl)ethenyl]dimesitylboranes and Related Compounds. Chem. Eur. J. 12 (10), 2758-2771. doi:10.1002/chem.200501096

Zeng, Z., Sung, Y. M., Bao, N., Tan, D., Lee, R., Zafra, J. L., et al. (2012). Stable Tetrabenzo-Chichibabin's Hydrocarbons: Tunable Ground State and Unusual 
Transition between Their Closed-Shell and Open-Shell Resonance Forms. J. Am. Chem. Soc. 134 (35), 14513-14525. doi:10.1021/ja3050579

Zhai, H.-J., Zhao, Y.-F., Li, W.-L., Chen, Q., Bai, H., Hu, H.-S., et al. (2014). Observation of an All-boron Fullerene. Nat. Chem 6 (8), 727-731. doi:10.1038/ nchem.1999

Zhang, F., Zhang, F., Qun, J., Pan, S., Yang, Z., and Jia, D. (2015). Synthesis, Characterization and Theoretical Studies of Nonlinear Optical crystal Sr2B5O9(OH).H2O. Phys. Chem. Chem. Phys. 17 (16), 10489-10496. doi:10.1039/c5cp00864f

Zhang, J., Liu, K., Xing, G., Ren, T., and Wang, S. (2007). Synthesis and In Vivo Study of Metallofullerene Based MRI Contrast Agent. J. Radioanal. Nucl. Chem. 272 (3), 605-609. doi:10.1007/s10967-007-0632-0

Zheng, C., Huang, J., Lei, L., Chen, W., Wang, H., and Li, W. (2018a). Nanosecond Nonlinear Optical and Optical Limiting Properties of Hollow Gold Nanocages. Appl. Phys. B 124 (1), 17. doi:10.1007/s00340-017-6888-3

Zheng, C., Huang, J., Lei, L., Chen, W., Wang, H., and Li, W. (2018b). Nanosecond Nonlinear Optical and Optical Limiting Properties of Hollow Gold Nanocages. Appl. Phys. B 124 (1), 1-8. doi:10.1007/s00340-017-6888-3

Zhou, S., Yang, X., Shen, Y., King, R. B., and Zhao, J. (2019). Dual Transition Metal Doped Germanium Clusters for Catalysis of CO Oxidation. J. Alloys Comp. 806, 698-704. doi:10.1016/j.jallcom.2019.07.297

Zhu, L., Xue, K., and Hou, J. (2019). A Theoretical Study of Alkaline-Earthides $\mathrm{Li}(\mathrm{NH} 3) 4 \mathrm{M}(\mathrm{M}=\mathrm{Be}, \mathrm{Mg}, \mathrm{Ca})$ with Large First Hyperpolarizability. J. Mol. Model. 25 (6), 1-10. doi:10.1007/s00894-019-4042-3
Zyss, J., and Ledoux, I. (1994). Nonlinear Optics in Multipolar media: Theory and Experiments. Chem. Rev. 94 (1), 77-105. doi:10.1021/cr00025a003

Zyss, J., Ledoux, I., Volkov, S., Chernyak, V., Mukamel, S., Bartholomew, G. P., et al. (2000). Through-space Charge Transfer and Nonlinear Optical Properties of Substituted Paracyclophane. J. Am. Chem. Soc. 122 (48), 11956-11962. doi:10.1021/ja0022526

Conflict of Interest: The authors declare that the research was conducted in the absence of any commercial or financial relationships that could be construed as a potential conflict of interest.

Publisher's Note: All claims expressed in this article are solely those of the authors and do not necessarily represent those of their affiliated organizations, or those of the publisher, the editors, and the reviewers. Any product that may be evaluated in this article, or claim that may be made by its manufacturer, is not guaranteed or endorsed by the publisher.

Copyright $\odot 2021$ Bano, Asghar, Ayub, Mahmood, Iqbal, Tabassum, Zakaria and Gilani. This is an open-access article distributed under the terms of the Creative Commons Attribution License (CC BY). The use, distribution or reproduction in other forums is permitted, provided the original author(s) and the copyright owner(s) are credited and that the original publication in this journal is cited, in accordance with accepted academic practice. No use, distribution or reproduction is permitted which does not comply with these terms. 